\title{
Análisis sobre la transparencia en el sector pesquero peruano
}

M. Gutiérrez \& J. C. Sueiro 
RESUMEN

RELACIÓN DE ABREVIATURAS

1. INTRODUCCIÓN: EL CONCEPTO DE TRANSPARENCIA EN EL SECTOR PESQUERO DEL PERÚ

1.1. Diagnóstico resumido sobre el estado de las pesquerías en el Perú

1.2. Ciencia y manejo pesquero: modelos End-to-End para el desarrollo de un enfo que ecosistémico en el manejo de las pesquerías del Perú

2. ACERCA DEL CONCEPTO DE TRANSPARENCIA EN LOS PRINCIPALES FOROS GLOBALES

2.1. Definiciones de transparencia a nivel internacional

2.2. Principios FiTI (Fisheries Transparency Initiative)

2.3. Los límites de la transparencia en relación con el enfoque precautorio promovido por ICES para el manejo pesquero

2.4. La transparencia en los organismos regionales de ordenamiento pesquero

2.5. La transparencia en el sector pesca en Chile y Argentina

3. LA TRANSPARENCIA EN EL SECTOR PESQUERO DEL PERÚ

3.1. La Ley General de Pesca vigente desde 1992

3.2. El Reglamento de la Ley General de Pesca, con especial referencia a los Reglamentos de Ordenamiento Pesquero

3.3. Planes de Acción Naciona
3.4. Metodología de la evaluación comparativa (benchmarking) para la gobernanza pesquera
3.5. Evaluación de los Reglamentos de Ordenamiento Pesquero vigentes a la fecha

3.5.1. ROP de la anchoveta $y$ anchoveta blanca para CHD

3.5.2. ROP para la pesquería del jurel $y$

$$
\text { la caballa }
$$

35.3. ROP de la Merluza

3.5.4. ROP del Calamar Gigante o Pota 3.5.5. Reglamento de la Ley General

de Pesca y medidas de ordenamiento complementarias para el perico

3.5.6. ROP de la Anguila

3.5.7. ROP del Bacalao de Profundidad

3.5.8. ROP de las Actividades Extractivas

Artesanales y de Menor Escala del

Ámbito Marítimo Adyacente al Departamento de Tumbes

3.5.9. Reglamento de Ordenamiento Acuícola (ROA) de la actividad de repoblamiento en la bahía de Sechura

3.5.10. ROP de las Macroalgas Marinas

4. SÍNTESIS DE LAS ENTREVISTAS CON EXPERTOS DEL SECTOR, CON ESPECIAL REFERENCIA A LA TRANSPARENCIA

YLA PESCA ILEGAL

4.1. Acerca de la definición del concepto de transparencia en el sector pesca

4.2. Sobre la transparencia en la gestión de las principales pesquerías nacionales

4.3. Medidas para incrementar la transparencia en la gestión de la pesca

4.4. Sobre las medidas de excepción

cuando las evaluaciones pudieran estar sesgadas 2
4.5. Transparencia en las recomendaciones de gestión de IMARPE

4.6. Sobre el nivel de información que IMARPE podría comparti públicamente

47. Sobre el nivelde información que PRODUCE podría compartir públicamente

4.8. Métodos para la evaluación del manejo de las pesquerías

4.9. Sobre el establecimiento de medidas diferentes a las actuales para reducir los descartes

4.10. Acerca de la adopción de esquemas de ecocertificación para las pesquerías Peruanas

4.11. Acerca de la adopción de esquemas de comanejo en las pesquerías de recurso: bentónicos

4.12. Sobre el alto nivel de pesca ilegal e informal

13. Sobre el uso que se da a los pagos por derechos de pesca mejorarla gobernanza y la transparencia en el sector pesca

5. SÍNTESIS DE UNA CONSULTA PÚBLICA (ON LINE) SOBRE EL ESTADO DE LA TRANSPARENCIA EN LA GESTIÓN DEL SECTOR PESCA

.1. Distribución de las personas encuestadas según las entidades en las que laboran

5.2. Definición del concepto de transparencia y su ejercicio actual en el sector

5.3. Sobre la participación de los grupos de interés y el cumplimiento de la Ley de Transparencia

5.4. Estado de la transparencia de la gestión para las principales pesquerías
4.14. Acerca de la necesidad de una intervención intersectorial para
55

6

57

5.5. Mecanismos adicionales para incrementar la transparencia en la gestión de las pesquerías

5.6. Sobre la publicación de la información del SISESAT y el establecimiento de nuevas reglas para el control de capturas

5.7. Sobre el esquema de derechos de uso territorial y el fortalecimiento de capacidades en las instituciones a cargo de contener la informalidad en el sector pesca

5.8. Acerca del uso que se da a los derechos de pesca y la atención que el Estado brinda a las pesquerías

CRITERIOS PARA PRIORIZAR ACCIONES EN FAVOR DE LA TRANSPARENCIA

6.1. La decisión política debe estar alinead con los objetivos y metas de sostenibilidad

6.2. Una fuerte institucionalidad para una gestión transparente y transversal de pesquerías

6.3. Institucionalización del diálogo y la participación en el diseño del marco normativo

6.4. Asignación de derechos para contener la informalidad y promover la sostenibilidad

6.5. Monitoreo y vigilancia ecosistémica con participación de los grupos de interés

6.6. Evaluación del manejo adaptativo y proceso de mejoras continuas

59 7. RECOMENDACIONES

8. REFERENCIAS BIBLIOGRÁFICAS

9. ANEXO: RELACIÓN DE EXPERTOS CONSULTADOS 
La evolución de la normativa legal para el manejo de las pesquerías peruanas en general, $\mathrm{y}$ de las artesanales en particular, ha conducido a niveles crecientes de informalidad y de captura ilegal o no reportada o reglamentada, lo que amenaza la sostenibilidad de los recursos y la subsistencia de las comunidades de pescadores artesanales, además de constituir una amenaza para la seguridad alimentaria Las causas más profundas de este problema radican en la falta de transparencia en el diseño de las normas (ROP) de cada pesquería, algunas de las cuales han sido estructuradas para la operación de naves de tipo industrial o de menor escala, de modo que se ha desatendido el sector artesanal. Los ROP son asimismo excesivamente reglamentaristas, y buscan normar aspectos que en la práctica es imposible atender. Asimismo, contienen un alto nivel de discrecionalidad para los funcionarios, y conllevan por ello un bajo nivel de transparencia en la gestión de las pesquerías. Otra de las raíces de la problemática actual se puede encontrar en una deficiente intervención intersectorial; es el caso, por ejemplo, de entidades que, como DICAPI, no cuentan con los recursos financieros y humanos necesarios para abarcar sus competencias en el sector pesquero. Un número elevado de embarcaciones artesanales y de menor escala se construyen de modo ilegal y transitan sin matrícula o con matrícula falsificada, o sin permiso de pesca. Algunos gobiernos regionales han asignado permisos de pesca sin tener competencia para ello.

La inversión en infraestructura sanitaria y de desembarque es insuficiente. El incumplimiento de las normas sanitarias no puede ser controlado sin una articulación funcional, actualmente inexistente, entre SANIPES, DICAPI y DIREPROS. De los desembarcaderos de la pesca artesanal (DPA), solo unos pocos cuentan con habilitación sanitaria, lo que significa que existe un alto riesgo de contaminación de las capturas. Asimismo, es notoria la falta de plantas de hielo, o la insuficiente producción de las que hoy existen. El incumplimiento de la normativa sanitaria en las embarcaciones también es un problema latente.

Por todo ello, el manejo de las pesquerías requiere un mayor grado de transparencia, no solo en la gestión sino tambien en el reconocimiento de las carencias y en el diseño de una estrategia para resolverlas. Algunas medidas de manejo son percibidas con escepticismo por no haber sido públicamente presentadas. No existen protocolos de procedimientos para los casos de excepción (como las pescas exploratorias, por ejemplo). Se carece de mecanismos independientes de evaluación de la gestión de las pesquerías. No hay indicadores de la gestión sectorial respecto al borde marino.

Las propuestas para establecer esquemas de cogestión, que resolverían en parte el problema de la falta de presencia del Estado en algunas pesquerías, no han sido aceptadas, pues persiste la opinión de funcionarios que no conciben que el Estado comparta competencias vigilancia a cambio de derechos de uso exclusivo, no obstante que en algunas pesquerías ya existen esquemas de derechos de uso (en la anchoveta para uso industrial, por ejemplo). También las propuestas de ecocertificación de pesquerías, que vinculan al consumidor final con pesquerías sostenibles, estos es pueden ser implementados.

De lo indicado hasta aquí se colige que resulta necesario mejorar las normas. Para abordar los problemas que aquejan al sector es preciso institucionalizar la de Coordinación Intersectorial o similares para cada pesquería, lo que permitiría articular los esfuerzos del Estado con los del sector privado, universidades, ONG, gremios, tanto para los propósitos del diseño de normas y políticas públicas como para su ejecución y cumplimiento.

En este documento se expone la definición del concepto de transparencia a nivel internacional y local, y se presentan las principales iniciativas que promueven la transparencia como elemento esencial de la gestión pública.
Asimismo, se propone la definición: Transparencia es el conjunto de procedimientos que demuestran el correcto uso de los bienes públicos. La transparencia es una característica deseable en lagestión pública, que consisteen la implementación de medidas que apoyen la credibilidad y la confianza de la sociedad en sus autoridades respecto al uso de los bienes naturales de la nación. Una autoridad que se ejerce con transparencia anticipa los hechos, es proactiva y busca que sus funcionarios estén imbuidos de la onstantes, $y$ ataja las resistencias que se dan en sentido contrario.

Con base en estos conceptos, se han realizado veintitrés entrevistas con expertos del sector, incluyendo a funcionarios del Estado, del sector privado industrial y artesanal, ONG, universidades, gremios y expertos independientes. Asimismo, se llevó a cabo una encuesta en línea para realizar similares consultas a la opinión pública del sector.

Se concluye que es necesario priorizar acciones como la institucionalización del diálogo y la participación de los grupos de interés en el diseño de las normas, su implementación y la evaluación de su eficacia. Estas acciones contribuyen a una gestión transparente de acuerdo con la definición propuesta. Sin embargo, su implementación demanda la decisión política de avanzar hacia la progresiva implementación de un manejo con enfoque ecosistémico que aborde la complejidad del equilibrio entre los aspectos sociales, económicos y ecológicos.

Para identificar acciones prioritarias en relación con la transparencia en el sector pesca se han evaluado los ROP disponibles a la fecha, de lo que se ha concluido que en general, aun cuando el sistema de gestión muestra algunos aspectos positivos, la mayoría de los aspectos relacionados con él merecen una baja calificación, por lo que resulta imprescindible introducir reformas en los reglamentos y, tal vez, en la misma Ley de Pesca y su Reglamento.

Se requiere asimismo realizar un nuevo censo de la pesca artesanal, para lo cual habría que convocar la participación de las entidades con competencias en el tema, de las universidades y de la sociedad civil en e proceso de diseño, ejecución y análisis de la información. Esta acción es imprescindible para contribuir a ordenar el sector y reducir drásticamente la informalidad con participación de los GORE.

Se concluye que la gobernanza de la pesca en el país es centralista e impuesta, lo que, sin embargo, ha tenido en general un resultado positivo en el caso de la pesca industrial. Perola complejidad ydiversidad de modalidades de pesca en el sector artesanal compromete la viabilidad y legitimidad de la normativa actual. El resultado es una gobernanza que no promueve el bienestar de los pescadores a pesar de su rol fundamental en el contexto de la seguridad alimentaria, y que más bien provoca la sensación de desorden e ineficacia en la acción de las entidades competentes.

Se concluye asimismo, de acuerdo con la opinión mayoritaria, que el íntegro de la flota artesanal debe ingresar al SISESAT y que, a su vez, este debe integrarse SIMTRAC. Hay alternativas tecnologicas asequibles $y$ más económicas que la emisión en tiempo real para el caso de las naves más pequeñas.

Se ha identificado también que el país requiere una Política Marítima que debe ser diseñada por CEPLAN con apoyo de las entidades públicas y privadas del sector, con el propósito de que el MEF incremente el flujo de inversiones estatales en el sector marino. En el caso pesquero, específicamente, se requiere mejorar la infraestructura sanitaria, de desembarque y provisión de hielo y agua potable. DICAPI y DIREPROS requieren recursos financieros y humanos para sostener una presencia completa en sus ámbitos de jurisdicción.

Finalmente, se ha hallado que es preciso diseñar Planes de Acción Nacional (PAN) para la movilización de recursos con el fin de generar el conocimiento biológico y ecológico necesario para diseñar más ROP para más especies, o bien para grupos de especies. 
ADET Análisis Diagnóstico Ecosistémico Transzonal

AGRORURAL Programa de Desarrollo Productivo Agrario Rura

AIS Sistema automático de identificación

AMERB Áreas de Manejo de la Extracción de Recursos Bentónicos

ANA Autoridad Nacional del Aguc

ANP Área Natural Protegida

ASC Aquaculture Stewardship Council

BGI Iniciativa de Crecimiento Azul

CAR Comisión Ambiental Regional

CCPR Código de Conducta para la Pesca Responsable

CCRVMA Comisión para la Conservación de los Recursos Vivos Marinos Antárticos

CENPAR Censo Nacional de la Pesca Artesanal

CEPLAN Centro Nacional de Planificación

CFP Consejo Federal Pesquero (Argentina)

CHD Consumo Humano Directo

CHI Consumo Humano Indirecto

CIAT Comisión Interamericana del Atún Tropical

CITC

COMUMA

COPMAR

COREVIPA

CSIRO

DEFENSA

DICAPI

DIGESA

DIREPRO

DS

E2E

EITI

ELBA

ERAEP

FAO

FOCAM

FONAM

GEF

GEMCH

GFW

GORE

HCR

IATI

ICES

IdSO

IFOP

IMARPE

INEI

INIDEP

INTELFIN
Cuotas Individuales Transferibles de Captura

Comisión Multisectorial de Gestión Ambiental del Medio Marino

Comunidad Pesquera Artesanal de San Juan de Marcona

Comités Regionales de Vigilancia de la Pesca Artesanal

Commonwealth Scientific and Industrial Research Organization (Australia)

Ministerio de Defensa

Dirección de Capitanías y Guardacostas de la Marina de Guerra del Perü

Dirección General de Salud

Dirección Regional de la Producción

Decreto Supremo

End to End Modelling

Iniciativa para la Transparencia en Industrias Extractivas

Estudio de Línea de Base

Evaluación del Riesgo Ecológico Asociado a Pesquerías

Organización de las Naciones Unidas para la Alimentación

Fisheries Transparency Initiative

Fondo de Camisea

Fondo Nacional para el Desarrollo de la Pesca

Fondo Mundial Ambiental

Gran Ecosistema Marino de la Corriente de Humboldt

Global Fishing Watch

Gobierno Regional

Reglas para el control de captura (Harverst Control Rules)

International Aid Transparency Initiative

Consejo Internacional para la Exploración del Mar

Indice de Salud de los Océanos

Instituto de Fomento Pesquero (Chile)

Instituto del Mar del Perú

Instituto Nacional de Estadística e Informática

Instituto Nacional de Investigación y Desarrollo Pesquero

Inteligencia Financiera

\section{ITP}

MEF

MINAGRI

MINAM

MOF

MPA

MPH

MSC

MSE

OEFA

ONG

ONU

OROP-PS

OSPA

PAE

PAN

PESEM

PLANAA

PNUD

PRL
PRO

PRODUCE

PRP

RM

RNSCH

RNSIIPG

ROA

ROP

SANIPES

SCH

SERNANP

SERNAPESC

SIMTRAC

SISESAT

SNIP

SNP

SPRFMO

SSPYA

SUBPESCA

SUNATTM

UICN

UNEP

USD

WWF
Instituto Tecnológico de la Producción

Ministerio de Economía y Finanzas

Ministerio de Agricultura

Ministerio del Ambiente

Manual de Organización y Funciones

Manejo Pesquero Adaptativo

Método de Producción de Huevos

Máximo Rendimiento Sostenible

Marine Stewardship Counci

Estrategias de Evaluación del Manejo

Organización para la Cooperación y el Desarrollo Económicos

Organismo de Evaluación y Fiscalización Ambiental

Organismo No Gubernamental

Organización de las Naciones Unidas

Organismo Regional de Ordenamiento Pesquero

Organismo Regional de Ordenamiento Pesquero para el Pacífico Sur Organización Social de Pesca Artesanal

Programa de Acción Estratégica

Plan de Acción Nacional

Presidencia del Consejo de Ministros

Plan Sectorial Multianua

Plan Nacional de Acción Ambiental

Programa de las Naciones Unidas para el Desarrollo

Puntos de Referencia Límite

Puntos de Referencia Objetivo

Ministerio de la Producción

Puntos de Referencia Precautor

Resolución Ministerial

Región Norte del Sistema de la Corriente de Humboldt

Reserva Nacional Sistema de Islas, Islotes y Puntas Guaneras

Reglamento de Ordenamiento Acuícola

Reglamento de Ordenamiento Pesquero

Organismo Nacional de Sanidad Pesquera

Sistema de la Corriente de Humboldt

Servicio Nacional de Áreas Naturales Protegidas por el Estado

Servicio Nacional de Pesca (Chile)

Sistema de Monitoreo del Tráfico Acuático

Sistema de Seguimiento Satelital

Sistema Nacional de Inversión Pública

Sociedad Nacional de Pesquería

South Pacific Regional Fisheries Management Organization

Subsecretaría de Pesca y Acuicultura de la Nación (Argentina)

Subsecretaría de Pesca y Acuicultura (Chile)$$
\text { Tonelada métrica }
$$

Unión Internacional para la Conservación de la Naturalezan

Organización de las Naciones Unidas para la Protección del Ambiente

Dólares de los Estados Unidos de América

World Wildlife Foundation

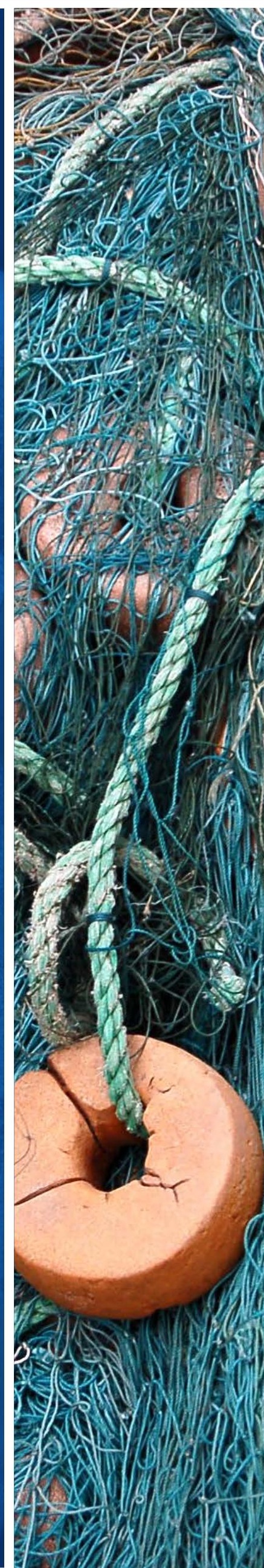


con el sector pesquero. El documento ADET incluye una minuciosa descripción de los impactos de cada problema e identifica las causas inmediatas, subsecuentes y la raíz de cada problema. Este se convierte, por lo tanto, en un documento guía para el desarrollo de Planes de Acción Nacional que deben diseñarse y ejecutarse bajo los principios de transparencia y participación pública en el diseño de políticas para la pesca.

Por otro lado, el Programa de Acción Estratégico (PAE) acordado por los gobiernos del Perú y Chile en el marco del Proyecto Binacional GEF-PNUD-Humboldt Hacia un Manejo con Enfoque Ecosistémico del Gran Ecosistema Marino de la Corriente de Humboldt (GEF-PNUD, 2016), contiene los lineamientos y la identificación de los objetivos que se busca alcanzar a través de Planes de Acción Nacional u otros equivalentes que permitan que, en el plazo de cinco años, los problemas identificados hayan sido contenidos o revertidos. El PAE se constituye así en un compromiso internacional de ejecución inmediata con el apoyo financiero de GEF y el soporte de PNUD. La fase de diseño se llevará a cabo durante 2017 y la ejecución de la parte 2 del Proyecto Binacional GEFPNUD-Humboldt debería iniciarse a comienzos de 2018.

Los cinco objetivos generales del PAE son:

1. Recuperar y mantener los niveles óptimos poblacionales de los principales recursos pesqueros considerando la variabilidad ambiental y manteniendo la salud y productividad del ecosistema.

2. Mejorar la calidad ambiental del ecosistema marino y costero mediante el manejo integrado, considerando las diversas fuentes de contaminantes.

3. Recuperar y mantener el hábitat y la biodiversidad de los sistemas marinos y costeros a nivel sostenible.

4. Diversificar $y$ agregar valor, creando oportunidades productivas dentro y fuera del sector pesquero, con personas socialmente organizadas e integradas.

5. Contribuir a la seguridad alimentaria de la población.

Los aspectos transversales para la consecución de estos objetivos son: (1) la incorporación del conocimiento técnico y científico en la gestión, es decir, en las normas; (2) la intervención intersectorial efectiva para la atención de los problemas prioritarios; $y$, (3) laincertidumbre respecto a la variabilidad ambiental y efectos del cambio climático.
1.2. Ciencia y manejo pesquero: modelos

End-to-End Modelling para el desarrollo de un enfoque ecosistémico en el manejo de las pesquerías del Perú

Habiéndose culminado la primera fase del Proyecto Binacional Perú Chile Hacia un Manejo con Enfoque Ecosistémico del Gran Ecosistema Marino de la Corriente de Humboldt (Proyecto GEF-PNUD-Humboldt PIMS 4147, 2011-16), corresponde continuar con la siguiente fase en el marco de este compromiso internacional acordado por ambos gobiernos. El compromiso consiste en implementar el PAE citado en el acápite anterior, es decir, en abordar los problemas de atención prioritaria identificados en el ADET. En otras palabras, el reto principal para los años venideros es la implementación del Manejo con Enfoque Ecosistémico (MEE) (Andrade et al., 2011) a través de facetas operacionales como el Manejo Precautorio Adaptativo (MPA), que ya se cita en la normativa vigente y que conviene desarrollar para abarcar el mayor número posible de especies. Sin embargo, el grado de conocimientos que se requiere para poder aplicar el MEE es muy amplio y diverso, y demanda el soporte de modelos ecosistémicos que ya están siendo desarrollados (Christensen et al., 2014; Oliveros, 2015) y que deben ser utilizados, probados y mejorados sin abandonar los métodos directos o tradicionales de evaluación y manejo.

El modelamiento de ecosistemas es necesario para entender los efectos de la pescay de la variabilidad natural y el cambio climático en todos sus componentes. Los modelos integrados y multidisciplinarios se denominan "modelos de extremo a extremo" ("End-to-End Models" o "E2E") e incluyen la física del ambiente, la producción primaria y secundaria, y las dinámicas e interacciones entre las especies explotadas. Oliveros (2015) ha desarrollado el primer modelo de este tipo aplicado a la región norte del Sistema de la Corriente de Humboldt. Los resultados iniciales son prometedores, aunque aún deben ser confrontados con los resultados de utilizar métodos directos, con el fin de calibrarlos y consolidar su credibilidad para emplearlos en el proceso de toma de decisiones.

Este modelamiento es una necesidad en el marco de la implementación de un manejo ecosistémico en las pesquerías. Sin embargo, el estado actual de su desarrollo no es lo suficientemente robusto como para tomar decisiones cruciales como la determinación de cuotas de pesca en pesquerías tan complejas y dinámicas como la de la anchoveta peruana (Engraulisringens). En cambio, un Manejo Pesquero Adaptativo (MPA) viene aplicándose en el Perú desde la década de 1990, con base en las lecciones aprendidas luego de dos colapsos sucesivos de la pesquería (1972 y1982).

La evolución e incremento de las metodologías y las mejores tecnologías hoy disponibles hacen posible un mayor desarrollo del MPA para considerar grupos de especies del mismo niveltrófico, ya que el número de conexiones tróficas entre las principales especies es demasiado amplio y complejo como para determinar el impacto específico de las cambiantes condiciones ecosistema.

El relativo éxito del MPA en el caso de la anchoveta ha estado en la atención más cercana o más frecuente del ecosistema, incluyendo el monitoreo continuo del reclutamiento y de los cambios en la distribución e índices de desove de las especies. Se han establecido puntos de referencia límite y objetivo (PRL y PRO, Guevara et al., 2010) para la anchoveta, y como resultado de este enfoque precautorio, varias temporadas de pesca (20102, 2012-2, 2014-2) han debido ser canceladas con base en la mejor evidencia científica disponible. La declinación de las capturas que se observa para esta especie en los años 2010, 2012, 2014, 2015 y 2016 es el resultado práctico del MPA, y no necesariamente una reducción de la biomasa provocada por la pesquería.

Es asimismo necesario reconocer las debilidades de los modelos monoespecíficos. Estos consideran como constantes parámetros que se sabe tienen una fuerte variabilidad (por ejemplo, la mortalidad natural). En este caso los modelos ecosistémicos ya proveen información acerca de esa variabilidad, y pueden por tanto ser incorporados para reducir la incertidumbre de los modelos monoespecíficos (Oliveros, 2015).

De la misma manera, los modelos ecosistémicos pueden pronosticar losimpactosdelavariabilidad ambiental sobre las especies explotadas. Existe entonces una marcada expectativa sobre la manera en que estos modelos serán utilizados en el marco de la implementación del MEE para las pesquerías del Perú. Otros modelos físicos y sistemas de información (como el monitoreo de la anomalía de altura media del mar) ya proporcionan información sobre escenarios ambientales provocados por eventos tipo $\mathrm{E}$ Niño.

Otra de las mejoras que se espera para los años venideros es la implementación de Estrategias de Evaluación del Manejo (MSE), otra faceta del MEE que comprende un conjunto de algoritmos y simulaciones para comparar el efecto de procedimientos alternativos de manejo (Butterworth 2007, 2010). De este modo, las MSE demandan la definición de objetivos operacionales tales como fijar límites al esfuerzo, para evaluar, a través de simulaciones, el efecto de escenarios alternativos de manejo respecto a los PRL y PRO.

Por otra parte, para el caso de pesquerías con bajo nivel de información, en los últimos años se han implementado $y$ realizado en el Perú, de modo experimental, Evaluaciones de Riesgo Ecológico Aplicado a Pesquerías (EREAP) (Ross et al., 2007; Smith et al., 2007; Hobday et al., 2011) siguiendo la metodología desarrollada por CSIRO para las pesquerías australianas con bajo nivel de información. Esta metodología debería ser utilizada de modo regular para varias pesquerías, ya que se ha capacitado fuertemente a un grupo de investigadores de IMARPE. Las EREAP poseen varios niveles de ejecución, y en cada una de ellas se puede extraer conclusiones y recomendaciones útiles para la gestión de las pesquerías, no solo por su condición semicuantitativa sino también incipio precautorio. Esto quiere decir que, ante la necesidad de cuantificar cada aspecto de la biología y ecología de las especies evaluadas, se opta por el valor más conservador si no se cuenta con el respaldo científico necesario.

Otra de las metodologías desarrolladas en el marco de la implementación del MEE es la del Índice de Salud de los Océanos (IdSO) (Halpern et al., 2012). El ISO es un indicador del estado de los bienes y servicios del océano en cada país, con énfasis en los aspectos ligados a la gobernanza, que es la capacidad de un Estado para cumplir sus funciones. El IdSO es un conjunto de diez grupos de indicadores que evalúan la performance de la gestión de cada país ribereño. El IdSO asimismo incluye un rankingmundial de desempeño por países. En el Perú, la Comisión Multisectorial de Gestión Ambiental del Medio Marino (COMUMA), coordinada por el Ministerio del Ambiente e integrada por varios sectores con competencias en relación con el océano, ha aprobado su uso formal y se halla diseñando su implementación.

Los diez indicadores principales son: (1) provisión de alimentos en relación con una pesca y producción sostenibles; (2) oportunidad de desarrollo para la pesca artesanal, asegurando su sostenibilidad; (3) producción 
publicadas sobre la base de información y procedimientos que son accesibles al público" (Hood, 1991). La idea de acceso público a la información y a los procedimientos está entonces vinculada a la transparencia.

Quienes abogan por la transparencia lo hacen por varias razones. Algunos argumentan que es un derecho humano básico (Birkinshaw, 2006). Apoya este argumento el artículo 19 de la Declaración Universal de Derechos Humanos de la ONU, que establece que "toda persona tiene derecho a recibir y difundir informaciones e ideas por cualquier medio y sin importar las fronteras" (ONU, 1948). Otros proponen que la transparencia es inherente a la democracia. En un estudio reciente se halló que "Ios incentivos electorales conducen a las democracias hacia una mayor apertura" (Hollier et al., 2011).

Aunque no la llamó explícitamente por su nombre, la Declaración de Río de 1992, sobre Medio Ambiente y Desarrollo, desempeñó un papel importante en el establecimiento de principios de transparencia en la gestión ambiental. El Principio 10 de Río declara: "las cuestiones ambientales son mejor manejadas con la participación de todos los interesados en sus niveles correspondientes". Especificamente, el Principio 10 fomenta el acceso del público a la información sobre el medio ambiente: A nivel nacional, cada individuo tendrá un acceso adecuado a la información sobre el entorno en que se lleva a cabo la gestión pública, incluyendo información sobre materiales y actividades peligrosas en el entorno de sus comunidades, así como la oportunidad de participar en los procesos de toma de decisiones. Los Estados deberán facilitar y fomentar la sensibilización y participación haciendo ampliamente disponible la información relevante. Asimismo, se facilitará el acceso efectivo a los procedimientos judiciales y administrativos, incluyendo la reparación o remedio que fuera pertinente aplicar (ONU, 1992).

Parael Comitéde Transparenciadela OCDE(Organización para la Cooperación y el Desarrollo Económicos, www. ocde.org), la transparencia es "el proceso por el cual la información de las condiciones existentes es accesible para la toma de decisiones y acciones, de manera visible y entendible". En sus Principios de Gobierno Corporativo, la OCDE (2004) vincula directamente la transparencia con el uso de la información.

Asuvez,enelsectordelapescalaFAO(1995)recomiendaa los Estados y a las organizaciones y arreglos subregionales o regionales de regulación pesquera que aseguren la transparencia en los mecanismos de ordenamiento y en el proceso de adopción de decisiones. La misma FAO (2012) enumera principios y directrices que incluyen la transparencia enfocada desde varios ángulos, tales como el uso de la información, la generación de leyes, políticas $y$ toma de decisiones, la rendición de cuentas y la lucha contra la corrupción.

Entre las trece Directrices Voluntarias para Asegurar Pesquerías Sostenibles de Pequeña Escala en el contexto de la seguridad alimentaria y erradicación de la pobreza con claridad y dar amplia publicidad a las políticas, procedimientos y leyes, empleando lenguajes $y$ formatos adecuados y accesibles a todos".

Transparencia Internacional (https://www.transparency. org/), una coalición con sede en Berlín y presencia en más decien países, define la transparencia como "la aclaración de asuntos oscuros en donde exista pobre gobernanza o falta de normas y prácticas ilícitas que socavan el buen gobierno, la ética de los negocios y a la sociedad en general".

El Banco Mundial (2008) apoya la Iniciativa para la Transparencia en Industrias Extractivas (EITI), que fue implementada en el año 2002 para mejorar la transparencia y la responsabilidad en países ricos en gas, petróleo y minerales. Desde entonces los países han ido comprometiéndose a publicar sus informes EITI anuales (Oge, 2016), lo que está incrementando el nivel de escrutinio sobre el buen desempeño del país y, consecuentemente, mejorando el clima para las inversiones. Aunque la EITI no incluye al sector Pesca, es conveniente rescatar el primero de sus doce principios, el cual es perfectamente aplicable a todos los recursos naturales: "el uso prudente de los recursos naturales debe ser un motor importante para un crecimiento económico que contribuya al desarrollo sostenible y a la reducción de la pobreza, pero que si no se lo maneja apropiadamente puede provocar efectos socioeconómicos negativos".

En el caso específico del sector Pesca se han desarrollado diversos esquemasque, entre otros principios, promueven la transparencia y la participación de los grupos de interés en los procesos de gobernanza. Por ejemplo, las ecocertificaciones de pesquerías como MSC (Marine Stewardship Council), Friend of the Sea, Krav, etcétera (Accenture, 2009). Asimismo, Fisheries Transparency Initiative (FiTl) (http://fisheriestransparency.org/) es una organización que muestra el compromiso de grupos internacionales de interés que promueven mejoras para alcanzar pesquerías sostenibles a través de la transparencia y la participación. FiTI busca que regularmente se publique información sobre el acceso a las pesquerías y sobre los derechos asignados a particulares, con el fin de mejorar la credibilidad de la gestión pesquera.

El décimo principio de la Declaración de la Conferencia sobre Medio Ambiente y Desarrollo de Río 1992 (UNEP, 1992) establece que los temas ambientales son mejor abordados cuando se logra la participación de la ciudadanía a todo nivel,y cuando ella accede a información e interviene en el proceso de toma de decisiones. Este principio promueve que los Estados faciliten y promuevan la intervención de la sociedad a través de la amplia difusión de la información que se utiliza para la gestión ambiental.

El filósofo inglés Jeremy Bentham identificó el vínculo entre la transparencia y la rendición de cuentas: "considero que es una verdad indiscutible, y es además una verdad que es una de las piedras angulares de la ciencia política, es decir que en tanto más estrictamente nos vigilan, mejor actuamos" (Bentham 2001, citado por Hood 2006). En otras palabras, el argumento final a favor de la transparencia es aquel que indica que ella conduce a una mayor rendición de cuentas por parte de las autoridades (Grigorescu, 2003).

Sin embargo, estudios más recientes sobre el tema sugieren que el vínculo entre la transparencia y la rendición de cuentas es menos cierto, pues la primera no necesariamente conduce a una mayor responsabilidad. Según Fox (2007), existen dos tipos de transparencia (clara y opaca) y dos tipos de rendición de cuentas (suave y dura). La transparencia opaca "consiste en la difusión de información que no revela cómo las instituciones se comportan realmente en la práctica", mientras que la transparencia clara es aquella que "arroja luz sobre el comportamiento de las instituciones, y permite a las partes interesadas (tales como legisladores, formadores de opinión o académicos) buscar estrategias para un cambio constructivo" (Fox, 2007). La rendición de cuentas "suave" se refiere al "derecho fundamental de las autoridades para justificar sus decisiones", y la rendición de cuentas "dura" incluye los elementos de rendición de cuentas de tipo "suave" pero tiene la capacidad de imponer sanciones (Fox, 2007).

\section{2. $\quad$ Principios FiTI (Fisheries Transparency} Initiative)

Según Head (2006), algunos especialistas arguyen que, siendo valorada intrínsecamente como un derecho fundamental o un pilar de la democracia, la transparencia debería ser vista como una herramienta cuyo uso permita la consecución de otros objetivos. Para el mismo autor, las personas que adoptan este concepto admiten que, habiendo muchos beneficios asociados con la transparencia, reconocen también que hay ciertos costos, y sostienen que la transparencia no debe ser perseguida como un fin en sí mismo sino como un medio para alcanzar una finalidad (por ejemplo, poner a disposición pública unas informaciones útiles para la gestión de los sectores económicos).

Es esencial que haya una mayor transparencia, y que ella pueda facilitarse publicando información sobre las actividades de desarrollo de forma oportuna, amplia y con miras al futuro en un formato electrónico común y abierto, según proceda. El acceso a datos y estadísticas fidedignos ayuda a los gobiernos a tomar decisiones fundamentadas, permite que todos los interesados puedan hacer un y desventajas de las acciones tomadas, y establece una rendición de cuentas mutua (IATI, 2015).

En esa dirección, la Iniciativa de Transparencia en Pesquerías es una propuesta explícita de múltiples actores alrededor del mundo, quienes buscan impulsar prácticas transparentes en todos los aspectos ligados a la actividad pesquera mundial. La FiTI será implementada con un estándar específico que se halla en fase de diseño (http:// fisheriestransparency.org/). Esta iniciativa se inició bajo el liderazgo del profesor Peter Eigen, ${ }^{1}$ fundador y presidente del Consejo Asesor de Transparencia Internacional. Se países pesqueros a escala mundial, y de contar con un Informe de País para la FiTI. En apoyo a los gobiernos, el estándar definirá:

- Qué información debe hacerse pública;

- Cómo lograr transparencia en la gestión; y

- Cómo será gobernada esta iniciativa. 
- Principio 1. Las pesquerías sostenibles aportan a la seguridad alimentaria, el alivio de la pobreza y el desarrollo sostenible. También contribuyen con la al y regional y generan resiliencia a los impactos del cambio climático.

- Principio 2. Los gobiernos soberanos son responsables de la gestión sostenible de las pesquerías, para lo cual han de utilizar la riqueza del país en beneficio de sus ciudadanos, y promueven el interés nacional y la seguridad alimentaria y nutricional con un desarrollo socioeconómico equitativo.

- Principio 3. Todas las partes interesadas tienen importantes y relevantes contribuciones que hacer, lo que incluye a los gobiernos y sus agencias de pesca a gran y pequeña escala, organizaciones multilaterales, organizaciones financieras, inversores, sociedad civil organizada y academia.

- Principio 4. La transparencia es esencial para la pesca responsable, ya que estimula las rendiciones toma de decisiones en la gestión pesquera.

- Principio 5. La transparencia es más efectiva cuando la información es compartida y verificada a través de la participación activa, libre, eficaz, significativa e informada de los gobiernos, empresas, sociedad civil, científicos y otras partes interesadas como socios iguales, lo que permite que todas ellas se aseguren de que la información sea creíble y legítima.

- Principio 6. Para que la transparencia sea efectiva, la información relevante debe estar disponible en un formato accesible y oportuno.

- Principio 7. Incrementar la transparencia y la participación es factible, yella puede ser implementada progresivamente con el fin de asegurar la amplia aceptación de esta iniciativa.
En la gestión de los recursos naturales, la transparencia es ampliamente vista como deseable, pues evita efectos negativos comola corrupcióny las desigualdades en el acceso a los beneficios derivados de los recursos (Ardron, 2014).

Un estudio de Hauge et al. (2007) analiza los límites del principio de transparencia en el enfoque precautorio Mar) promueve para el caso del manejo de pesquerías. El enfoque de ICES se basa en el establecimiento de puntos de referencia límite (PRL) que reflejan el estatus de una especie explotada, $y$ en el establecimiento de puntos de referencia precautoria (PRP) que reflejan los niveles de riesgo de las opciones de manejo. Como los PRL se basan en la ciencia y los PRP en la gestión, este enfoque de ICES describe el objetivo ideal de alcanzar una clara división entre la ciencia y las responsabilidades del manejo. Para decirlo de otra manera: el manejo tiene dos componentes, aquel estrictamente científico y el que aborda consideraciones de otro tipo (sociales, económicas) bajo una condición precautoria.

Sin embargo, el estudio de Haugue et al. (2007), que discute la variedad de definiciones técnicas sobre los puntos de referencia y su utilización en el proceso de asesoramiento en el manejo, halló inconsistencias y una tendencia a minimizar la incertidumbre, que a su vez es una disminución del principio precautorio. En primer lugar, encontró que la transparencia respecto a supuestos de incertidumbre requiere de un marco entendible, y que trasladar la complejidad de la interacción entre un sistema natural y la actividad humana a conceptos simples conduce a problemas de estandarización. En segundo lugar que no es factible determinar una clara división que los PRL no pueden estar exclusivamente basados en la ciencia y a que los PRP no pueden sustentarse solo en el manejo.

Haugue etal.(2007) concluyeque tales dilemas establecen límites a lo que puede esperarse del enfoque precautorio de ICES en materia de manejo y comunicación de la incertidumbre. En este sentido, sugieren un continuo y amplio diálogo entre ciencia y manejo, con el propósito de reflexionar sobre sus respectivos roles con miras a lograr más eficiencia en lugar de persistir en la búsqueda del ideal de una separación estricta entre ciencia y manejo.
La comunidad internacional que estudia los progresos de la gobernanza medioambiental comenzó a hablar sobre la transparencia en la década de 1990, cuando pidió a las organizacionesregionalesdepesca(OROP)queaumentaran la transparencia de sus medidas de gestión (Clark, 2015). A la transparencia se le atribuye una serie de cualidades benéficas, incluyendo el fomento de la responsabilidad enel cumplimiento por parte de los gobiernos. Estos y las OROP prácticas actualmente utilizadas para ciertas pesquerías. Los Estados y las organizaciones y arreglos subregionales o regionales de ordenación pesquera deberían asegurar la transparencia en los mecanismos de ordenamiento y en el proceso de adopción de decisiones en esta materia (FAO, 1995).

Clark et al. (2015) han realizado la primera evaluación del principio de transparencia en las Organizaciones Regionales de Ordenamiento Pesquero, la cual regula las pesquerías en zonas que se ubican por fuera de las jurisdicciones nacionales (ABNJ). Una evaluación previa de la efectividad del manejo en las OROP (Cullis-Suzuki \& Pauly, 2010) mostró que la gestión en términos generales es deficiente por haber antepuesto los intereses de las pesquerías a la sostenibilidad de los recursos. Clark et al. (2015) hacen notar que en el sector pesca la transparencia sigue siendo un principio de cumplimiento voluntario o declarativo, y que los documentos de la FAO, como el Código de Conducta para la Pesca Responsable (E Código, FAO, 1995), aún no han conducido a su explícita implementación a pesar de haber transcurrido más de veinte años de su publicación.

A la fecha están vigentes 11 OROP. La metodología empleada por Clark et al (2015) para medir la transparencia en la gestión de cada organización fue simple pero efectiva: se desarrolló un cuestionario de 34 preguntas divididas en tres secciones: (i) acceso a la información detallada y actualizada, (ii) participación pública en el proceso de toma de decisiones y (iii) acceso a los resultados. Cada pregunta fue en sí misma una herramienta de diagnóstico para establecer la condición de cada OROP, pues se empleó un sistema de puntuación de desempeño. El resultado muestra un conjunto de buenas prácticas en las OROP, aunque ninguna puede ser identificada como especialmente transparente; al mismo tiempo, ninguna OROP obtuvo un pobre desempeño respecto a la transparencia.
En el documento Estado de las Pesquerías y Acuicultura Mundial (FAO, 2016) se presenta la Iniciativa FAO para el Crecimiento Azul (BGI), un enfoque con múltiples metas y dimensiones del desarrollo sostenible (económico, social y ambiental). Con el BGI se busca revertir el estado declinante de muchas pesquerías alrededor del mundo, y se hace especial referencia a que la transparencia es una condición clave para producir una buena asesoría científica para la gestión. Esto significa que no solo se requiere buena y adecuada información sino, además, que las metodologías y el intercambio de experiencias serán fundamentales para incrementar el desempeño de los Estados respecto a su manejo de las pesquerías.

\subsection{La transparencia en el sector pesca en Chile y Argentina}

En Chile está vigente la Ley N.․ 20.285, de Transparencia, vigente desde el 20 de agosto de 2008, que regula el principio de acceso a la información pública. Esta Ley obliga a implementar la transparencia en todas las reparticiones públicas, lo que quiere decir que el acceso a la información está regulado por esta Ley y se refiere a la normativa, resultados de investigaciones o estadísticas. Estas últimas (las estadísticas) están a cargo del Servicio Nacional de Pesca y Acuicultura (SERNAPESCA), que, por ser una agencia del Estado, también está obligada por la Ley.

Por otro lado, la nueva Ley (N. 20.657) de Pesca y Acuicultura, del 9 de febrero de 2013, creó los Comités Científicos Técnicos (CCT) para las principales pesquerías nacionales, con el fin de asesorar a la SUBPESCA en el proceso de toma de decisiones. Los informes de los CCT son públicos. La Ley también crea los Comités de Manejo (CM), en los que participan todas las partes interesadas, pero la mayoría de estos todavía están en formación. Los informes del CM también son públicos. Los CCT reciben además los informes del Instituto de Fomento Pesquero (IFOP) y de universidades respecto a evaluaciones de especies sometidas a pesquería. La SUBPESCA publica los informes que describen la condición de las principales pesquerías.

En Chile, la decisión última respecto a las pesquerías no la tienen los CCT o los CM, que son órganos de asesoramiento del Ministerio de Economía, Fomento y Turismo, donde se encuentra la SUBPESCA. Los CM tienen también como función asesorar a SUBPESCA en la elaboración de los planes de manejo para cada pesquería. Asimismo, participan los Consejos Zonales de Pesca (CZP) 
y el Consejo Nacional de Pesca (CNP). La conformación formal y permanente de estos y sus responsabilidades están previstas en la Ley General de Pesca y Acuicultura.

En cuanto a las normas, su publicación no pasa por una etapa de prepublicación, pero el ministerio y la SUBPESCA recurren a los comités para realizar procesos SUBPESCA recurren a los comités para realizar procesos flotas, en Chile no se publica la información del sistema de seguimiento satelital de las embarcaciones de pesca, de modo que solo cumplen objetivos de fiscalización desarrollando capacidades para darle un uso científico a
esta información.

Los portales con información sobre la pesca son el Ministerio de Economía, Fomento y Turismo, la SUBPESCA, el Fondo de Investigación Pesquera y de Acuicultura y el SERNAPESCA. Gracias a la creación de un sistema de registro de información con participación de los propios pescadores, en enero de 2015 se ha logrado obtener la certificación MSC para la pesquería de la langosta del Archipiélago de Juan Fernández. Recientemente las pesquerías del langostino colorado y e en mérito a su buen manejo.

En Argentina se encuentra vigente el Decreto 1172/2003, de acceso a la información pública, por medio del cual se aprueban los Reglamentos Generales de Audiencias Públicas para el Poder Ejecutivo Nacional, para la Publicidad de la Gestión de Intereses en el ámbito del Poder Ejecutivo Nacional, paralaElaboración Participativa de Normas, del Acceso a la Información Pública para e Poder Ejecutivo Nacional y de Reuniones Abiertas de los Entes Reguladores de los Servicios Públicos, formularios de inscripciones, registro y presentación de opiniones y propuestas. Existe también un acceso libre y través de internet a la edición diaria del Boletín Oficial de la República Argentina.

En este mismo país, el Código de Conducta para la Pesca Responsable (CCPR) es un documento fundamental de referencia. La Ley Federal de la Pesca (24.922) data de 1998, y fue elaborada según los lineamientos del CCPR. Esta Ley creó el Consejo Federal Pesquero (CFP), compuesto por representantes del Poder Ejecutivo Nacional, la Subsecretaría de Pesca y Acuicultura de la Nación (SSPyA), el Ministerio de Ambiente y Desarrollo Sustentable, la Cancillería Argentina, y de cada una de las provincias argentinas con litoral marítimo. Todas las actas y resoluciones del CFP son publicadas en su sitio web (http://www.cfp.gob.ar/). La SSPyA se encuentra en el sector administrado por el Ministerio de Agroindustria y tiene una página en el sitio de este ministerio (http://www.agroindustria.gob.ar/sitio/areas/ss pesca_acuicultura/).

En esta página se publican semanalmente actualizaciones de los datos de captura por especie, tipo de flota y puerto de desembarque. La información allí contendida proviene de las declaraciones de desembarque provistas por los armadores, integradas a los datos de control de descargas de los inspectores en puerto (el link es: http://www.agroindustria.gob.ar/ sitio/areas/pesca maritima/desembarques/). Existe información histórica desde 1988, aunque solo desde información histórica desde 1988, aunque solo desde sitio se publican informes regulares de coyuntura con datos de captura, exportaciones, importaciones y precios de comercialización, además de informes especiales que se realizan según requerimientos de la Autoridad de Aplicación (SSPyA) o el CFP.

Esta misma página presenta una sección de Monitoreo Satelital donde se publican actualizaciones, cada doce horas, de las posiciones de todos los buques que se encuentren operando cada día. Las embarcaciones que operan en aguas nacionales están obligadas a reportar su posición cada hora. Esta información se compila y se generan dos mapas de posicionamiento por día, que son publicados en la página web para conocimiento del público general, lo que le permite verificar el cumplimiento de las vedas pesqueras vigentes (http://www.agroindustria.gob.ar/sitio/areas/ pesca_maritima/monitoreo/).

También hay una sección para la pesca continental, pero allí los datos se presentan por años. Argentina es un país federal, y los recursos naturales de cada provincia son administrados autónomamente por cada una de ellas. Sin embargo, se generan estadísticas a nivel nacional que son publicadas en esta página, al igual que los proyectos nacionales que se llevan a cabo, principalmente en la cuenta parano-platense (http://www.agroindustria.gob.ar/sitio/areas/pesca continental/estadisticas/).

La información de la pesca marítima se publica por especie, mes, puerto y tipo de flota. En algunos informes especiales se incluyen detalles por embarcación, generalmente sobre capturas totales anuales. La información de cada viaje por barco no está disponible, y tampoco es posible suministrar información registral de las empresas.
El INIDEP (Instituto Nacional de Investigación y Desarrollo Pesquero) es la entidad responsable de la evaluación y conservación de los recursos marinos. Elabora informes por especie y por pesquerías, que luego son elevados al CFP, ente que decide la política pesquera en función de esas reco en funcion de esas recomdion. biológicos y recomendaciones elevados al CFP por el INIDEP son públicos una vez que hayan sido recibidos por el CFP y figuren en sus actas (http://www.inidep.edu. ar/publicaciones/catalogo/). El CFP puede, sin embargo, tener en consideración otras variables, además de las Máximas Permisibles (CMP) se establecen con base en las recomendaciones del Instituto.

Asimismo, se cuenta con Comisiones de Seguimiento de las principales pesquerías, que se reúnen dos veces por año para analizar la situación de cada pesquerí. Las Comisiones se componen de representantes de las autoridades pesqueras pertinentes, tanto de nivel nacional como provincial, el sector científico (INIDEP principalmente, aunque también se convoca a otras entidades) y el sector privado. En estas reuniones se presentan las evaluaciones de los recursos y se analizan las perspectivas con participación de la industria.

En Argentina no realizan procesos de consulta pública ni prepublicación de resoluciones. La interacción con la industria $u$ otros actores se formaliza en las ya mencionadas reuniones de las Comisiones de Seguimiento, en las que se va anticipando lo que ocurre en las pesquerías. Son comisiones asesoras en las que la industria puede plantear su posición para que sea tomada en cuenta, pero no son vinculantes. En algunas pesquerías costeras participan representantes de la flota menor, y algunos artesanales también. Se debe precisar que en el caso de la pesca artesanal, que opera dentro de las doce millas de jurisdicción provincial, la interacción directa corresponde a las autoridades provinciales, que son las que otorgan los permisos y establecen las medidas de manejo en esas áreas.

El proceso de toma de decisiones puede ser seguido y analizado a través de las actas y resoluciones del Consejo Federal Pesquero (CFP), que se reúne cada quince días, aunque puede convocarse también según sea necesario tratar temas específicos. La SSPyA preside el CFP y también tiene autoridad para establecer medidas, pero lo hace solo por razones de emergencia o extrema necesidad.

Las reglamentaciones de las políticas determinadas por el CFP corresponden a la autoridad de aplicación, y pueden establecerse por resoluciones de la Subsecretaría de Pesca y Acuicultura o alguna de sus Direcciones Nacionales.

No obstante el CFP no cuenta con un documento de planificación sectorial, sí tiene, en cambio, Planes de Acción Nacional: para combatir la pesca ilegal no declarada y no reglamentada (IUU); para la reducción de la interacción con aves marinas; para la conservación y el manejo de condrictios -tiburones, rayas y quimeras-, y recientemente se ha aprobado uno para la reducción de la interacción con mamíferos marinos. Todos estos planes fueron elaborados mediante procesos participativos a los que se convocó a todos los expertos en la temática, tanto científicos o académicos como de organizaciones de la sociedad civil. Los planes se monitorean todos los años a través de informes de los Grupos de Asesoramiento Técnico, o en talleres plenarios con todos los responsables de su elaboración. Estos Planes de Acción Nacional pueden ser revisados, tal como ya se ha hecho con el PANTiburones.

Para las pesquerías existen marcos normativos sólidos establecidos por Resolución del CFP, tales como las asignaciones de Cuotas Individuales Transferibles de Captura (CITC). Actualmente ya se cuenta con CITC para cinco recursos de importancia de Argentina: merluza hubbsi (hake -Merluccius hubbsi), merluza de cola (hoki - Macruronus magellanicus), merluza negra (Patagonian toothfish - Dissostichus eleginoides), polaca (Southern Blue Whiting - Micromesistius australis) y vieiras (Scallops - Zygochlamys patagónica). Las cuotas se otorgaron a fines de 2009 por quince años, y cuentan con un marco normativo general y uno específico para cada especie.

Además de las normas de regulación general de la pesca, también se cuenta con un marco normativo específico para los pequeños pelágicos: anchoíta (Engraulis anchoíta), calamar (Illex argentinus), langostino (shrimp - Pleoticus muelleri), abadejo (Pink cuskeel - Genypterus blacodes), centolla (King crab - Lithodes santolla), y para el conjunto íctico de la costa bonaerense, al que se denomina "variado costero".

Las actividades llevadas a cabo en la Zona Común de Pesca compartida con el Uruguay son reguladas por la Comisión Técnica Mixta del Frente Marítimo (http:// www.ctmfm.org/) la cual publica sus reglamentaciones online. La CTMFM cuenta con grupos de trabajo de científicos de ambos países que dan recomendaciones técnicas a la toma de decisiones.

Finalmente, se debe tomar nota de que Argentina cuenta actualmente con tres pesquerías certificadas por MSC: Ia anchoíta, la merluza de cola y la vieira. 


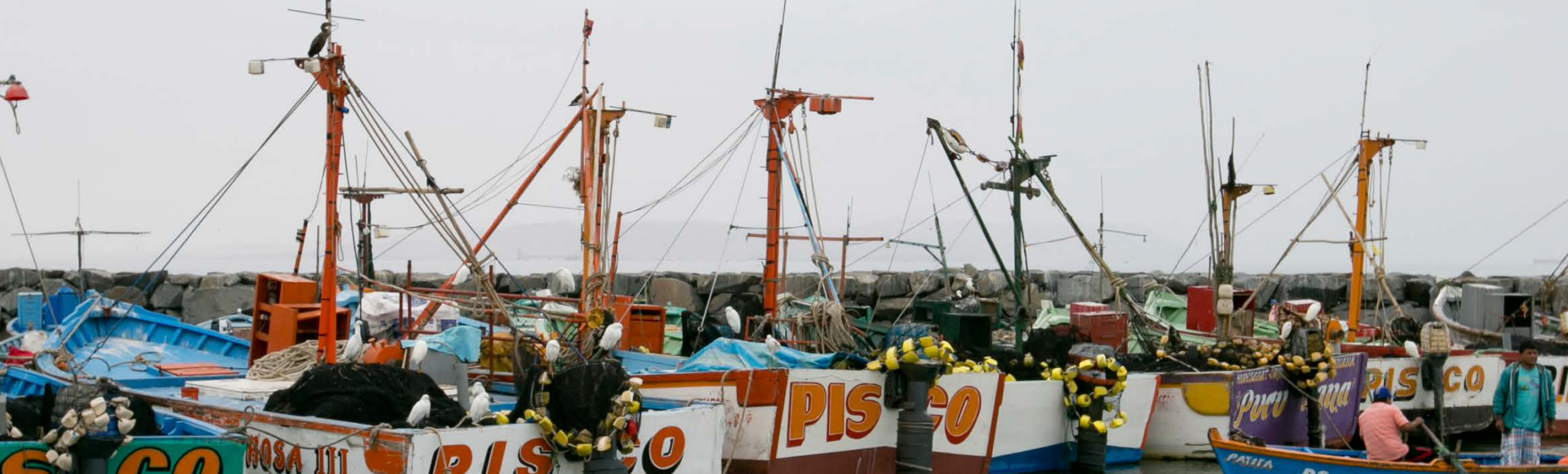

\subsection{LA TRANSPARENCIA EN EL SECTOR PESQUERO DEL PERÚ}

En la normativa peruana la palabra "transparencia" es poco citada, y cuando lo es se refiere únicamente a la gestión financiera y contable de las entidades públicas, no a las decisiones de gestión. Sin embargo, la Ley Peruana de Transparencia (Ley N. . 27806) alude al habeas data, es decir, que existe información que puede ser de interés público y que debe ser suministrada sin tener que dar cuenta de las razones para las que se solicita. Es de interés público, por ejemplo, conocer cómo se han calculado las cuotas de pesca, así como poder revisar estos cálculos empleando las mismas fuentes de origen.

La transparencia ha sido reconocida durante mucho tiempo como un principio básico de la gobernabilidad democrática, tanto en la política tradicional del Estado como en las instituciones internacionales. Ella se acredita con el aumento de la cooperación entre los actores, lo que permite diseñar soluciones a los problemas de interés común, fomenta el cumplimiento, aumenta la capacidad de rendir cuentas y la capacidad de respuesta de los gobiernos, y promueve el uso de la información, la participación y la prevención de conflictos. El concepto de transparencia se ha instalado en áreas tan diversas como lade los derechos humanos, la política fiscal y la seguridad. La literatura disponible no revela en qué medida la noción de transparencia ha influido en la gobernanza marina. Aunque la transparencia ha sido citada como un factor crítico en la gestión eficaz de los recursos marinos, pocos estudios abordan su adopción práctica para este ámbito (Clark, 2015)

La Constitución Política del Perú de 1993 cita a la transparencia una sola vez, en el capítulo 35, para referirse a las normas orientadas a asegurar el
Nacional al 2021, elaborado el año 2010 por el Centro Nacional de Planeamiento Estratégico (CEPLAN), y el Plan Acción Nacional Ambiental - PLANAA del 2011 al 2021 (aprobado por DS N.. 014-2011-MINAM). Ambos instrumentos recurrentemente citan la transparencia como elemento indesligable de la gestión pública.

En el sector pesca, el Plan Estratégico Sectoria Multianual (PESEM) 2012-2016, aprobado con RM N. 107-2012-PRODUCE, cita como su octavo objetivo: "Institucionalizar una cultura de transparencia en la gestión pública y consolidar un marco institucional facilitador y promotor del desarrollo sostenible pesquero y acuícola". El mismo PESEM, en cuanto a los principios que impulsa el Ministerio de la Producción, cita en tercer lugar a la transparencia: "El sector brinda información veraz, completa, confiable y oportuna, que permita conciencia certera acerca del resultado de cada procedimiento". En su Política 14 el PESEM propone: "Establecer una política sectorial de transparencia y lucha contra la corrupción". La Estrategia 43 de esta Política 14 indica la necesidad de "[f] ortalecer la participación ciudadana, la transparencia en la gestión pública, el derecho al acceso a la información.

Sin embargo, una nueva versión del PESEM, aprobada por RM NNo 345-PRODUCE-2015, es menos explícita respecto a la transparencia, pero es necesario precisar que este nuevo PESEM ha sido desarrollado de acuerdo con las directivas del Centro Nacional de Planeamiento Estratégico y abarca el período 2016-21.

El establecimiento de una política de transparencia no se ha expresado aún en hechos concretos; es decir, está presente en las normas solo de modo declarativo. Hay varios atributos de la transparencia que no se han implementado o institucionalizado, como la publicación de los puntos de pesca y estadísticas de desembarque; la participación y registro de los aportes de los grupos de interés en el proceso de diseño de las normas; la publicación de indicadores de desempeño económico y ecosistémico de las pesquerías; los montos tributados por derechos de pesca, así como su uso; las coordinaciones interinstitucionales que a menudo son citadas en las normas pero que en los hechos no es posible verificar; las evaluaciones independientes del desempeño de la gestión de cada pesquería; y el estado de la normativa pesquera, que actualmente abarca a un número reducido de especies. La investigación es citada a menudo en la normativa, pero no se indica de modo expreso, y en cada caso, cuáles son las necesidades o requerimientos específicos de la investigación.
En temas de gobernanza pesquera, el concepto de transparencia no llega tampoco a abordar cuestiones cruciales como el establecimiento de vedas o cuotas, o la estimación de la biomasa, pues al ser temas técnicos sobre los cuales hay en realidad pocos expertos, se genera en cambio un limbo en el que muy pocas personas tienen posibilidad real de participar. Asimismo, la gobernanza pesquera actual no cuenta con una estrategia de mejora de los procedimientos que conduzca a reducir la discrecionalidad existente en el proceso de toma de decisiones.

3.1. La Ley General de Pesca vigente desde 1992

El Decreto Ley N. 25977 , o Ley General de Pesca (LGP), se halla vigente desde 1992, y es la tercera del sector. Consta de doce títulos, de los cuales el quinto, destinado a normar las actividades acuícolas, fue derogado por la Ley N.o 27460 o Ley de Promoción y Desarrollo de la Acuicultura, que a su vez fue derogada por el Decreto Legislativo N. 1195 del año 2015, el cual aprueba la Ley General de Acuicultura.

El título primero comprende los artículos del 1 al 9, y en él se describe el objetivo de la norma y sus facultades sobre los recursos hidrobiológicos, y se establece quiénes pueden participar en la explotación y en el procesamiento de las capturas.

El título segundo establece, en sus artículos 10 al 12, que la gestión de los recursos hidrobiológicos se realiza a través de Reglamentos de Ordenamiento Pesquero (ROP).

En sus artículos 13 al 31, el título tercero determina los objetivos de la investigación pesquera y las acciones para su promoción. Asimismo, define y clasifica los conceptos de extracción y procesamiento, y destaca la libre comercialización en concordancia con la Constitución. El artículo 14 establece que el Estado promueve e incentiva la investigación y capacitación pesquera que realizan los organismos públicos especializados del sector y las universidades, así como la que provenga de la iniciativa de personas naturales o jurídicas del sector privado, cuyos resultados deberán ser oportunamente difundidos por medios apropiados.

A su turno, entre sus artículos 32 y 36, el título cuarto define la pesca artesanal y las acciones del Estado para su promoción y desarrollo, aunque debe señalarse que la ley no ha sido adecuada a la descentralización y existencia de los gobiernos regionales (Ley de Bases de la Descentralización, N. 27783). 
El título sexto, entre los artículos 43 y 46 , aborda las facultades y prerrogativas de la administración pesquera, así como los alcances de los derechos administrativos que se otorgan a los particulares respecto a la extracción transformación y otras actividades contempladas en la Ley.

Las condiciones en las que, por excedentes de pesca, las flotas foráneas pueden operar en la zona marina de jurisdicción nacional están establecidas en el título sétimo, entre sus artículos 47 y 50 .

A su vez, el título octavo, artículos 51 y 55, fija las condiciones para el registro general de las pesquerías en el caso de contratos que sean susceptibles de inscripción.

En sus artículos 56 al 63, el título noveno define las condiciones para la promoción de la actividad pesquera, así como los alcances del Fondo Nacional de Desarrollo Pesquero (FONDEPES).

Los artículos 64 al 75, pertenecientes al título décimo, describen al órgano rector administrativo del sector pesquería (Ministerio de Pesquería y, desde el año 2002, el Ministerio de la Producción), y cómo se relaciona con los demás poderes del Ejecutivo para el cumplimiento de sus funciones.

El título undécimo, en sus artículos 76 al 83 , señala las prohibiciones y sanciones ante el incumplimiento. El DS N.o 016-2007-PRODUCE creó el Texto Único del Reglamento de Inspecciones y Sanciones Pesqueras y Acuícolas (RISPAC), que ha sido posteriormente modificado por diversos decretos supremos.

Finalmente, los artículos 84 al 90, del título decimosegundo, establecen las disposiciones transitorias y finales para la adecuación de todas aquellas pe naturales o jurídicas que ya venían operando en la pesquería.
3.2. El Reglamento de la Ley General de Pesca, con especial referencia a los Reglamento de Ordenamiento Pesquero

(DS N. 012-2001-PE)

La Ley General de Pesca (LGP) constituye el marco para el ejercicio de los derechos y obligaciones que se asigna tanto a la administración como a los administrados o agentes que intervienen en las actividades propias del sector. En ese sentido, se implementa a través de un reglamento. La actual LGP ha tenido dos: el primero

EI DS N.o 01-94-PE aprobó en 1994 el primer Reglamento de la LGP. En su artículo 3 se precisa que todos los gastos en que el Estado incurra para garantizar la conservación y aprovechamiento serán cubiertos por quienes se benefician de la actividad pesquera a través del pago de derechos, permisos o licencias. El artículo 11 dispone que son los Planes de Ordenamiento Pesquero (POP) los que regulan pesquerías específicas. También es conveniente agregar que el Reglamento de 1994 tiene un enfoque multidisciplinario, en tanto que el segundo es notoriamente reglamentista y prescinde de la experiencia práctica o de campo en laque se debería basar toda norma pesquera.

Es el DS N. 012-2001-PE el que aprobó el Reglamento de la Ley General de Pesca, el cual se halla vigente desde el año 2001.

En lo referido al ordenamiento pesquero (título segundo), las disposiciones del Reglamento de la Ley General de Pesca son las siguientes:

El artículo 5 establece la necesidad de contar con Reglamentos de Ordenamiento Pesquero para especies o recursos hidrobiológicos que tengan que ser administrados como unidades diferenciadas según el hábitat que ocupan o la distribución geográfica que abarcan; se modificó así la denominación de POP del primer reglamento (de 1994) por la de ROP. Se establece que los ROP deben ser aprobados por Decreto Supremo (DS) y contener los principios y medidas de regulación de la pesca para cada caso específico.

El artículo 6 describe el contenido que deben tener los ROP: (1) el objetivo del ROP; (2) el régimen de acceso; (3) la capacidad total de la flota o del procesamiento de los recursos hidrobiológicos; (4) los requerimientos de investigación para sostener la pesquería; (5) las temporadas de pesca; (6) las artes y métodos de pesca autorizados; (7) las tallas mínimas de los recursos cuya extracción se autoriza; (8) las zonas prohibidas o restringidas para la pesca; $y,(9)$ las acciones de monitoreo control y vigilancia. El artículo 7 establece una evaluación periódica del o de los objetivos de cada ROP, así como que el resultado de tales evaluaciones debe ser de conocimiento público.

El artículo 8 clasifica los recursos hidrobiológicos por su estado de explotación en tres categorías: (1) inexplotados, cuando no se ejerce explotación sobre el recurso; (2) subexplotados, cuando el nivel de explotación que se ejerce permite márgenes excedentarios para la extracción del recurso; y, (3) plenamente explotados, cuando el nivel de explotación alcanza el máximo rendimiento sostenible.

El artículo 9 define las condiciones en las cuales los recursos hidrobiológicos pueden ser declarados en estado de recuperación, en el caso en que su integridad biológica haya sido negativamente impactada por eventos oceanográficos adversos que ponen en riesgo su sostenibilidad. En este caso se establecen también las condiciones para la declaración de una explotación bajo un regimen provisional, como establecer límites al esfuerzo de captura y disponer un seguimiento continuo de las condiciones de la especie explotada. Respecto a este punto, se debe hacer la observación de que en algunas pesquerías (merluza, anguila) se recurre constantemente a la excepción prevista de desarrollar pescas exploratorias o provisionales, por lo que deberían hacerse explícitos los supuestos en los que se basa el establecimiento de esas condiciones de excepción a la luz del principio precautorio de la FAO (1995).

El artículo 10 explicita la situación de plena explotación de un recurso hidrobiológico. Establece que esta no requiere declaración expresa y que, si hubiera tal declaración administrativa, deberá entenderse como declarativa de esa situación. En este artículo también se establece que las resoluciones administrativas que denieguen algún derecho sin que exista declaración expresa de recurso plenamente explotado deberán sustentarse en los informes científicos o técnicos y en las evidencias disponibles que a esa fecha acrediten la situación de explotación del recurso.

El artículo 11 define el régimen de acceso a la pesquería. El acceso tiene dos componentes: (1) respecto a la actividad pesquera propiamente dicha, la cual requiere autorizaciones de incremento de flota y sus correspondientes permisos de pesca; y, (2) las actividades de procesamiento pesquero, que demandan autorizaciones de instalación y sus correspondientes licencias de operación

El artículo 12 aborda el tratamiento de los recursos plenamente explotados. Se establece que, en el caso de los recursos hidrobiológicos que se encuentren plenamente explotados, no se autorizarán incrementos de flota ni se otorgarán permisos de pesca, salvo que se sustituya igual capacidad de bodega de la flota existente. El requisito de embarcaciones de mayor escala y a las de menor escala o embarcaciones con capacidad de bodega de hasta 32,6 $\mathrm{m}^{3}$ implementadas con modernos equipos y sistemas de pesca, cuya actividad extractiva no tiene la condición de actividad pesquera artesanal. El DS N.006-2015PRODUCE prohíbe la construcción de cualquier tipo de embarcación de pesca, salvo que se trate de la sustitución de otra dada de baja o siniestrada. En este punto se debe indicar que son múltiples las evidencias de un incremento no autorizado de la capacidad de bodega, así como de otras irregularidades (por ejemplo, la construcción ilegal de embarcaciones), que hacen actualmente impracticable la aplicación de este artículo. En otras palabras, ha habido un incremento no regulado ni autorizado del poder de pesca de la mayor parte de las flotas en el segmento artesanal y de menor escala.

El artículo 13 se refiere a recursos hidrobiológicos cuya extracción no es regulada por un ROP. Las pesquerías o recursos hidrobiológicos que no se encuentren específicamente considerados en los ROP se regularán por las normas contenidas en el presente Reglamento y demás disposiciones que le fueren aplicables. Vale la pena resaltar que si bien el Reglamento de la LGP dispone que el ordenamiento se apruebe a través de ROP, no se establecen criterios para priorizar qué especies o pesquerías deben tener un ROP, o un plazo para que PRODUCE cumpla con elaborarlos al menos para las principales pesquerías comerciales.

El artículo 14 establece la obligación de publicar la relación de embarcaciones autorizadas para realizar actividades extractivas en el primer $y$ tercer trimestre de cada año, tanto para las naves de mayor y menor escala, de acuerdo con los derechos conferidos a cada una de ellas.

El artículo 15 se refiere a los recursos hidrobiológicos subexplotados, de oportunidad o altamente migratorios. 
Se autorizarán incrementos de flota y se otorgarán los permisos de pesca procurando el crecimiento ordenado de sus pesquerías, y en relación con el potencial de los recursos hidrobiológicos que se explotan, salvo que se considere que se puede poner en riesgo a otras especies, en cuyo caso se aplicará el artículo 19 del Reglamento.

El artículo 16 concierne a los recursos hidrobiológicos considerados como inexplotados. En este caso se fomenta la investigación de tales recursos mediante la realización de pescas exploratorias y experimentales. El plazo para ejercer estas actividades no será mayor de seis meses, pudiéndose renovar el acceso por una sola vez, por igual plazo y previa evaluación y difusión de sus resultados. El proyectodeinvestigación requerirádelaopiniónfavorable de IMARPE, y de ser aprobado estará exceptuado del pago de derechos por permiso de pesca. Asimismo. se establece que IMARPE y las universidades participarán en la ejecución de las mencionadas actividades. También se establece que se podrá establecer regímenes de acceso a la extracción de estos recursos bajo modalidades distintas a la prevista en el artículo 11 del Reglamento, con el fin de promover su aprovechamiento.

El artículo 17 establece el régimen de abastecimiento permanente a la industria conservera, congeladora y de curados. Este régimen guardará armonía con el principio de aprovechamiento responsable de los recursos hidrobiológicos.

El artículo 18 se refiere a las embarcaciones siniestradas con pérdida total, y establece que podrá solicitarse nueva autorización de incremento de flota dentro de un periodo no mayor de un año de ocurrido el siniestro, siempre que la correspondiente solicitud sea formulada por el armador afectado para dedicarla a la pesquería originalmente autorizada.

El artículo 19 puntualiza la facultad para limitar el acceso a determinados recursos o actividades del sector con base en razones de ordenamiento y aprovechamiento responsable de los recursos hidrobiológicos o protección del medio ambiente. Asimismo, puede limitar el acceso a un recurso hidrobiológico mediante un determinado sistema de extracción o procesamiento.

Finalmente, el artículo 20 se refiere a la atribución o facultad de autorizar, con carácter transitorio, la extracción de recursos subexplotados, inexplotados, de oportunidad o altamente migratorios sobre la base de sustento técnico científico correspondiente, mediante disposición de carácter general que contiene las condiciones que para tal efecto se establezcan.

\section{3. $\quad$ Planes de Acción Nacional}

A partir del artículo 9 de la Ley General de Pesca (LGP), en el Perú se ha desarrollado también otra modalidad de gestión de pesquerías. Específicamente, el citado artículo 9 de la LGP dispone que PRODUCE determine, según el tipo de pesquerías, los sistemas de ordenamiento pesquero, las cuotas de captura permisibles, las pesquero, los métodos de pesca, las tallas mínimas de captura y demás normas que requieran la preservación y explotación racional de los recursos hidrobiológicos. Estas consideraciones se han contemplado en el caso del perico o mahi mahi (Coryphaena hippurus) y de los tiburones.

Por medio de Resolución Vice Ministerial N. 81-2016-PRODUCE/DVPA se aprobó el Plan de Acción Nacional para la Conservación y Manejo del Recurso Perico en el Perú (PAN Perico - Perú). En este caso, la iniciativa para el diseño del PAN Perico ha provenido de la Comisión Permanente del Pacífico Sur (CPPS), que promueve el cumplimiento de las directivas de la Organización de las Naciones Unidas para la Alimentación y la Agricultura (FAO), y ha llevado a cabo talleres sobre ecocertificación de pesquerías en los que se acordó promover entre sus países miembros el establecimiento de planes de manejo para la pesquería internacional del perico. Además, la Comisión Interamericana del Atún Tropical (CIAT) ha identificado que una de las especies con alta interacción con la pesquería de atunes es el recurso perico, por lo que promueve también el desarrollo de estudios sobre él. Vale la pena tener presente que a partir del año 2000 el Perú ha registrado las mayores capturas de perico, lo que representa alrededor de $50 \%$ de la captura mundial en el periodo $2000-2013$, y $86 \%$ en el Pacífico sudoriental. No obstante lo indicado, aún es incipiente el conocimiento sobre el estado actual de esta especie, incluyendo sus aspectos sociales, económicos y ecológicos relacionados, por lo que se espera que el PAN Perico sea efectivo para generar el conocimiento específico que requiere la gestión de esta pesquería.

A través del DS N. 002-PRODUCE-2014 se aprobó el Plan de Acción Nacional para la Conservación y Ordenamiento de Tiburones, Rayas y Especies afines en el Perú (PAN Tiburón - Perú). Con base en las conclusiones de tres talleres llevados a cabo los años 2005, 2009 y 2013, también con apoyo de CPPS y la FAO y la participación de los grupos de interés, se logró perfeccionar el PAN diseñado luego del primer taller llevado a cabo el año 2005.

3.4. Metodología de la evaluación comparativa (benchmarking) para la gobernanza pesquera

Grafton et al. (2007) desarrolló una metodología para evaluar la gobernanza pesquera como una manera de promover pesquerías rentables y ecosistemas resilientes. En especial, la generación y acceso a la información es un atributo que se propone resaltar, dado que hay muchas pesquerías sin información a pesar de que en algunos casos se cuenta con complejos sistemas de control. Pauly \& Zeller (2016) han hallado que, en general, continúa la declinación global de las pesquerías, y que la determinación de las capturas en muchos casos está subestimada.

La metodología de Grafton et al. (2007) comprende la determinación del cumplimiento de cinco componentes clave y sus correspondientes indicadores:

(1) La responsabilidad, es decir, la capacidad de asumir y conducir un proceso público de manejo que además debe tener evaluadores externos. Los indicadores específicos son:

(1.1) Objetivos explícitos para las pesquerías; (1.2) Informes independientes que evalúan periódicamente el desempeño de la pesquería:

(1.3) Capacidad para rendir cuentas, en el sentido de articular una cadena de responsabilidades que involucra todos los niveles de la gestión;

(1.4) Participación de todo el rango de los grupos de interés en el proceso de toma de decisiones;

(1.5) Contar con indicadores de performance de la pesquería;

(1.6) Contar con indicadores de performance económica de la pesquería; $y$

(1.7) Contar con indicadores de performance ecosistémica que ha de requerir, en muchos casos, la aplicación de las metodologías EREAP (Daley et al., 2007; Hobday et al., 2011).

(2) La transparencia, representada por el acceso a toda la información de la pesquería y también por el proceso de registro de la participación de los grupos de interés. Los indicadores específicos son:

(2.1) La información que no es considerada confidencia es fácilmente accesible;
(2.2) Contar con un registro del proceso público de toma de decisiones; $y$,

(2.3) Proceso abierto y sistemático para evaluar las decisiones tomadas.

(3) Los incentivos, que por un lado garantizan los derechos de acceso a las pesquerías y, por otro, desarrollan un control efectivo y promueven buenas prácticas de pesca. Los indicadores específicos son:

(3.1) Derechos de pesca o de acceso asegurados a individuos o comunidades;

(3.2) Monitoreo y vigilancia efectiva de las actividades de pesca

(3.3) Existencia de un mercado para derechos de pesca, que sea competitivo y bien desarrollado; $y$,

(3.4) Que existan incentivos para no descartar o dañar el hábitat.

(4) La evaluación y manejo de riesgos, que establece escenarios de riesgo y que emplea puntos de referencia con base en un estrecho seguimiento de las capturas. Los indicadores específicos son:

(4.1) Uso de estrategias de evaluación para el manejo;

(4.2) Uso efectivo de los puntos de referencia límite y objetivo que hayan sido definidos (Puntos de Referencia Límite y Objetivo, Punto de Referencia de Riesgo);

4.3) Control y manejo efectivo de todas las capturas, cosechas o descargas; es decir, el registro de toda la información producida por la pesquería; $y$

(4.4) Límites de riesgos aceptables están bien definidos y acordados.

(5) La adaptabilidad, que es la disposición a introducir cambios sobre las medidas de manejo que han sido tomadas, con base también en un proceso de consultas continuo con los actores de la pesquería.

Los indicadores específicos son:

(5.1) Existe una toma de decisiones responsable y adaptativa;

(5.2) Se realizan ajustes y mejoras continuas en el manejo;

(5.3) Existencia de estructuras anidadas para la toma de decisiones con el fin de compartir las responsabilidades del manejo; $y$,

(5.4) Que exista un uso sistemático del conocimiento e información que aportan los pescadores. 
Colectivamente, estos veintidós factores proporcionan un marco para evaluar y mejorar la gobernanza de las pesquerías. Para el caso presente se utilizará esta metodología con el propósito de evaluar preliminarmente la efectividad de los ROP vigentes a la fecha en el Perú, con el fin de identificar las posibles mejoras en su contenido para beneficio de la gobernanza de las pesquerías de captura.

\subsection{Evaluación de los ROP vigentes a la fecha}

El artículo sétimo del Reglamento de la Ley General de Pesca, aprobado por DS N. . 012-2001-PE, establece una evaluación periódica del o de los objetivos de cada ROP. En esta sección se presenta un análisis preliminar que podría conducir a la introducción de mejoras en los ROP, adecuándolos a estándares internacionales, como se propondrá a continuación.

La metodología de Grafton et al. (2007) propone evaluar el desempeño de una pesquería comparándola con el concepto ideal para cinco conjuntos de componentes (benchmarking). Cada uno de ellos fue descrito en el acápite anterior (3.3). Para los propósitos de esta publicación, en la que se busca también impulsar mejoras en la gestión, se ha realizado el ejercicio de contrastar el desempeño de las diez pesquerías marinas que cuentan con ROP vigente.

La relación de las diez pesquerías, con indicación del dispositivo o dispositivos legales a los cuales está vinculado cada Reglamento de Ordenamiento Pesquero se presentan a continuación:

(1) ROP de la anchoveta (Engraulis ringens) y anchoveta blanca (Anchoa nasus) para CHD, DSN.

005-2017-PRODUCE.

(2) ROP para la pesquería del jurel (Trachurus murphyi) y caballa (Scomber japonicus), DS N. 011-2007PRODUCE.

(3) ROP del recurso merluza (Merlucius gayii), DS N. 016-2003-PRODUCE.

(4) ROP del calamar gigante o pota (Dosidicus gigas), DS N.. 014-2011-PRODUCE.

(5) Reglamento de la Ley General de Pesca y medidas de ordenamiento complementarias para el perico (Coryphaena hippurus), como el DS N 032-2003-PRODUCE.

(6) Reglamento de Ordenamiento Pesquero del Recurso Anguila (Ophichthus remiger), DS N. 013-2011PRODUCE.
(7) ROP del bacalao de profundidad (Dissostichus eleginoides), RM N. 236-2001-PE.

(8) ROP de las actividades extractivas artesanales $y$ de menor escala del ámbito marítimo adyacente al departamento de Tumbes, DS N. 020-2011-PRO DUCE.

(9) ROA de la actividad de repoblamiento en la bahía de Sechura, DS N. 0 016-2009-PRODUCE.

(10) ROP de las macroalgas marinas, DS N. 009-2009-PRODUCE.

Se ha evaluado cada pesquería comparando el cumplimiento de cada componente en función de cada ROP. Se han tomado en cuenta, en todos los casos, los aportes que pudieran estar realizando universidades, ONG u otros para el cumplimiento de cada ROP. Se ha construido una tabla-resumen y asignado uno de cuatro colores para cada componente: el color verde indica que tanto el ordenamiento como el desempeño de la pesquería cumplen con el componente; el celeste, un buen grado de avance en el indicador; el amarillo, que se constata un bajo cumplimiento; y el fucsia indica la ausencia de cumplimiento o, al menos, carencia de la información necesaria para evaluar el componente. La tabla 1 presenta el resultado de la indicada evaluación de tipo cualitativo.

En términos generales, se observa que hay fortalezas como la capacidad de adaptación. El Perú en general,

e IMARPE en particular, tienen la buena reputación de recomendar medidas que obedecen a la alta variabilidad e incertidumbre que el ecosistema genera. Otro componente que en general arroja buenos resultados es el de la responsabilidad, que se expresa en la articulación de la cadena de responsabilidades.

Los aspectos deficientes son aquellos ligados a la transparencia lo que quiere decir que los ROP esta diseñas para evitar el acceso del público en gen la información. Desde el año 2012 se dejaron de publicar las estadísticas mensuales de captura, lo que ha impedido generar estudios sobre el desempeño económico o ecológico. Por otro lado, la mención y articulación con las universidades es mínima. Asimismo, el manejo de las pesquerías se desarrolla sin evaluaciones independientes bajo metodologías ya existentes. Estas evaluaciones podrían implementarse para impulsar un programa de mejoras continuas en la gestión.

A continuación se presenta una síntesis de la evaluación de los diez ROP disponibles para las pesquerías marinas según la metodología cualitativa de Grafton et al. (2007).
ESTADO DE LA TRANSPARENCIA EN LAS PRINCIPALES PESQUERÍAS PERUANAS

\begin{tabular}{|c|c|c|c|c|c|c|c|c|c|c|}
\hline & - & $m$ & $\infty$ & - & $\infty$ & م & 4 & 米) *** & 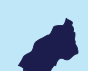 & 2 \\
\hline $\begin{array}{l}\text { Componentes / ROPs } \\
\text { 1. Responsabilidad }\end{array}$ & $\begin{array}{c}\text { Anchoveta } \\
\text { CHD }\end{array}$ & $\begin{array}{l}\text { Jurely } \\
\text { Caballa }\end{array}$ & Merluza & Pota & Perico & Anguila & Bacalao & Macroalgas & Tumbes & Sechura \\
\hline 1.10bjetivos o reglas de juego explicitas & - & - & - & 0 & - & - & - & - & - & - \\
\hline 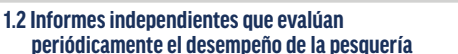 & - & - & - & - & - & - & - & 0 & - & - \\
\hline 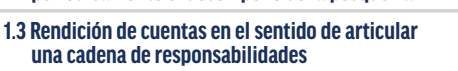 & - & 0 & - & - & - & - & - & - & - & - \\
\hline 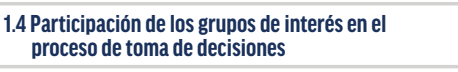 & 0 & $\bullet$ & $\bullet$ & $\bullet$ & O & 0 & 0 & - & - & $\bullet$ \\
\hline 1.5 Indicadores de performance de la pesqueria & - & - & - & 0 & - & - & - & - & - & - \\
\hline 1.6Indicadores de performance econonomica & - & - & - & - & - & - & - & 0 & - & - \\
\hline 1.7Indicadores de performance ecosistetemica & - & - & - & - & - & - & - & - & - & - \\
\hline \multicolumn{11}{|l|}{ 2. Transparencia } \\
\hline 2.1 Data no confidencialf fracilmente accesible & - & - & - & - & - & - & - & - & - & - \\
\hline $\begin{array}{l}\text { 2.2 Registrod del proceso oublicico de toma de } \\
\text { decisises }\end{array}$ & - & - & 0 & - & 0 & - & - & 0 & - & - \\
\hline $\begin{array}{l}\text { 2.3Processo abierto ysitsemático para evaluar las } \\
\text { decisiones tomadasa }\end{array}$ & - & - & 0 & - & - & - & - & - & - & - \\
\hline \multicolumn{11}{|l|}{ 3. Incentivos } \\
\hline $\begin{array}{l}\text { 3.1 Derecthos de pesca od a access asegurados a } \\
\text { individuos o comunidadades as }\end{array}$ & - & $\bullet$ & - & - & - & $\bullet$ & $\bullet$ & - & $\bullet$ & $\bullet$ \\
\hline 3.2Monitoreo yvigilancia efectiva & - & $\bullet$ & - & - & $\bullet$ & $\bullet$ & - & O & $\bullet$ & $\bullet$ \\
\hline $\begin{array}{l}\text { 3.3 Mercado para derechos de pesca competitivo y } \\
\text { bien desarrollado }\end{array}$ & - & - & - & - & - & - & - & - & - & - \\
\hline 3.4 Incentivos para no descartar o dañar el habititat & - & - & - & - & - & - & - & - & - & - \\
\hline \multicolumn{11}{|l|}{ 4. Evaluación y manejo de riesgos } \\
\hline 4.1 Uso de estrategia de evaluación para el manejo & - & - & - & - & - & - & - & - & - & - \\
\hline 4.2 Uso efectivo de los suntos de referencial linite & - & $\bullet$ & - & - & - & - & - & - & - & - \\
\hline $\begin{array}{l}4.3 \text { Control y manejio ferctivo de las capturas, } \\
\text { cosechas o descargas }\end{array}$ & $\bullet$ & $\bullet$ & $\bullet$ & $\bullet$ & O & $\bullet$ & $\bullet$ & 0 & $\bullet$ & $\bullet$ \\
\hline 4.4Limites deriesgo bien definindos y acordadas & - & 0 & - & - & 0 & - & - & - & - & - \\
\hline \multicolumn{11}{|l|}{ 5. Adaptabilitad } \\
\hline 5.1 Toma de edecisiones responsables y adaptativa & $\bullet$ & $\bullet$ & - & - & - & $\bullet$ & - & $\bullet$ & $\bullet$ & $\bullet$ \\
\hline 5.2 Aiustes continuos al manejo & - & $\bullet$ & O & - & - & $\bullet$ & - & - & - & $\bullet$ \\
\hline 5.3 Estructuras anidaddes parar I t toma de decisiones & - & $\bullet$ & - & - & - & $\bullet$ & $\bullet$ & O & $\bullet$ & $\bullet$ \\
\hline $\begin{array}{l}\text { 5.4 Uso sistemático del conocimiento e información } \\
\text { de los pescadores }\end{array}$ & - & - & - & - & - & - & 0 & 0 & - & - \\
\hline
\end{tabular}

Tabla 1.

Resultados de la evaluación comparativa (benchmarking), según Grafton et al. (2007) para cinco componentes de lagobernanza pesquera de las diez actividades pesqueras que actualmente cuentan con Reglamentos de Ordenamiento Pesquero en el ámbito marino. Los colores están asociados al desempeño: verde indica cumplimiento; celeste, cumplimiento parcial; amarillo, un bajo cumplimiento; yel fucsia, falta de cumplimiento. 
El Reglamento de Ordenamiento Pesquero de la Anchoveta (Engraulis ringens) y de la anchoveta blanca (Anchoa nasus) para consumo humano directo (CHD), aprobado por DS N. 010-2010-PRODUCE, ha sido objeto de sucesivos cambios y normas complementarias, tales como el DS N. 005-2012-PRODUCE, la Resolución Ministerial N.o 433-2012-PRODUCE, el DS N. 011-2013-PRODUCE y el DS N.o 006-2015-PRODUCE. Un nuevo ROP ha entrado en vigencia en el mes de abri de 2017 y es el que se analiza a continuación.

En general, la evaluación comparativa de la pesquería con el presente ROP indica un desempeño correcto (tabla 1), pero se requiere la implementación de ciertas acciones contempladas en el ROP y que implican el despliegue de una alta capacidad de coordinación entre PRODUCE y las Direcciones Regionales de la Producción de los gobiernos regionales. Asimismo, el ROP contiene un desafío en lo que concierne a la capacidad de hacer cumplir las disposiciones relativas al control y vigilancia con especial referencia a un segmento de flota y de plantas informales que se resisten a acatar las disposiciones de la autoridad.

En los componentes que tienen que ver con la responsabilidad en la gestión de esta pesquería, para el indicador (1.1) se considera que esta pesquería cuenta con objetivos apropiadamente establecidos, es decir, se procura un aprovechamiento sostenible de la anchoveta $y$ : para el cons de alimentos para personas, procurando además un abastecimiento sostenido como fuente de alimentación, empleo e ingresos. En el indicador (1.2) se estima que hay un cumplimiento parcial, ya que las evaluaciones independientes existen pero no están incorporadas como elemento del manejo (por ejemplo, Paredes \& Gutiérrez, 2008; Paredes, 2010; De la Puente et al., 2011; Paredes, 2013; Heck, 2015). Para el indicador (1.3) se considera que hay una cadena de responsabilidades claramente definida, aunque está en fase de articulación con los gobiernos regionales, dado que, de acuerdo con el nuevo ROP, estos deben ahora informar continuamente sobre los permisos otorgados en el ámbito de su competencia. El indicador (1.4) evalúa un cumplimiento parcial respecto a la participación de los actores, dada la buena disposición al diálogo que se observa tanto en PRODUCE como en IMARPE, aunque se debe hacer notar que esta participación no obedece a disposiciones formalmente establecidas. El indicador (1.5) muestra un cumplimiento parcial debido a que, si bien los estudios sobre la performance de la pesquería existen, no deben reducirse a la entrega de un informe semestral o anual. Estos podrían, en cambio, tener una entrega más dinámica para beneficio de la transparencia en la gestión, pero también para un uso práctico en la gestión interna de las mismas empresas, considerando que esta pesquería está dirigida al CHD, pero que ha estado sometida a un alto grado de desvío hacia el $\mathrm{CHI}$ (el nuevo ROP aún contiene porcentajes de tolerancia para el descarte: $10 \%$ en el punto dedescargay $40 \%$ en planta con loque $10 \%$ en el para el desvío aún existe; $y$, por otro lado, el nuevo ROP no incluye una definición ni contempla el descarte entendido como la devolución de las capturas al mar). En el caso de los indicadores (1.6) y (1.7), se considera que no hay cumplimiento en lo referido a los indicadores de desempeño económico y ecosistémico, y tampoco está expresamente identificada en el ROP la conveniencia de contar con estos instrumentos. Se considera que, por la magnitud del valor de esta pesquería, y por la diversidad y cantidad de informaciones que se recopila diariamente, se debería contar con estos indicadores, que pueden ser propuestos por PRODUCE, IMARPE o por entidades académicas (como se muestra en Paredes \& Letona, 2013; Fréon et al. 2014; Avadi \& Fréon, 2014; 2013; Fréon et al., 2014; Avadi \& Fréon, 2014; Avadi al., 2014).

En el caso de los componentes que tienen que ver con la transparencia, el (2.1) muestra un cumplimiento parcial, pues se genera información que se coloca por lo general de modo fragmentado, se refiere solo a datos de desembarque y no se indica la presencia de otras especies o la estructura de tallas en las capturas, entre otras informaciones. En el indicador (2.2) se ha hallado que no existe un registro formal de acceso público acerca del proceso de toma de decisiones. En cambio, en el caso del indicador (23) que evalúa las decisiones tomadas, se considera que existe cierto nivel de participación de los agentes de la pesquería.

En lo que concierne al componente que evalúa los incentivos para participar de la pesquería, el (3.1) arroja que sí hay ciertos derechos asegurados, y que están vinculados al requisito previo de formalización de acuerdo con las disposiciones de PRODUCE (además, el nuevo ROP establece que se determinará una cuota específica nacional y anual para el CHD). Y en el caso de los indicadores que evalúan el monitoreo y vigilancia, así como el esquema de derechos de pesca y los incentivos para no dañar el ecosistema (3.2 a 3.4), muestran cierto grado de cumplimiento dadas las correcciones recientes en el manejo. El nuevo ROP incorpora importantes medidas, como la creación del Registro Nacional de Embarcaciones Pesqueras para CHD, y, además, zanja el tema de la permisividad que se tenía con la flota de cerco en la zona de las primeras tres millas, debiendo toda embarcación de menor escala operar fuera de ese límite. Asimismo, el ROP establece que toda embarcación de cerco para la pesca de anchoveta que cuente con medios mecanizados para la operación de su aparejo pasará a ser considerada y registrada en la categoría de menor escala, siempre que su eslora sea menor de 15 metros, y deberá además contar con algún sistema de localización remota. Aunque estas son acciones importantes y positivas, el reto mayor consiste en desarrollar las acciones para hacer cumplir estas disposiciones.

En el caso del componente que se relaciona con la evaluación y manejo de riesgos, en el indicador (4.1), sobre el uso de una estrategia de evaluación del manejo de esta pesquería, debe decirse que aquella no está puesta en práctica a pesar de que en el marco de la gestión de la pesca industrial de anchoveta (DL N. . 1084) se establecen tallas, vedas y límites de captura; es decir, se fijan límites de riesgo. No obstante, CnelDSN ${ }^{\circ} 005-P R O D U C E-2017$, con el que se aprueba el ROP, se resalta la alta variabilidad ambiental e incertidumbre que esto genera para la gestión, que debe entonces tener un carácter adaptativo y acorde con las circunstancias ambientales, biológicas, sociales y económicas. Por las mismas razones, el manejo de esta pesquería se vería significativamente beneficiado si contara con una estrategia de evaluación del manejo. En el caso de los indicadores sobre el uso efectivo de los puntos de referencia y el control estricto de las descargas (4.2 y 4.3), se halla solamente un cumplimiento parcial debido a la alta informalidad que aún se observa en esta pesquería. En lo que se refiere al indicador que evalúa el establecimiento de límites de riesgo (4.4), se considera que estos están bien definidos y se expresan en el continuo cierre de zonas de pesca ante la presencia, por ejemplo, de desovantes o juveniles. Asimismo, la nueva restricción a la pesca de cerco en las primeras tres millas es una medida positiva que reduce los riesgos ecológicos en la franja más delicada del litoral.

El conjunto de componentes con el mejor desempeño es el de la adaptabilidad. En los indicadores de desempeño sobre el proceso de toma de decisiones, ajustes continuos al manejo y existencia de estructuras anidadas (5.1 a 5.3) existe un cumplimiento pleno gracias a la creciente articulación entre PRODUCE, IMARPE y otras entidades encargadas de la supervisión, incluyendo a los gobiernos regionales. Sin embargo, respecto del indicador sobre el aprovechamiento de la información que genera la flota (5.4) solo se verifica un cumplimiento parcial, dado que el nuevo ROP dispone una amplia recolección de informaciones, pero no se dispone un carácter abierto para el acceso público a esta información, con excepción del Registro Nacional de Embarcaciones Pesqueras.

Un enfoque importante contenido en el DS N.o 005-PRODUCE-2017 es la descripción del contexto actual en el que se desarrolla la pesquería. Se menciona la secuencia de eventos cálidos que se vienen repitiendo desde 2014 y que configuran un escenario distinto al observado en la década previa, lo que de alguna manera significa que las condiciones han cambiado de frías a cálidas, y que las especies como la anchoveta están respondiendo a tales variaciones a través de, por ejemplo, cambios en su distribución espacial.

Otro aspecto novedoso contenido en el DS $\mathrm{N}$. -005-PRODUCE y del nuevo ROP es la tipificación como infracción grave del ejercicio de cualquier actividad pesquera sin contar con el derecho específico otorgado por PRODUCE (se modificó el artículo 132 del Reglamento de la Ley General de Pesca). Asimismo, el artículo 5 del ROP prohíbe la emisión de nuevos permisos de pesca de anchoveta (excepto por sustitución de embarcaciones pesqueras), lo que incluye a los gobiernos regionales, que quedan obligados (en virtud del artículo 7 del ROP) a inscribir los permisos que otorguen y los actos administrativos que generen en el Registro Nacional de Embarcaciones Pesqueras para CHD. La quinta disposición complementaria dispuesta en el ROP establece que la flota de menor escala pagará derechos de pesca a partir del 31 de diciembre de 2018.

Finalmente, a través del artículo 8 se estipula que en la zona ubicada al sur del paralelo 16 se podrá autorizar actividades extractivas temporales, de acuerdo con las condiciones del momento, lo cual se refiere a permitir la pesca dentro de la zona de las tres millas marinas. El artículo 10 dispone que toda embarcación CHD cuente con insulado y métodos de preservación; asimismo, no se permite el uso de métodos de bombeo que dañen la captura, lo cual debe ser certificado por el Instituto Tecnológico de la Producción (ITP). Tampoco se autoriza la descarga en lugares no habilitados sanitariamente, $y$ se establecen diversas medidas de fiscalización y sanción para el proceso de descarga y transporte de las capturas en vehículos registrados y habilitados. 
Todas estas medidas son positivas y están orientadas no solo a proteger la zona costera, a la anchoveta y recursos asociados y promover el desarrollo de la industria CHD, sino también a acabar con la informalidad que caracteriza a esta importante y estratégica pesquería.

\subsubsection{ROP para la pesquería del jurel y la caballa}

La evaluación del desempeño de esta pesquería es en general positivo,ysecuentacon el incentivo de que se halla en proceso de regulación por parte de la Organización Regional de Ordenamiento Pesquero para el Pacífico Sur (OROP-PS), por tratarse de especies transzonales que son objetivo de pesca para varias flotas internacionales (tabla 1). El Perú ha ratificado la convención OROP-PS, lo que le confiere la condición de Estado contratante. Sin embargo, su déficit está en el bajo grado de participación formal de los grupos de interés en la toma de decisiones, a pesar de que el sector industrial viene acompañando y apoyando el proceso de gestión que se da en el marco de Ia OROP-PS, lo que ha permitido generar valiosos aportes al monitoreo y evaluación de esta pesquería.

Respecto al primer conjunto de indicadores que evalúan la responsabilidad en la gestión, el ROP de jurel y caballa cumple con determinar objetivos explícitos (1.1) al promover una explotación racional de los recursos, así como la protección de la biodiversidad y del ecosistema marino. En el caso de indicador (1.2), que establece la disposición de informes independientes que periódicamente evalúen el desempeño de la pesquería, hay un cumplimiento parcial, ya que si bien el ROP no establece esta necesidad, se han llevado a cabo estudios como el de Paredes (2013) que abordan, entre otros, los aspectos económicos y regulatorios de la pesquería. También la Sociedad Nacional de Pesquería (SNP) ha cooperado con entidades académicas (UNFV, IMARPE, IRD, ONG) en este objetivo, al desarrollar evaluaciones independientes de la abundancia, como se muestra en diversos informes generados entre 2011 y 2015 . En el indicador (1.3), que determina la condición de contar con una cadena de responsabilidades, se observa que existe una articulación entre IMARPE y PRODUCE, hallándose en proceso la intervención de los GORE en el caso de la flota artesanal, que es un segmento que no está suficientemente regulado.

Asimismo, el ROP establece la obligación de que las embarcaciones que intervienen en la pesquería cuenten con sistemas de refrigeración de agua tipo RSW, o con sistemas de congelación. La Ley N.․ 26920 autoriza la concesión de permisos de pesca a embarcaciones de madera de hasta $110 \mathrm{~m} 3$, que. a la fecha de la dación de la Ley (enero de 1998), no tuvieran el correspondiente permiso de incremento de flota. Se ha generado así la situación especial de un número de embarcaciones de madera (alrededor de sesenta) que cuentan con permisos de pesca, sea para CHD o CHI (según el DS N. 003-2000$\mathrm{PE}$, que modifica el artículo 4 del DS N. ${ }^{\circ} 003-98-\mathrm{PE}$ o Reglamento de la Ley N. 26920). Estas embarcaciones no tienen sistemas de frío y tampoco se cuenta con un registro diferenciado de sus capturas ni desempeño estadísticas en sus informes anuales sobre jurel y caballa. El ROP tendría que modificarse para integrar a esta flota de madera, considerando además la viabilidad técnica de que porten sistemas tipo RSW, o, en su defecto, establecer la obligación de que, por ejemplo, los zarpes sean autorizados siempre que se demuestre la disponibilidad cada nave.

En el caso del indicador (1.4), que evalúa la participación formal de los grupos de interes en la toma de decisiones, se observa que su participación no está establecida en el ROP, a pesar del apoyo ya descrito de los actores. En lo que atañe al indicador (1.5), que evalúa la existencia de indicadores de performance de la pesquería, se ha hallado que si bien estos no están definidos como tales en el ROP, sívienen siendo llevados a cabo de modo minucioso como parte de los compromisos asumidos en la OROP-PS. En el caso de los indicadores de performance económica y ecosistémica (1.6 y 1.7), estos no están establecidos de modo explícito en el ROP, pero se considera que hay abundante información (no necesariamente disponible) como para implementarlos.

En el componente que evalúa la transparencia en la (21). En lo que concierne a los indicadores (2.2 y 2.3), que evalúan el registro del proceso público de toma de decisiones y la participación de los grupos de interés, no están establecidos en el ROP correspondiente.

En lo tocante al componente que evalúa los incentivos para el acceso a la pesquería se halla que los indicadores para el establecimiento de derechos, y el monitoreo y vigilancia (3.1 y 3.2) son positivos. En el caso de los derechos de pesca, el indicador (3.3) reconoce que hay un cumplimiento parcial, en el sentido de que esta pesquería tributa por este concepto, pero el ROP no establece un mecanismo de mercado para este aporte Sidel indicador que evalúa los incentivos para no descartar y dañar el hábitat (3.4) se trata, se constata que sí está contemplado en el ROP al establecer condiciones y zonas para el empleo de diversos tipos de aparejos de pesca.

En el componente sobre evaluación y manejo de riesgos se observa que los indicadores sobre el uso de estrategias de evaluación del manejo y uso efectivo de puntos de referencia límite (4.1 y 4.2), se encuentra que no están contemplados en el ROP, salvo la definición de tallas mínimas de captura. En cambio, se cumple con en el indicador (4.3) sobre el control de las capturas. El indicador sobre los límites de riesgo en la pesquería (4.4) no está completamente establecido en la normativa, aunque se considera que existe información técnica y científica para implementarlo.

En el componente sobre adaptabilidad se observa un cumplimiento completo en todos los indicadores, lo que constituye el aspecto más fuerte de la gestión adaptativa de la pesquería.

\subsubsection{Reglamento del Ordenamiento Pesquero de} la Merluza

De acuerdo con la metodología empleada, el desempeño general de esta pesquería es correcto, pero requiere ciertas mejoras que son factibles dado el alto grado de monitoreo y capacidad de regulaciones que se ha generado en esta pesquería en proceso de recuperación (tabla 1).

En elcasodel primercomponente,sobrelaresponsabilidad en la gestión de la pesquería, se observa que en el indicador que evalúa los objetivos (1.1) se consideran tres elementos claves para la pesquería de merluza: (a) lograr la recuperación del recurso en el mediano plazo para el posterior aprovechamiento sostenido; (b) armonizar la participación de los diferentes agentes involucrados en la extracción y procesamiento del recurso merluza y de su fauna acompañante; $y$, (c) optimizar la eficiencia operativa de la flota arrastrera de modo que pueda acceder a nuevas áreas de pesca reduciendo la presión en las zonas tradicionales, lo cual se complementa con el hecho de que se han definido diversos aspectos sobre la clasificación de los barcos y métodos de pesca, la selectividad de las artes de pesca, así como se ha considerado a las especies con las cuales la merluza tiene un alto grado de interacción y que en su gran mayoría sustentan pesquerías artesanales. Actualmente está en funciones un Grupo de Trabajo Sectorial encargado de analizar el estado situacional de la pesquería del recurso merluza, con la finalidad de proponer medidas para fortalecer el ordenamiento de la actividad pesquera del citado recurso; este grupo incluye a representantes del sector artesanal e industrial. En lo que se refiere al indicador que evalúa la emisión de informes independientes sobre el desempeño pesquero (1.2), se reconoce que hay un alto nivel de información, pero el ROP no considera este aspecto a pesar de que se han hecho evaluaciones independientes (como las realizadas por CEDEPESCA en el marco de un proyecto de mejoras para esta pesquería) y de que se ha convocado a talleres de expertos internacionales sobre la materia. Asimismo, se han llevado a cabo reuniones entre expertos de IMARPE, PRODUCE y universidades, promovidos por la misma industria en cooperación con la Universidad Nacional de Piura. La evaluación de los indicadores sobre la articulación de una cadena de responsabilidades y la participación de los grupos de interés (1.3y 1.4) es positiva y ha sido fundamental en una pesquería que tuvo serios problemas de sostenibilidad a partir del año 2002. El indicador sobre la existencia de índices de performance de la pesquería (1.5) muestra un cumplimiento parcial en el sentido de que se sabe que estos indicadores existen pero no están formalmente establecidos en el ROP. En cambio, se observa falta de cumplimiento en los indicadores sobre la disposición de diagnósticos económicos yecosistémicos (1.6 y 1.7), a pesar de la abundante información de la que se dispone para este propósito.

En lo que concierne al segundo componente, sobre transparencia, el indicador (2.1) sobre la disponibilidad pública de información no alcanza una buena calificación, noobstantela abundante informaciónque se genera sobre recorridos de barcos, capturas por lance, desembarque, tallas, presencia de otras especies distintas a la merluza, etcétera Los indicadores sobre registro público de toma de decisiones y la existencia de un proceso sistemático para evaluar las decisiones tomadas (2.2 y 2.3) también indican un bajo nivel de cumplimiento.

En el componente sobre incentivos, se observa un buen desempeño en tres de los cuatro indicadores (3.1, 3.2 y 3.4), pues se trata de una pesquería sometida a severos controles pero con derechos asegurados a través de cuotas globales de pesca, cuotas individuales y medidas restrictivas para controlar los impactos sobre el ecosistema. Sin embargo, a pesar de que el ROP lo dispone, no se publican las cuotas individuales, y las cuotas por lo general no llegan a cubrirse. En el caso del indicador referido a un mercado sobre derechos de pesca

(3.3), se aprecia un cumplimiento parcial, ya que se trata de una pesquería de acceso cerrado y con derechos ya 
asignados, cuya revisión no está prevista en el ROP. Es importante precisar que la de la merluza es una pesquería en recuperación, lo que explica que su acceso esté cerrado.

Respecto del componente sobre evaluación y manejo de riesgos, el indicador sobre el uso de estrategias de de riesgos, el indicador sobre el uso de estrategias de o considerado en el ROP. En cambio, se observa el cumplimiento de los restantes indicadores sobre uso de puntos de referencia límite, el control de las capturas y la existencia de una estrategia de manejo de riesgos (4.2, 4.3 y 4.4).

En lo que atañe al componente sobre adaptabilidad todos los indicadores, excepto uno, son positivos, es decir, se considera que la toma de decisiones es responsable y adaptativa (5.1), y se realizan constantes ajustes en el manejo, incluyendo decisiones de cambio de zonas de pesca mediante la interacción entre los TCI de IMARPE $y$ los pescadores (5.2). Existe una estructura anidada para la toma de decisiones (5.3) y hay un uso sistemático de la información generada por la propia flota para efectos prácticos, como decidir sobre los cambios de zonas de pesca. Aun así, para el caso de la merluza permanece sin atención un segmento artesanal que no se halla regulado. Asimismo, debe mencionarse que la pesquería en general no está conducida en el marco del ROP sino de regímenes especiales previstos en el último artículo de la norma, lo que incluye la eventual disminución del tamaño de malla de captura. Por todas las razones indicadas, el ROP debe ser actualizado para reflejar la realidad poblacional del recurso, así como las limitaciones tecnológicas existentes.

\subsubsection{Reglamento del Ordenamiento Pesquero del} Calamar Gigante o Pota

El método empleado para el análisis de la pesquería de pota, en lo que concierne al contenido de su ROP, arroja un desempeño deficiente, a pesar de tratarse de la principal pesquería artesanal del país y la primera de su tipo en el mundo (tabla 1). En especial, el alto nivel de informalidad, la construcción clandestina de embarcaciones y la falta de sistemas adecuados de preservación a bordo son problemas que afectan el rendimiento socioeconómico de la pesquería, todo lo cual no ha sido convenientemente abordado en el ROP vigente.

La cronología de la normativa sobre pota presenta los siguientes hitos: el DS N. 005-91-PE aprueba el Reglamento para la Operación de Barcos Calamareros; la Resolución Ministerial N.․ 155-94-PE aprueba el Plan de
Ordenamiento Pesquero(POP) del calamargiganteo pota; la Resolución Ministerial N. 047-98-PE modifica el POP de la pota; el DS N. 013-2001-PE aprueba el Reglamento de Ordenamiento de la Pesquería(ROP) de la pota dejando de lado el POP inicial, diseñado para barcos extranjeros de cualquier capacidad de bodega y barcos nacionales con capacidad de bodega mayor a 32,6 m3; la Resolución Ministerial N.. 286-2010-PRODUCE establece que cualquier faena industrial debe realizarse por fuera de $80 \mathrm{mn}$ de la línea de costa; el DS N.․ 014-2011-PRODUCE modifica el ROP de la pota; finalmente, la Resolución Ministerial No 036-2012-PRODUCE determina la

El ROP vigente señala que esta pesquería es de oportunidad (acápite 4.1 del artículo 4 del ROP), lo cual es discutible y contrasta con el amplio conocimiento científicoque se haalcanzado sobre estaespecieendémica que cumple un importante papel como predador y como presa en el ecosistema (Alegre et al., 2014).

La situación de esta pesquería se agrava por el creciente número de embarcaciones que ingresan de modo irregular y compiten con las embarcaciones cuya situación legal ta potera captura asimismo perico, aunque debe precisarse que solo las de mayor tamaño se dedican a esa actividad. Hay disposiciones que prohíben la construcción de naves artesanales de más de $5 \mathrm{~m}^{3}$. La primera prohibición se dio en 2006 por dos años, en 2008 esta disposición fue prorrogada, y en el año 2010 se prohibió la construcción de naves de más de $5 \mathrm{~m}^{3}$. No obstante, en 2010, debido al desarrollo de un evento El Niño (RM N.o 027-2010-PRODUCE), se autorizó la operación de las naves sobre recursos de oportunidad. En el caso de la flota potera, que abarca naves desde $5 \mathrm{~m}^{3}$ a $32,6 \mathrm{~m}^{3}$, en realidad pesca también otras especies que estén disponibles al emplear varios tipos de aparejos, ya que el numeral 42.2.2 del DS N.o 007-2009-PRODUCE, que modifica artículos del Reglamento de la Ley General de Pesca, permite la extracción de recursos $\mathrm{CHD}$ distintos a los autorizados en el correspondiente permiso de pesca. Así, en la práctica, salvo las naves autorizadas para pescar anchoveta, merluza, anguila y bacalao, todas las otras naves artesanales pueden capturar cualquier otro Sermisividad, que debió ser transitoria, está vigente desde el año 2009, pero es necesario que esta situación sea revertida por insostenible.

Por otro lado, la Organización Regional de Ordenamiento Pesquero para el Pacífico Sur ya ha iniciado el proceso de ordenación de esta pesquería internacional para esta especie transzonal. En este aspecto, es importante hacer notar que el Perú, a pesar de ser el país que más captura esta especie, no cuenta con registros de pesca en alta mar y, por lo tanto, no podrá acceder a una cuota de pesca en esa zona. Por su parte, el Perú ha dado cuota de pesca de pota solo para el año 2012, a pesar de que el ROP dispone que se haga cada año. Por lo general, la flota artesanal no requiere alejarse demasiado de la costa para hallar zonas de pesca, pero no opera fuera de la ZEE, por lo que es preciso preguntarse si resulta conveniente conceder permisos de pesca a la flota industrial para que opere en alta mar, donde la flota internacional (principalmente china) captura pota y compite directamente con la flota artesanal peruana. Por lo demás, en el marco de la OROPPS, el Perú está realizando diagnósticos anuales sobre el desempeño de la pesquería en aguas nacionales, pero no cuenta aún con información para sustentar la presencia nacional en la pesquería de alta mar.

La evaluación del componente de responsabilidad indica que para el indicador acerca de la existencia de objetivos o reglas de juego explícitas (1.1) se tiene un bajo nivel de cumplimiento, debido a que el ROP no ha logrado regular el acceso de naves de bandera nacional incluyendo las artesanales; tampoco se ha conseguido constituir una flota nacional especializada y con sistemas de frío (a pesar de la prepublicación de una norma que buscaba normar este aspecto, la RM N. 404-2014-PRODUCE)) y, por tanto, no se está logrando un aprovechamiento del recurso. Asimismo, el ROP está diseñado para la pesca industrial, no para la artesanal. Actualmente no hay actividad pesquera industrial sobre este recurso, dado que los permisos de pesca no fueron emitidos a pesar de lo que dispone el propio ROP. El ROP además señala, en su numeral (3.1.4), que "el acceso a la pesquería de calamar gigante o pota para embarcaciones artesanales no requiere de autorización de incremento de flota, de acuerdo al artículo $35^{\circ}$ del Reglamento de la Ley General de Pesca". En todo caso, disposiciones posteriores han prohibido la construcción de más embarcaciones. Ese artículo 35 generó un acceso abierto, lo que se agregó a la falta de medios o de competencias específicas para DICAPI. Ha habido también corrupción de los procedimientos, todo lo cual ha alentado la construcción informal de embarcaciones principalmente en la región Piura, aun cuando el DS N. 006-2015-PRODUCE prohíbe la construcción de más embarcaciones.

Asimismo, los actores de esta pesqueria se oponen a que se otorguen permisos de pesca a naves industriales, principalmente por el temor a que su ingreso deprima aún más el rendimiento de la pesquería. Esta situación hace indispensable un análisis socioeconómico. En el caso del indicador que evalúa la existencia de informes independientes (1.2), se halla un cumplimiento parcial, dado que si bien el ROP no establece este requerimiento, encambio síse han producido estudios como el de Paredes \& De la Puente (2014), que evalúa exhaustivamente el desempeño de la pesquería. En el caso del indicador que mide la articulación de responsabilidades (1.3), se halla que sí hay cumplimiento en el sentido de que existe una estructura para la gestión e instituciones para sostenerla. En lo que atañe al indicador que evalúa la participación de los grupos de interés en la toma de decisiones (1.4), se aprecia que no hay cumplimiento, pues no es un mecanismo considerado en el ROP, aunque desde hace varios años los grupos de interés formales de esta pesquería se hallan en cierto modo organizados y reclaman mayor participación para ayudar a resolver los problemas existentes (FIUPAP, 2014). En cuanto a la existencia de indicadores que evalúan la performance de la pesquería (1.5), se encuentra un cumplimiento solamente parcial que se explica por el registro de las capturas y la existencia de un programa de observadores a bordo de IMARPE que, sin embargo, solo estuvo vigente de 2015 a 2016 para el registro de información de CPUE. La fuente usual de consulta de desembarques son las exportaciones, y no se conoce que PRODUCE esté registrando información de capturas con excepción de las encuestas mensuales que se hace a las plantas. Se da el caso de que la FAO ha registrado una captura de 600 mil toneladas para el año 2014, pero PRODUCE registra 500 mil toneladas; en este caso se aprecia claramente la necesidad de tener un registro de capturas único. En cuanto a los indicadores sobre performance económica y ecosistémica (1.6 y 1.7), se observa falta de cumplimiento. Se debe señalar, a propósito de estos dos indicadores, que una parte de la flota artesanal que pesca pota captura también perico entre los meses de octubre y abril. Este fenómeno será abordado más adelante en el contexto del análisis del ROP del perico.

En el caso del componente sobre transparencia, se halla que todos los indicadores $(2.1,2.2$ y 2.3) muestran una falta de cumplimiento respecto a que la data generada por la pesquería no es fácilmente accesible, como ocurre, por ejemplo, con las actas de las reuniones de la Mesa de Pota

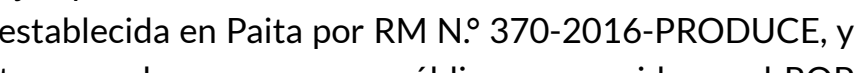
tampoco hay un proceso público reconocido en el ROP que permita la participación de la sociedad civil en la generación de decisiones de gestión y su evaluación. 
Respecto del componente de incentivos, se observan resultados negativos para los indicadores sobre derechos de pesca asegurados, sobre el monitoreo y vigilancia efectiva, dado el alto grado de informalidad e ilegalidad, $y$ sobre la carencia de un sistema para el pago de derechos de pesca (3.1, 3.2 y 3.3). En cuanto al indicador sobre incentivos para no dañar el hábitat, se halla que sí hay cumplimiento gracias a que el método de pesca empleado (jigging) es altamente selectivo (3.4).

En lo que atañe al componente sobre evaluación y manejo de riesgos, se aprecia que hay incumplimiento en lo referente a contar con una estrategia de evaluación para el manejo (4.1), y que tampoco están establecidos los puntos de referencia límite (actualmente solo se ha emitido una cuota global de 500 mil toneladas; RM N. 036-2012-PRODUCE), que no cuenta con un método de determinación acordado) (4.2). Tampoco se ha cumplido con el control y manejo efectivo de las capturas (4.3), dado que los desembarques en general no están registrados por PRODUCE o IMARPE y, además, la identificación de las unidades (barcos) de pesca está trastocada por la existencia de varios de ellos que portan el mismo número de matrícula; es decir, los datos de un armador formal son replicados en otras embarcaciones. En el caso del indicador sobre el establecimiento de límites de riesgo (4.4) se observa un cumplimiento parcial gracias al cercano seguimiento que IMARPE está haciendo de esta pesquería.

En el caso del componente de adaptabilidad se ha descubierto que, no obstante los problemas descritos, existe una toma de decisiones responsable y adaptativa existe una toma de decisiones responsable y adaptativa
(5.1). Sin embargo, en lo que se refiere al indicador sobre ajustes continuos al manejo (5.2), se halla que no hay cumplimiento, pues el ROP ha sido diseñado para un escenario de pesquería industrial, de modo que se ha dejado desregulado el segmento artesanal. No obstante, en el caso del indicador sobre la existencia de estructuras anidadas para la toma de decisiones (5.3) se observa que sí se está desarrollando un esfuerzo para procurar mejoras en la gestión con participación de IMARPE, PRODUCE y DIREPRO del Gobierno Regional de Piura. Finalmente, respecto al indicador sobre el uso sistemático de información proporcionada por los pescadores (5.4), se aprecia que hay un cumplimiento parcial, pues si bien se colecta información, esto se hace de modo discontinuo y, asimismo, no hay registro de que esta información sea utilizada para los propósitos del ROP. medidas de ordenamiento complementarias para el perico

La pesquería de perico es netamente artesanal y no cuenta con un ROP propio que la norme, por lo que se regula bajo las disposiciones del Reglamento de la Ley General de Pesca, como la mayoría de especies de la pesca artesanal. Existen algunas medidas regulatorias adicionales como la prohibición de otorgar permisos de pesca para el acceso a perico a embarcaciones de mayor escala, el establecimiento de la talla mínima y porcentaje de tolerancia de captura de otras especies, así como el periodo de veda para la protección de juveniles. El ROP del atún (DS N.․ 032-2003) regula la pesquería de mayor escala, por lo que al estar prohibidos los permisos de pesca de perico a estas embarcaciones, no tenía objeto que se contemple al perico en este ROP. EI DS N ${ }^{\circ}$ 005-2015-PRODUCE modificó el artículo 3 del ROP del atún que regula las especies objetivo. La lista ya no incluye especies afines (entre las que estaba el perico).

De acuerdo con la metodología utilizada, el desempeño de la pesquería de perico es en general deficiente, a pesar de ser la segunda pesquería artesanal del país por su volumen y la primera del mundo que captura esta especie cosmopolita (tabla 1). Se debe precisar también que la Comisión Interamericana del Atún Tropical (CIAT) es el Organismo Regional de Manejo Pesquero que tiene que regular esta pesquería en aguas internacionales.

Segúnesta metodología, en el caso del primer componente -responsabilidad en la gestión-, el indicador sobre objetivos explícitos para la pesquería (1.1) es deficiente, pues el Reglamento fue diseñado para otro contexto muy distinto al actual, en el que la pesquería se ha extendido pero en medio de un alto grado de informalidad. En lo que concierne alindicador que evalúa la existencia deinformes independientes acerca del desempeño de la pesquería (1.2), se observa un cumplimiento parcial, pues si bien estos estudios no figuran en la normativa, hay entidades que, como WWF, vienen realizando investigaciones y diagnósticos para, posteriormente, implementar programas de mejoras para esta pesquería, y que ha de alcanzar la certificación MSC (Hervás y Ambrosio, 2013). Asimismo, con base en este estudio WWF propuso un Plan de Acción para el Proyecto de Mejoramiento de la Pesquería de Perico en Perú (Hervás y Medley, 2013b). Asimismo, Amorós et al. (2015) han realizado una caracterización y análisis de la cadena productiva de la pesquería de perico en el Perú. En el caso del indicador sobre articulación de responsabilidades se observa un buen grado de cumplimiento, ya que PRODUCE e IMARPE han propuesto un Plan de Acción Nacional para la Conservación y Manejo del Recurso Perico (Coryphaena hippurus) en el Perú (PAN PERICO - PERÚ), que contiene cinco líneas estratégicas: (1) la investigación científica y tecnológica aplicada a la conservación; (2) el sistema de recolección de información y base de datos; (3) el ordenamiento pesquero; (4) el seguimiento, control y vigilancia; y, (5) la educación, difusión y sensibilización Sin embargo (5) la educación, difusion y sensibizacion. diseñado a lolargo de dos a tres años sin la participación de los actores o de otros entes especializados; además, este PAN no considera aspectos como la captura incidental o el manejo a nivel regional o internacional, dado que esta pesquería es compartida principalmente con Ecuador.

En cuanto al indicador sobre la participación formal de los grupos de interés en el proceso de toma de decisiones (1.4), se observa que el cumplimiento es deficiente, no obstante el alto grado de aportes y de muestras de interés por parte de los actores en favor de mejorar el desempeño de la pesquería, que es un aspecto que tampoco está considerado en el PAN PERICO. En el caso del indicador de performance de la pesquería (1.5) se verifica un cumplimiento parcial gracias al aporte de entidades como WWF, que han generado diagnósticos sobre el tema, aunque no hay evidencia de que estos aportes estén siendo cabalmente aprovechados por el Estado. Asimismo, ha habido aportes de la CIAT (2016a y 2016b), que ya ha realizado una medición del stock, y se ha evaluado también varios escenarios con distintas herramientas de control de la captura (distintos periodos de veda y talla mínima), además de que se propone una estrategia de evaluación para el manejo. En cuanto a los indicadores sobre performance económica y ecosistémica (1.6 y 1.7), estos arrojan un resultado negativo, pues la necesidad de contar formalmente con estos indicadores aún no ha sido establecida.

En lo que concierne al componente sobre transparencia, el resultado en general es deficiente: la pesquería sigue siendo de acceso abierto y la data que genera no es fácilmente accesible (2.1); además, hay un pobre registro del proceso público de toma de decisiones (2.2) y un limitado proceso para evaluar de modo público las decisiones tomadas (2.3). Sin embargo, debe destacarse la buena disposición de las actuales autoridades en el sentido de avanzar hacia un manejo participativo de la pesquería.
En el componente de incentivos se tiene, en general, un desempeño negativo. El indicador sobre derechos de pesca asegurados (3.1) no muestra cumplimiento debido a que los armadores formales no han podido consolidar su posición de derecho frente a una mucha más numerosa flota que participa de la pesquería de modo ilegal o informal. Se da el caso de que a los armadores formales no se les permiten capacidades de bodega de más de $10 \mathrm{~m}^{3}, y$, en cambio, en el segmento informal se cuenta con embarcaciones de hasta $32,6 \mathrm{~m}^{3}$. El indicador que refleja el monitoreo y vigilancia (3.2) también revela incumplimiento, por la resistencia de un amplio segmento de flota a ser monitoreado satelitalmente o a cumplir con otras regulaciones referidas a la seguridad y preservación. También el indicador sobre los derechos de pesca (3.3) arroja un resultado negativo, dado el escenario de alta informalidad en el que los pescadores formales ven amenazada su participación en la pesquería. En el caso del indicador sobre incentivos para no dañar el hábitat (3.4) el resultado también es negativo. Gran parte de la flota que captura perico también participa de la pesca de pota, pero llega a distribuirse ampliamente en la ZEE, e incluso opera fuera de las 200 millas. La pesca de perico requiere carnada, principalmente pota (en este caso la captura no queda de ningún modo registrada, incluyendo la que eventualmente realizan en alta mar, donde el Perú carece de registro de pesca de este recurso), pero no hay registro ni control efectivo de la pesca de otras especies, por lo que cabe recordar que, en general, según el CENPAR 2012, cerca de $70 \%$ de embarcaciones artesanales no cuentan con matricula o carecen de permiso de pesca. También debe indicarse que no existe un registro adecuado de las capturas, y que solo gracias a las declaraciones en planta, más las cifras de exportación y de los mercados mayoristas de Lima, se ha podido tener una aproximación a los volúmenes desembarcados.

En cuanto al componente sobre evaluación y manejo de riesgos, el indicador acerca de una estrategia de evaluación para la gestión (4.1) es negativo, por cuanto no se cuenta con una herramienta de este tipo para esta pesquería. Asimismo, en el indicador sobre el uso efectivo de puntos de referencia límite (4.2) el resultado es negativo debido a la falta de evaluaciones de la abundancia de perico, lo cual impide fijar, por ejemplo, cuotas globales de pesca, con el agravante de que esta pesquería -al menos regionalmente- es compartida con Ecuador. Existe entonces una necesidad de implementar no solo un sistema de evaluación como el propuesto por CIAT, sino también se requiere una articulación con Ecuador en el marco del proceso de certificación MSC 
de la pesquería. El indicador que evalúa el control o registro de las capturas (4.3) muestra un cumplimiento deficiente, pues gran parte de la producción es exportada lo que permite al menos conocer de modo indirecto los volúmenes de pesca; sin embargo, el perico también tiene una significativa comercialización interna que no está bien registrada. El indicador sobre límites de riesgo bien definidos (4.4) muestra un cumplimiento parcial, al haberse establecido una temporada de veda entre mayo y septiembre, así como se ha establecido una talla mínima de captura de $70 \mathrm{~cm}$ a la horquilla.

En el caso del componente sobre adaptabilidad, el resultado que se observa es positivo. El indicador sobre una toma de decisiones responsable y adaptativa (5.1) es positivo, dado que el Reglamento de la Ley de Pesca vigente dispone de esta flexibilidad, además de que el PAN PERICO está ya empezando a implementarse, a lo cual se suman los aportes de otras entidades como CIAT, WWF e INTELFIN. El indicador sobre ajustes continuos al manejo (5.2) también es positivo, por las razones citadas en el acápite anterior y por las normas (RM N. 249-2011-PRODUCE y RM N.o 245-2014-PRODUCE) que disponen una temporada de veda y una talla mínima de captura. El indicador sobre la existencia de una estructura anidada para la toma de decisiones (5.3) también es positivo, dado el grado de articulación que también se está alcanzando para la pesca artesanal con la participación de la DIREPRO del Gobierno Regional de Piura. Finalmente, el indicador sobre un uso sistemático de la información generada por la pesquería (5.4) arroja un cumplimiento parcial, dados los limitados recursos asignados para este propósito. Sin embargo, vuelve a destacar aquí el aporte de WWF, que está haciendo pruebas piloto de toma de datos con participación de los mismos pescadores y monitoreando satelitalmente sus operaciones.

3.5.6. Reglamento de Ordenamiento Pesquero de la Anguila

La percepción general sobre la gestión de esta pesquería de menor escala es correcta, aunque se requieren mejoras, especialmente en lo que se refiere a la transparencia de la gestión (tabla 1). Esta es una pesquería concentrada en la región Piura (Talara y Paita, y Sechura en menor medida), con eventuales capturas en Tumbes. Sin embargo, la anguila se distribuye a lo largo de toda la zona costera del Perú y de Sudamérica, pero en la costa peruana solo en Piura se ha consolidado una pesquería especializada que opera con "trampas anguileras", que son tramos de tubos plásticos con conos estriados en sus extremos que facilitan el ingreso de la anguila pero impiden su salida. Para esta pesquería se emplea carnada (peces) a bordo de embarcaciones de menor escala; cada nave porta entre 800 y 1200 trampas. Actualmente secaptura un promedio de una tonelada por viaje y cada viaje dura más o menos dos días. En todo caso, esta pesquería está considerada en estado de recuperación según el numeral (5.4) del ROP, "por lo que se requiere reducir el esfuerzo pesquero hasta permitir que los principales puntos de referencia biológicos se encuentren en niveles sostenibles". Como se verá más adelante, la captura 2016 recomendada por IMARPE ha sido mayor que la de años recientes, lo que puede indicar cierta recuperación de la abundancia del recurso.

En lo que atañe al componente sobre responsabilidad en la gestión, el indicador que evalúa los objetivos explícitos del ROP (1.1) cumple satisfactoriamente con esta condición. Sin embargo, en el caso del indicador que mide la existencia de informes independientes que evalúen el desempeño de la pesquería (1.2), el ROP no cumple esta condición y, salvo los estudios de IMARPE, no se conocen investigaciones de alguna otra entidad académica u una cadena de responabilide de una cadena de responsabilidades de gestión (1.3), se considera que este aspecto ha sido tomado en cuenta en el ROP y en los regímenes provisionales de extracción, como el que se implementó durante el año 2016 (RM N. 438-2015-PRODUCE). En cuanto al indicador sobre la participación de los actores en la toma de decisiones (1.4), en efecto el ROP contempla este aspecto, pero no se ha podido verificar el cumplimiento de tal condición. En lo que concierne al indicador de performance de la pesquería (1.5), se reconoce que IMARPE los genera pero no son de dominio público, o, al menos, no se ha difundido esta información de modo sistemático, tarea que sí

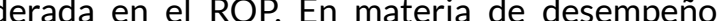
económico y ecosistémico (1.6y 1.7), se ha hallado que no se cumple con la condición.

Respecto al componente sobre transparencia, ninguno de los indicadores ha sido atendido en el ROP, lo que quiere decir que actualmente no hay acceso a la información de la pesquería (2.1), no se cuenta con un registro público de toma de decisiones (2.2) y no existe un proceso abierto para evaluar la toma de decisiones (2.3)

En cuanto al componente de incentivos, se observa un desempeño aceptable pero susceptible de mejoras. En el caso de los derechos de acceso (3.1), estos están asignados pero a la vez cerrados a nuevos actores (sobre esta pesquería operan alrededor de treinta embarcaciones cuyas bodegas fluctúan entre los $5 \mathrm{~m}^{3} \mathrm{y}$ los $15 \mathrm{~m}^{3}$ ). Asimismo, el Régimen Provisional de Extracción incluye una cuota de pesca de 5500 toneladas para todo el año 2016, siendo el promedio de 3000 toneladas para los últimos diez años. En el caso del indicador sobre monitoreo y vigilancia (3.2), se verifica el cumplimiento de esta condición, pues el régimen provisional antes citado reitera la obligación de contar con baliza para la vigilancia satelital. En cambio, el indicador sobre la existencia de un mercado de derechos de pesca (3.3) no está establecido, aunque esta pesquer aunque esta pesquería sí tributa derechos de pesca, según se establece en el ROP. El indicador que evalúa los incentivos para no dañar el hábitat (3.4) arroja un resultado positivo, en vista de que el ROP y el régimen provisional establecen condiciones tales como tamaño mínimo de captura. Se debe tener presente que existe cierta probabilidad de pérdidas de las trampas, lo que puede producir contaminación y pesca fantasma.

En el caso del componente sobre evaluación y manejo de riesgos, se constata que el indicador sobre el uso de un sistema de evaluación para el manejo (4.1) no se cumple en esta pesquería. A su vez, el referido al uso de puntos de referencia límite (4.2) solo muestra un bajo nivel de cumplimiento, dado que no se conocen detalles de la metodología de la evaluación que conduce a determinar las cuotas de pesca o los puntos de referencia empleados, aunque se sabe que existen informes detallados de IMARPE, tal como se señala en la RM N. 438-2015-PRODUCE. El indicador sobre el control de las capturas (4.3) indicaque síhay un adecuado cumplimiento, e incluye disposiciones específicas para reducir la captura de juveniles, al tiempo que dispone medidas de precaución para reducir la pérdida de trampas que podrían causar daños al ecosistema si no se les recupera. En cambio, el indicador sobre límites de rieso definidos (4.4) tiene un bajo nivel de cumplimiento, a pesar de que el ROP establece en su numeral 3.5 que IMARPE difundirá el resultado de sus investigaciones para su empleo por la sociedad en su conjunto y particularmente por el sector pesquero.

En el componente sobre adaptabilidad se observa un buen desempeño de la pesquería. El indicador sobre la toma de decisiones responsable y adaptativa (5.1) muestra un adecuado nivel de cumplimiento. En el caso del indicador sobre ajustes continuos al manejo (5.2), se halla que en efecto hay un seguimiento cercano de la pesquería, pero que este no incorpora la participación formal de los actores, por lo que se ha determinado un cumplimiento parcial. En lo que concierne al indicador sobre la existencia de una estructura anidada para la toma de decisiones (5.3), se verifica que esta existe y es funcional. Finalmente, el indicador sobre uso sistemático del conocimiento de los pescadores (5.4) también arroja un resultado positivo gracias al cercano seguimiento que hace IMARPE de la pesquería, y también por la obligación establecida en el ROP respecto a la necesidad de que cada embarcación cuente con una bitácora de pesca donde se anoten los detalles de los viajes de pesca, capturas, tallas, pesca incidental, etcétera.

\subsubsection{Reglamento de Ordenamiento de la Pesquería del Bacalao de Profundidad}

De acuerdo con la metodología empleada, el desempeño global de la pesquería indica que se tendrían que introducir mejoras sustanciales en el manejo (tabla 1). Con excepción de los componentes de incentivos y adaptabilidad, los restantes indicadores reflejan una necesidad de contar con un proceso participativo y más transparente. Si bien se trata de una pesquería pequeña, esta es una especie longeva que debe ser manejada con un grado mayor de seguimiento e indicadores. Asimismo, esta pesquería es regulada también por una Organización Regional de Ordenamiento Pesquero, en este caso la Comisión para la Conservación de los Recursos Vivos Marinos Antárticos (CCRVMA).

El bacalao de profundidad se distribuye ampliamente desde el norte del Perú hasta la región antártica. Verticalmente se distribuye en aguas profundas comprendidas entre los $300 \mathrm{~m}$ y más de $3000 \mathrm{~m}$ (Arana, 2008). El bacalao es una especie bento-demersal, pero realiza desplazamientos verticales en procura de organismos que componen su dieta. Esta especie alcanza su madurez sexual a la talla de $60 \mathrm{~cm}$, lo que en general se logra a los diez años de vida. Es entonces una especie frágil, de crecimiento lento y que puede llegar a $1,50 \mathrm{~m}$ de longitud total a la edad de cincuenta años (Arana, 2008). El principal método de captura es con espineles de fondo.

En la evaluación preliminar llevada a cabo según la metodología de Grafton et al. (2007) se halla, en el componente de responsabilidad, que para el indicador que evalúa los objetivos del manejo (1.1) se ha considerado el uso racional del recurso y de su fauna acompañante, teniendo en cuenta las características biológicas y poblacionales y los principios de pesca responsable, la conservación del medio ambiente y la biodiversidad. Sin 
embargo, el conocimiento biológico actual de la especie incluye su vulnerabilidad, dada su relativamente baja fertilidad y lento crecimiento para alcanzar la madurez sexual. Estos son conocimientos científicos que deben ser incorporados de modo explícito en el ROP. Por tanto, el cumplimiento actual de este indicador es incompleto.

En el caso del indicador que evalúa la existencia de informes independientes sobre el desempeño de la pesquería (1.2), se considera que no hay cumplimiento, pues disposiciones incluidas en el ROP determinan que la información sea estrictamente reservada, y que además en un principio se permitió a la flota autorizada operar sin portar balizas de seguimiento satelital, disposición posteriormente modificada. En cambio, en lo que atañe al indicador que evalúa la existencia de una cadena de responsabilidades (1.3) se considera que sí hay un adecuado nivel de desempeño. En el caso del indicador que evalúa la participación de los grupos de interés en el proceso de toma de decisiones (1.4) se aprecia un bajo nivel de cumplimiento, a pesar de que el ROP lo establece de modo expreso en su numeral 1.3. Asimismo, los indicadores de performance de la pesquería (1.5) no están disponibles al público por restricciones de tipo legal respecto a la publicación de información sobre esta pesquería Los indices sobre performance económica (1.6) y performance ecosistémica (1.7) tampoco están disponibles.

En el componente sobre transparencia, el indicador que evalúa el acceso a la información sobre la pesquería (2.1) arroja un resultado negativo debido a las restricciones antes citadas, a pesar de que el ROP establece esta necesidad en su numeral 4.4. En el caso del indicador que evalúa el registro del proceso público de toma de decisiones (2.2) se considera que tampoco se observa cumplimiento, pues el manejo en este caso no implica consultas formales. El indicador que mide el proceso abierto para analizar la toma de decisiones (2.3) también es negativo. Esta actividad de pesca está destinada a la exportación y, por tanto, en algún momento podría ser objeto de cuestionamientos debido al bajo nivel de transparencia que proyecta el ROP vigente.

Respecto del componente que alude a los incentivos se constata un mejor desempeño global. El indicador sobre derechos de pesca (3.1) es positivo debido a que esta pesquería se halla cerrada al ingreso de nuevas embarcaciones. Sin embargo, se sabe que lacuota de pesca anual ha sido reducida de 160 toneladas a 120 toneladas anuales, de acuerdo con la RM №. 156-2016-PRODUCE, atendiendo a principios precautorios ante la carencia de información suficiente que permita al menos mantener a cuota del año anterior. El indicador que evalúa el monitoreo y vigilancia (3.2) también es positivo, dado que esta pesquería, que cuenta con un reducido número de barcos, es monitoreada satelitalmente $y$, además, el IMARPE tiene la facultad de embarcar observadores científicos. El indicador sobre la existencia de un mercado para los derechos de pesca (3.3) es negativo debido al esquema cerrado que existe para esta pesquería, aunque debe precisarse que la flota de menor escala que opera en esta actividad tributa derechos de pesca. El indicador que evalúa los incentivos para no descartar o dañar el medidas adicionales imponen restricciones como la que limita el uso de anzuelos (15 000). Asimismo, existe una disposición según la cual cada embarcación está obligada a registrar sus capturas de bacalao y de la fauna asociada a ella.

En cuanto al componente sobre evaluación y manejo de riesgos, el desempeño en general es deficiente. El indicador que mide el uso de una estrategia de evaluación para el manejo (4.1) revela la ausencia de este requisito. Asimismo, el indicador que evalúa el uso de puntos de referencialímite (42) noestáincluidoenelROP,y tampoco científica. Se sabe que IMARPE utiliza diversos métodos de análisis, incluyendo la determinación del Máximo Rendimiento Sostenible (MRS), y su utilización tendría que ser incorporada en el ROP. En el caso del indicador que evalúa el control de las capturas (4.3), se considera que existe un adecuado desempeño. Sin embargo, no se cumple aquel referido al establecimiento de límites de riesgo (4.4)

En lo que atañe al componente de adaptabilidad el desempeño es bueno, y es uno de los aspectos más fuertemente desarrollados en el Perú En el caso del indicador que evalúa la toma de decisiones (5.1) se observa un cumplimiento satisfactorio, dado el permanente seguimiento que se da a la pesquería. El indicador sobre ajustes continuos al manejo (5.2) también es positivo, y se demuestra con los constantes cambios en la gestión. Un buen ejemplo es la emisión de la RM N. 395-2016-PRODUCE, que dispone una pesca exploratoria para evaluar si la cuota de 120 toneladas pudiera ser incrementada. En lo que toca al indicador que evalúa la existencia de una estructura anidada para la toma de decisiones (5.3), se considera que esta existe, es efectiva y articula al IMARPE con PRODUCE y sus entidades de fiscalización. No obstante, el último indicador, sobre el uso sistemático de la información de los pescadores (5.4), indica un bajo desempeño, pues esta pesquería, se supone, cumple con la entrega de las bitácoras de pesca, embarque de observadores y seguimiento satelital, por lo que el grado de certidumbre sobre la estimación de cuotas y puntos de referencia tendría que ser más robusto.

3.5.8.

Reglamento de Ordenamiento Pesquero de las Actividades Extractivas Artesanales de Menor Escala del Ámbito Marítimo

Adyacente al Departamento de Tumbes

Desde la década de 1990, y hasta mediados de la década de 2000, se suscitó en el litoral de Tumbes un conflicto con pescadores de otras regiones, o entre pescadores de la misma región que operaban aparejos de pesca distintos, a la vez que se observó una disminución de las capturas (Inga y Ordinola, 2001). Se abordó este problema con la aprobación del DS N. 023-2005-PRODUCE, que aprueba el primer ROP Actividades Extractivas Artesanales y de Menor Escala del Ámbito Marítimo Adyacente al Departamento de Tumbes. Se encargó de modo expreso a IMARPE monitorear el desempeño y capturas de las numerosas especies que son objeto de pesquerías en la zona. Al año 2010 se halló que, en general, las capturas y las tallas de todas las pesquerías continuaban disminuyendo, que los descartes se habían incrementado y, además, que los conflictos no se habían erradicado del todo (Vera et al., 2010). También Ordinola et al. (2010) confirman la continua presencia de flotas provenientes de Sechura y Santa Rosa en la zona costera, y el incremento del número de buzos y recolectores de orilla. Martínez \& Pérez (2005) describen en detalle las demandas de los pescadores de la zona respecto a que se incremente el número de extensionistas y se la vigilancia y control. Asimismo, el CENPAR 2012 muestra un aumento en Tumbes de 627 embarcaciones en 2009 a 1138 en 2012. La observación de un continuo incremento del número de embarcaciones a partir de 2009 motivó que se hicieran cambios en el ROP, con lo que la versión actual se publicó a través del DS N.o 020-2011-PRODUCE.

La incursión de embarcaciones de pesca desde otras regiones es una de las principales fuentes de conflicto en Tumbes. Por ello, se dispuso que las naves autorizadas porten una radiobaliza para verificar su ubicación y evitar que pesquen dentro de las cinco millas. Sin embargo, los cronogramas de instalación de balizas han sido postergados varias veces. El GORE Tumbes no efectuó este proceso, como fue su compromiso, y, en cambio, cedió a presiones; tampoco se ha tomado acción en coordinación con el GORE Piura. Por ejemplo, se sabe que en Talara, en La Poza y Quebrada Verde se concentran las arrastreras que operan también en Tumbes, y no se ha tomado acción sobre ellas. Por las razones indicadas, la vigilancia y el control son fundamentales para la sostenibilidad de las pesquerías, reconociendo además que en el litoral de Tumbes hay muchos lugares que se prestan para una fácil descarga de las capturas gracias a la abundancia de playas arenosas. Asimismo, se debe precisar que la flota arrastrera artesanal de Piura, que eventualmente incursiona y causa conflictos con los pescadores de Tumbes, opera en cambio libremente en las primeras cinco millas del litoral de la región Piura.

Habiendo realizado una evaluación preliminar de la pesquería con base en el ROP del departamento de Tumbes, se halla un cumplimiento deficiente en materia de gestión (tabla 1). En el componente de responsabilidad, el indicador que evalúa la existencia de objetivos explícitos para el manejo (1.1) arroja un resultado de parcial cumplimiento, debido a que si bien el ROP describe ampliamente todos los aspectos ecológicos, económicos y sociales esenciales, en la realidad no se han implementado medidas específicas para su cumplimiento. En cuanto al indicador que mide la existencia de evaluaciones independientes de las pesquerías (1.2), se encontró que no hay cumplimiento o, al menos, que esas evaluaciones no están disponibles. En el indicador que evalúa la existencia de una cadena de responsabilidades (1.3) se considera que sí hay cumplimiento y una articulación que involucra a DIREPRO, IMARPE y PRODUCE. EI índice que mide la participación de los grupos de interés en el proceso de toma de decisiones (1.4) arroja un cumplimiento deficiente, por cuanto este proceso existe pero no está formalmente implementado. Los indicadores sobre performance de la pesquería (1.5), performance económica (1.6) y performance ecosistémica (1.7) son todos negativos, a pesar de que se sabe que se colecta información continuamente, pero esta no es empleada de modo abierto. Como información adicional puede mencionarse que, de acuerdo con Galarza \& Kámiche (2015), el ingreso medio de los pescadores de Tumbes es el más bajo de toda la costa; lo mismo ocurre con su nivel educativo. En ese sentido, es conveniente precisar que el ROP dispone el desarrollo de estudios socioeconómicos.

En el componente sobre transparencia, los tres indicadores son negativos; es decir, no es posible acceder a información sobre las pesquerías (2.1), a pesar de que existe una cantidad interesante de boletines a través del 
portal de IMARPE, pues estas informaciones se refieren a hechos pasados, además de presentar, por lo general, datos agregados. Asimismo, no es posible encontrar un registro público de toma de decisiones (2.2), ni un proceso abierto para evaluar las decisiones tomadas (2.3), no obstante que este está contemplado en el ROP.

Respecto del componente sobre incentivos, el indicador de derechos de pesca asegurados para las comunidades (3.1) es positivo: aun cuando, en general, la situación de los recursos no es buena, se verifica una voluntad política regional paraque lagestión pesquera se oriente a reservar los recursos para las comunidades locales. El indicador que evalúa el monitoreo y vigilancia efectiva (3.2) arroja un cumplimiento parcial, pues si bien existe una vigilancia de DIREPRO y hay extensionistas, además de que el ROP dispone que haya zonas en veda y el SISESAT está implementado también para la flota artesanal, los Comités Regionales de Vigilancia de la Pesca Artesanal (COREVIPAS), que tendrían que estar a cargo de los pescadores, no llegaron a ser formalmente creados, como se estipulaba en el ROP. Los indicadores sobre la existencia de un mercado de derechos de pesca bien desarrollado (3.3) son negativos, ya que aún no han sido especificados. Asimismo, el indicador que evalúa los incentivos para no descartar o dañar el hábitat (3.4) da un resultado negativo, pues no existe evidencia de que se hayan controlado efectivamente los impactos que generan en zonas costeras la pesca de cerco y la pesca de arrastre. Es conveniente precisar que el ROP establece que, dadas las condiciones de deterioro de las poblaciones de recursos hidrobiológicos, no se concederán nuevos permisos de pesca hasta que se compruebe su recuperación.

El componente sobre evaluación y manejo de riesgos en general muestra un desempeño deficiente. El indicador sobre uso de una estrategia de evaluación para el manejo (4.1) es negativo por la carencia de esta herramienta. El índice sobre el uso efectivo de puntos de referencia límite (4.2) no ha podido ser establecido, por la complejidad de esta pesquería multiespecífica. El indicador sobre control y manejo de las capturas (4.3) muestra un cumplimiento parcial, dado que no todos los puntos de descarga son monitoreados. A su vez, el indicador que evalúa la existencia de límites de riesgo (4.4) es negativo porque, dada la complejidad de la actividad, estos límites tampoco están definidos, aun cuando son citados en el ROP.

Mejor es la situación del componente sobre adaptabilidad. Elindicador que evalúa latomadedecisiones responsables y adaptativa (5.1) es positivo, dada la voluntad política actual de resolver los problemas de la región a través de la implementación de nuevas regulaciones. El índice sobre ajustes continuos al manejo (5.2) muestra un cumplimiento parcial, en virtud de que hay acciones que se han venido concertando en el marco del punto anterior, pero que aún ( que evalúa la presencia de una estructura anidada para la toma de decisiones (5.3), esta existe y está articulada entre las instancian regionales (DIREPRO, IMARPE) y nacional (PRODUCE). Finalmente, el indicador sobre el uso sistemático del conocimiento o información parcialmente, a pesar de la necesidad de profundizar en el estudio de los impactos que provoca cada uno de los numerosos tipos de aparejos de pesca que se emplean en la zona.

3.5.9. Reglamento de Ordenamiento Acuícola (ROA) de la actividad de repoblamiento en la bahía de Sechura

La de Sechura es la bahía más grande de la costa peruana, y en ella se llevan a cabo actividades acuícolas, pesqueras, mineras, petroleras y portuarias. Estas labores se superponen y ocasionan conflictos entre los usuarios. La Comisión Ambiental Regional Piura viene trabajando estrechamente con todos los sectores e instituciones para la implementación del Plan de Manejo Integrado de la Zona Marino Costera de la Provincia de Sechura (GORE Piura, 2014).

La actividad más importante que se desarrolla en la bahía de Sechura, en materia socioeconómica, es el cultivo de concha de abanico en áreas de repoblamiento a través de concesiones, cada una de las cuales no puede ser mayor de 100 hectáreas. Cada área de repoblamiento se halla bajo la administración y cuidado de una Organización Social de Pesca Artesanal (OSPA). Las OSPA existen a lo largo de toda la costa del país, y muchas de ellas están conformadas por los integrantes de una misma familia, lo que en algunos casos les ha permitido cumplir ciertos requisitos para el acceso a una zona de repoblamiento, como en el caso de Sechura.

Las semillas que se utilizan en el repoblamiento son captadas del medio $\mathrm{u}$ obtenidas del banco natural de la Isla Lobos de Tierra (ILT), a la que se concedió la condición de Área Natural Protegida (ANP) en el año 2009. Asimismo, mediante RM N.o 293-2006-PRODUCE se determinó que este recurso se encuentre en veda hasta la actualidad, pero continuamente buzos artesanales extraen semilla de concha de abanico de manera ilegal para que sea trasladada a las áreas de repoblamiento de la bahía de Sechura. Como se ha señalado, la ILT y sus alrededores marinos constituyen un ANP que forma parte de la Reserva Nacional de Islas, Islotes y Puntas Guaneras (RNSIIPG). En esta ANP el banco natural de concha de abanico (Argopecten purpuratus) no puede ser explotado sin contar previamente con un plan de manejo, cuya versión preliminar ya existe y ha sido diseñada por la autoridad sectorial (PRODUCE), pero debe ser aprobada y supervisada por el SERNANP.

Dada esta circunstancia, se emitió el Reglamento de Ordenamiento Acuícola (ROA) de la actividad de repoblamiento en la bahía de Sechura a través del DS N. 016-2009-PRODUCE. Como se ha visto, actualmente está en proceso de implementación un Plan de Manejo para la Concha de Abanico del ANP-ILT, como uno de los productos de una mesa técnica instalada en Sechura en abril de 2014 para este efecto. Además, en esta zona pescadores artesanales que emplean artes de línea y redes de cerco y cortina realizan actividades de pesca extractiva. Asimismo, en las caletas de Matacaballo, Las Delicias, Constante, Parachique y Puerto Rico se concentra un gran número de embarcaciones artesanales y de menor escala que pescan principalmente pota y perico.

La Dirección Regional de la Producción del Gobierno Regional de Piura ha emprendido un proceso de ordenamiento de todas las pesquerías artesanales, incluyendo las actividades de repoblamiento de concha de abanico. También está en funciones una Mesa Técnica Ampliada de la bahía de Sechura, para abordar la problemática relacionada con la trazabilidad de la cadena productiva de la concha de abanico, con participación del SANIPES, entre otros. En Sechura se ha detectado una alta informalidad en el procesamiento de la concha de abanico, y los residuos sólidos son desechados en terrenos designados, donde, sin embargo, pobladores de bajos recursos se alimentan de los despojos de esta actividad. Esta zona se conoce como El Botadero, y es uno de los pasivos ambientales y sanitarios más graves que padece la región.

Vistos estos antecedentes a modo de preámbulo, a continuación se presenta la evaluación comparativa según la metodología de Grafton et al. (2007) en relación con el ROA para Sechura (tabla 1). En general, la evaluación que se ha hecho sobre gestión de los recursos bentónicos y actividades acuícolas en Sechura es positiva, a pesar de ciertos problemas que persisten y que serán descritos a continuación.
En el componente sobre responsabilidad, el indicador sobre objetivos específicos de gestión contenidos en el ROA (1.1) es positivo, en tanto aborda las condiciones preexistentes en relación con conflictos entre sectores $y$ entre grupos de pescadores o acuicultores. En este punto, el ROA no se enfoca solamente en aspectos bioecológicos sino también socioeconómicos, dada la alta informalidad y la falta de normalización en los permisos y concesiones existentes en la zona. En el indicador que evalúa el desempeño de la pesquería (1.2) se verifica un cumplimiento parcial, pues estos informes existen -como en Carbajal (2013) o Zavala (2015), entre otros- pero no son resultado de disposiciones contenidas en el ROA, sino aportes de ONG u organismos internacionales. En el indicador que evalúa la articulación de las responsabilidades (1.3) se observa que sí hay cumplimiento, ya que el ROA dispone que la Dirección Regional de la Producción coordine con los organismos públicos adscritos al Ministeriode la Producción (IMARPE, Instituto Tecnológico Pesquero del Perú - ITP, SANIPES y el Fondo de Desarrollo Pesquero - FONDEPES) para abordar interinstitucionalmente la solución a todos los problemas existentes, apelando también a la cooperación con otras organizaciones gubernamentales y no gubernamentales. El indicador sobre la participación de los grupos de interés en el proceso de toma de decisiones (1.4) es positivo y ha conducido a la conformación de Mesas Técnicas con la participación del Comité de Apoyo al Ordenamiento de la Maricultura de la bahía de Sechura, que incluye a más de $80 \%$ de las asociaciones existentes en la zona. El indicador sobre la performance de la pesquería (1.5) es positivo en tanto existe información que se obtiene en puntos de descarga, y también a través de información sobre exportaciones. En ese sentido, el indicador sobre performance económica (1.6) también es positivo, por las razones indicadas en el punto anterior. En cambio, el índice de performance ecosistémica (1.7) es negativo en tanto estos indicadores no han sido establecidos, no obstante los diversos monitoreos que se llevan a cabo en la bahía; aun así, debe precisarse que en el marco del Comité de Apoyo se ha comenzado a definir indicadores con base en investigaciones de SANIPES, IMARPE, OEFA, ANA, etcétera, con la participación de estas entidades.

En cuanto al componente sobre transparencia, el indicador que evalúa el acceso a la información que genera la actividad que es objeto de regulación (2.1) tiene un cumplimiento parcial, pues si bien existe información accesible, esta no corresponde a disposiciones que estén específicamente señaladas en el ROA. El indicador que 
mide la existencia de un registro público de toma de decisiones (2.2) muestra un cumplimiento parcial, pues se tienen registros gráficos y actas pero no hay informes de avances que sean detallados y analíticos. El indicador de la existencia de un proceso abierto para evaluar las decisiones tomadas (2.3) es positivo, $y$ como consecuencia deestadisposición contenidaen el ROA, se han establecido las Mesas Técnicas y los mecanismos de consulta para un mejor desarrollo de las actividades acuícolas. Se evalúa continuamente las decisiones tomadas con alta cobertura mediática, por lo que la población está al tanto. Cuando se considera que las decisiones son incorrectas, se hacen petitorios ante el GORE o la Defensoría del Pueblo. También es de resaltar que este tipo de gestión está abordando problemas como: i) la problemática de incidentes letales en la maricultura (muerte de buzos, malas prácticas), por loque se ha comenzado a hacer cursos de buceo, entre otros;ii) se están haciendo investigaciones para elaborar un sistema de detección temprana y gestión de la presencia de dinoflagelados tóxicos; iii) se están llevando a cabo investigaciones participativas con maricultores para medir parámetros oceanográficos en las zonas de cultivos; $y$, iv) se están formado grupos de mujeres y jóvenes que están diversificando la actividad en diferentes rubros, incluso aprovechando sus residuos.

En lo que atañe al componente sobre incentivos, e indicador que evalúa el acceso o derechos de pesca (3.1) es positivo en cuanto se ha asignado derechos $y$ ordenado el uso de la bahía, se ha establecido corredores y áreas de amortiguamiento, y se está mejorando la señalización de la zona. En lo que concierne al indicador que evalúa el monitoreo y vigilancia (3.2), se halla un cumplimiento parcial, pues si bien los monitoreos de diverso tipo existen (ANA, OEFA, SANIPES, IMARPE, DIREPRO, empresas), no están integrados tal como manda el ROA. En el caso de los índices sobre la existencia de un mercado de derechos competitivo (3.3) e incentivos para no dañar el hábitat (3.4), se observa incumplimiento. Por un lado, las concesiones se otorgan por un plazo de diez años, sin prever mecanismos de retribución para el Estado, $y$, por otro lado, los efectos contaminantes no han sido controlados, y, entre otros problemas, están generando impactos ambientales y sanitarios en la zona destinada para la disposición de residuos sólidos.

En el componente relativo a la evaluación y manejo de riesgos, se observa que el indicador sobre el uso de estrategias de evaluación para el manejo (4.1) es negativo, ya que esta herramienta no está implementada. En el caso del indicador que evalúa el uso de puntos de referencia límite (4.2) se constata un cumplimiento parcial pues, por ejemplo, se han establecido medidas como la cosecha de ejemplares con un diámetro mínimo, pero no se ha determinado la capacidad de carga de la bahía o del banco de la ILT, no se ha logrado controlar los aspectos sanitarios, etcétera, lo que de modo constante introduce la posibilidad de posibles sanciones a las exportaciones acuícolas de Sechura. El indicador que evalúa el control y manejo efectivo de las descargas (4.3) es negativo dada la relativamente alta informalidad que existe en el procesamiento primario de la actividad. El indicador que evalúa la existencia de limites de rieşo bien dr (4.4) en el desempeño de la actividad es deficiente, no obstante el alto riesgo de ocurrencia de hipoxia, con la consiguiente mortandad masiva de los cultivos. En este sentido, debe señalarse que en la Mesa Técnica se acordó instalar sensores de oxígeno y temperatura, pero a la fecha de elaboración de este reporte no se tiene información 的 marco del ROA.

Respecto del componente sobre adaptabilidad, se aprecia un buen desempeño. Los indicadores que evalúan la toma de decisiones responsable y adaptativa (5.1), la implementación de ajustes continuos al manejo (5.2) y la existencia de estructuras anidadas para la toma de decisiones (5.3) son positivos, y se espera que en ese marco de flexibilidad que articula en primer término a la DIREPRO, y a PRODUCE, IMARPE y SANIPES, se continúen logrando progresos. Finalmente, en el indicador que evalúa el uso sistemático del conocimiento e informaciones que pueden aportar los pescadores (5.4) se observa un cumplimiento parcial, pues apenas se está organizando el desarrollo de capacidades para la colección de información con participación de los acuicultores en el proceso de monitoreo.

\subsubsection{Reglamento de Ordenamiento Pesquero de} las Macroalgas Marinas

Vásquez et al. (2012), Maquera et al. (2012) y Cruz et al. (2012) indican que en el Perú las algas marinas pardas se exportan para utilizarse como materia prima en la industria de alginatos, carragenanos y agar; además, en menor grado, se consumen localmente como alimento para humanos. Afirman también estos autores que su creciente importancia económica ha conducido a incrementar los niveles de explotación a través de la recolección o extracción, promoviendo una importante participación de mano de obra, ya que la recolección es efectuada por pescadores artesanales y sus familias. Las macroalgas son también ecológicamente importantes, pues sostienen la cadena trófica bentónica y constituyen el hábitat y zonas de asentamiento larval o lugares de refugio para invertebrados y peces.

Según lo descrito por Castillo et al. (2011), al año 2007, en 25 localidades analizadas a lo largo del departamento de Arequipa, $90 \%$ presenta zonas sin cobertura de algas, especialmente Agua Salada, Chorrillos y Atico. La extracción y/o recolección de algas que observaron se efectúa sobre aracanto o Lessonia nigrescens. Asimismo, comprobaron un uso intenso del "barreteo" y recolección de alga varada, y un diámetro medio del rizoide por debajo de $20 \mathrm{~cm}$. Castillo et al. (2011) concluyen que las macroalgas estaban en riesgo de sobreexplotación. Por otro lado, Flores et al. (2015) describen una disminución de las macroalgas, especialmente el alga roja Chondracanthus chamissoi o "yuyo" en la bahía de Paracas.

El Instituto del Mar del Perú ha intervenido en esta actividad, investigando y generando conocimiento para el manejo sostenible de las praderas de macroalgas, con el apoyo de empresas privadas y de gremios organizados de pescadores algueros. En los últimos años se han generado hasta cinco experiencias orientadas a mejorar la gestión de las macroalgas: (i) Programa de Investigaciones de las Algas Pardas del Sur del Perú: 2012-2016; (ii) Plan de Mejora de la Producción; (iii) Plan de Capacitación sobre las Algas Pardas; (iv) Plan de Negocios de las Algas Pardas; y, (v) Plan Integral de Acción para el repoblamiento de 34 hectáreas en la bahía Paracas a través de la técnica de esporocultivo en hatchery de cuerdas de nylon. Se espera que todas estas experiencias sean replicadas en todo el litoral.

Como reflejo de todas esas experiencias, el Reglamento de Ordenamiento Pesquero de las macroalgas marinas, aprobado por DS N. 009-2009-PRODUCE, constituye el marco normativo para la actividad alguera, $y$ ha sido evaluado bajo la metodología de Grafton et al. (2007), que mide diversos componentes de una gestión ideal de pesca. En ese sentido, se considera que, en general, el ROP para el manejo de la actividad alguera es positivo, aunque se requieren mejoras que en gran parte pasan por considera los incentivos y el manejo de riesgos en esta actividad, que además enfrenta una alta tasa de informalidad en lo que concierne a los pescadores dedicados a ella (tabla 1).

En el componente sobre responsabilidad, el indicador que evalúa los objetivos y reglas explícitas (1.1) indica que la gestión es positiva, dado que considera no solo los aspectos ecológicos sino también los socioeconómicos. El indicador que mide la existencia de informes independientes sobre la actividad alguera (1.2) es de bajo cumplimiento, ya que, si bien esta herramienta no está implementada en el ROP, los monitoreos que hace IMARPE en el ámbito de Ica cuentan con el apoyo de los mismos actores, pero en otras regiones como Arequipa y Moquegua esto no ocurre. El indicador que evalúa la existencia de una articulación de responsabilidades en la gestión (1.3) existe y es funcional. Los indicadores que miden la participación de los grupos de interés en el proceso de toma de decisiones en la macrorregión sur son parcialmente cumplidos (1.4), y aquellos acerca del desempeñodela pesquería(1.5) sonde bajocumplimiento, pues si bien el ROP no los establece de modo explícito, en la práctica se verifica que hay un acompañamiento de los actores en el proceso de gestión de la actividad. Aunque en el momento se está tomando información sobre los volúmenes recolectados o extraídos solo en la región Ica, resta, sin embargo, mejorar estas informaciones, pues no especifican los detalles, en vista de que en gran parte son exportadas sin indicar de qué especies se trata. Por ello, el indicador sobre performance económica (1.6) tiene un bajo nivel de cumplimiento. A su turno, el índice sobre performance ecosistémica (1.7) no está contemplado en el ROP, y no se tiene conocimiento de que se esté evaluando el impacto de la actividad alguera sobre otras comunidades bentónicas. Es conveniente precisar aquí que IMARPE ha desarrollado la metodología para conducir estudios de línea de base (ELBA), y que ella ha sido replicada varias veces desde 2013 en las zonas de Paracas, Ballestas y Marcona e Isla Lobos de Tierra. Su uso debería extenderse a todo el litoral, con apoyo de las universidades.

En lo que atañe al componente sobre transparencia, el indicador que evalúa el acceso a la data generada por la actividad alguera (2.1) es negativo, dado que actualmente ella se puede obtener de modo indirecto, es decir, a través de informaciones disponibles en el portal de Aduanas, aunque en este caso la información parece no estar bien estructurada (no se tiene la información por especies). El indicador sobre la existencia de un registro público de toma de decisiones (2.2) indica un cumplimiento bajo, ya que si bien esta herramienta no está prevista en el $\mathrm{ROP}$, en cambio se conoce que hay una activa y positiva interacción, aunque incipiente, entre las entidades que tienen la responsabilidad de manejar de modo sostenible la actividad alguera (DIREPROS y PRODUCE, principalmente). En ese mismo sentido, el indicador que evalúa el proceso de toma de decisiones (2.3) también 
muestra un cumplimiento bajo, pues es un mecanismo que no está previsto en la normativa.

El componente sobre incentivos muestra, en general, un resultado deficiente. El indicador que evalúa la seguridad del acceso de las comunidades a la actividad alguera (3.1) indica un desempeño bajo, pues todavía no se emplean en el país mecanismos como los derechos de uso territorial, es decir, la garantía que da el Estado sobre la exclusividad en la extracción de ciertas especies, siempre que se reúnan determinados requisitos como la vigilancia y la existencia de planes de manejo para la extracción de las especies. Asimismo, se observa que los GORE tienen la potestad de otorgar carnés de pescador de modo muy superficial o con una escasa evaluación, lo cual está contribuyendo a aumentar las presiones sobre el ecosistema. Por las razones arriba expuestas, e indicador sobre el monitoreo y vigilancia efectiva (3.2) tiene un cumplimiento insuficiente, dado que, además, los COREVIPAS (RM N.. 045-2003-PRODUCE, que autoriza a las Direcciones Regionales de Pesquería a conformar Comités Regionales de Vigilancia de Pesca Artesanal) no han sido implementados. El indicador que evalúa la existencia de un mercado para los derechos de pesca (3.3) arroja un resultado negativo, en vista de que no existen derechos de pesca para esta actividad alguera, ni se ha previsto la retribución por este derecho (que no necesariamente deber ser de tipo monetario sino expresada en el servicio de control, monitoreo, estudio del ecosistema, etcétera).

En lo que respecta al componente sobre evaluación $y$ manejo de riesgos, su condición es también deficiente. El indicador que mide el uso de una estrategia de evaluación para el manejo (4.1) es negativo, pues este instrumento no está implementado en el ROP. El índice acerca de uso efectivo de puntos de referencia límite (4.2) muestra un escaso cumplimiento, pues las únicas regulaciones que suelen proponerse son una cuota a la extracción y diámetros mínimosderizoide.Enestesentido,esnecesario realizar con frecuencia evaluaciones completas de la abundancia al menos en las zonas principales, así como establecer de modo sistemático la rotación estacional de áreas, tal como se dispone en el ROP. El indicador sobre control y manejo efectivo de la extracción o recolección (4.3) arroja un resultado deficiente dado el hecho de que, si bien el ROP contempla una serie de obligaciones para esta condición, en la práctica sucede que el cumplimiento es escaso. Urge fortalecer la presencia de las DIREPROS en las principales zonas y establecer formalmente los COREVIPA de acuerdo con lo dispuesto
045-2003-PRODUCE. El indicador sobre límites de riesgo definidos y acordados (4.4) arroja un resultado negativo, pues estos límites no están establecidos. Todo el litoral del país está sometido a una alta variabilidad climática, y las amenazas de El Niño se han convertido en más frecuentes . 2016). Asmos del cambio climático (Gutiérrez D. et al., 2016). Asimismo, las praderas son vulnerables a los cambios térmicos bruscos (Mamani et al., 2012) como los que provoca el arribo de ondas Kelvin. Por último, las macroalgas también son sensibles a la contaminación que se origina en las zonas costeras, por lo que SANIPES Ase habilitar sanitariamente las zonas de extracción. Asimismo, el ROP establece la necesidad de crear zonas de reserva donde la actividad alguera no estará permitida, para que sea posible contar con una reserva genética que permita una más rápida recuperación en el caso de eventos nocivos.

El componente de adaptabilidad muestra que en el indicador sobre la toma de decisiones responsable y adaptativa (5.1) sí existe un marco conveniente, y que la flexibilidad del manejo está establecida en el ROP. Sin embargo, el indicador sobre la realización de ajustes continuos al manejo (5.2) tiene un bajo nivel de ser los grupos de interés quienes presionan ya sea a las DIREPRO o a PRODUCE para que tomen acción con el fin de realizar evaluaciones o autorizar cuotas adicionales de extracción. La recurrencia del evento El Niño debe conducir a una observación más frecuente y completa sobre el estado de las praderas. El indicador que evalúa la existencia de estructuras anidadas parala toma como de modo funcional, e implica varios niveles de coordinación entre instituciones. El índice que mide el uso sistemático del conocimiento de los pescadores (5.4) arroja un resultado deficiente, dado que si bien el ROP dispone una activa participación de los pescadores en el procesode gestión, estase expresa de modo reactivo yno chismo permanente que permita articular programas de vigilancia para la toma de información que enriquezca la gestión de la actividad.

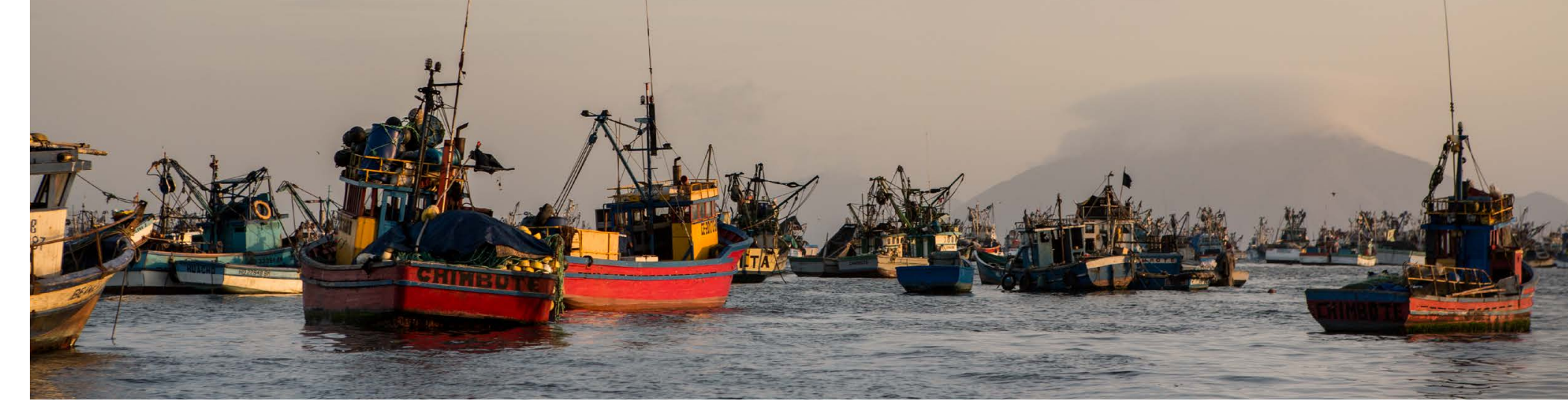

\subsection{SÍNTESIS DE LAS ENTREVISTAS CON EXPERTOS DEL SECTOR, CON ESPECIAL REFERENCIA A LA TRANSPARENCIA YLA PESCA ILEGAL}

Se ha empleado un método de prospectiva (Delphi) para consultar la opinión experta de personas que cumplen labores ejecutivas desde el gobierno y desde las empresas, con el fin de identificar las coincidencias cuyo planteamiento pudiera facilitar mejoras en la gestión pública de la pesca.

Se solicitó una entrevista con 84 expertos del sector pesquero, incluyendo a funcionarios del Estado $y$ de sector privado, ONG $y$ C sultores independientes. Veintitrés de estas personas accedieron a conceder una entrevista, fuera esta presencial o mediante una encuesta escrita. El objetivo de estas consultas era recoger propuestas en general orientadas a incrementar la transparencia en la gestión del sector pesca, e identificar acciones para contener la informalidad existente y la consecuente pesca ilegal.

Se planteó un cuestionario de catorce preguntas sobre la definición de transparencia; el estado de las principales pesquerías nacionales; las medidas de excepción que eventualmente se toman (pesca exploratoria, por ejemplo) en el contexto del manejo pesquero; el rol de IMARPE como entidad clave del sector; sobre los sistemas de información disponibles que pudieran tener un carácter público y accesible (SISESAT y las estadísticas de pesca, por ejemplo); los métodos de evaluación de la gestión que podrían implementarse para mejorar las medidas de manejo; las mejoras en los ROP para abordar de modo práctico el problema de los descartes y la pesca ilegal en las pesquerías; las barreras comerciales a las pesquerías no sostenibles; la asignación de derechos de uso como alternativa de gestión; sobre el pago de derechos de pesca; y sobre la articulación entre entidades que también tienen competencias en el sector pesquero.

Se presenta a continuación una síntesis de las opiniones vertidas.

\subsection{Acerca de la definición del concepto de}

transparencia en el sector pesca

Se propuso a las y los entrevistados el siguiente concepto de transparencia:

"La transparencia es una característica deseable en la gestión pública, que consiste en la implementación de medidas que apoyen la credibilidad y confianza de la sociedad en sus autoridades respecto al uso de los bienes naturales de la nación. Una autoridad que se ejerce con transparencia anticipa los hechos, es proactiva y busca que sus funcionarios estén imbuidos de la necesidad de aportar a un proceso de mejoras constantes, y ataja las resistencias que se dan en sentido contrario

La pregunta que se les hizo fue: ¿Coincide usted con esa definición de transparencia en el caso del sector pesca? ¿Cuál sería, en todo caso, la definición que usted propondría? En general, hubo un acuerdo con esta definición, pero se puntualizaron los siguientes conceptos o propuestas:

a) Institucionalización de la transparencia. Se requiere diseñar acciones encaminadas a demostrar la transparencia de la gestión. Las medidas que sean acordadas deben ser cuantificables, y es preciso 
conceder plazos paralas metasfijadas. Debeimpulsarse un proceso de mejoras constante para solucionar los problemas que hayan sido identificados, como, por ejemplo, reducir la alta informalidad y la pesca ilegal. Al mismo tiempo, es necesario acordar métodos de verificación independiente, para fortalecer un sistema que incluya la participación de los actores y la sociedad civil en general.

b) Transparencia y acceso a la información. Si bien las instituciones del sector cumplen los principios de la y la publicación de sus finanzas, en cambio no ofrecen información sobre la gestión propiamente dicha. Por ejemplo, las estadísticas de pesca por especies y por puertos no han sido publicadas regularmente. Asimismo, estas informaciones de carácter público deben estar disponibles en un formato tal que facilite su uso por quienes la requieren. Otro ejemplo es la información que se recaba para propósitos científicos y de manejo, como la que se procesa para estimar la biomasa y cuotas de pesca de especies explotadas y sus especies asociadas.

Existe un potencial que podría ser aprovechado por los centros académicos que no cuentan con un fácil acceso a estas informaciones, lo que limita la investigación ecológica y económica necesaria para contribuir con la gestión del Estado. Por ello, las entidades que generan información deben asimismo contar con indicadores de imagen institucional para evaluar el desempeño de cumplimiento de la Ley de Transparencia.

c) Diálogo y participación. Una constante en el sector es la incertidumbre en cuanto al conocimiento de ecosistema marino, pues a menudo las previsiones son superadas por eventos climáticos que se han intensificado desde EI Niño 2010. Hay pocos canales de difusión y discusión del conocimiento, a pesar de que una meta del sector es mantener la actividad extractiva en medio de estas condiciones de incertidumbre.

Asimismo, no se promueve formalmente, desde el Estado, la participación de los grupos de interés en los procesos de generación de normas y otras acciones como consultas públicas, con lo que se pierden iniciativas que podrían contribuir a la gobernanza del sector. Por lo general las normas entran en vigencia con una prepublicación, pero el diseño de esas propuestas de normas no es participativo, con lo que se adquiere la impresión de que los funcionarios no le dan importancia al aporte de los usuarios, que son quienes más conocen la realidad del sector. Por ello, los funcionarios deberían tener experiencia en el sector independientemente de su profesión.

d) Conocimiento de la variabilidad climática y su impacto en la gestión. Para beneficio de la transparencia es necesario que la opinión pública conozca cómo se manejan los recursos pesqueros, y esto implica hacer llegar al público toda la información disponible. En especial, es necesario que se comprendan los criterios empleados para tomar ciertas acciones (por ejemplo, pescas exploratorias), dado que la complejidad y variabilidad del mar peruano no permite definir un "recetario", en vista de que cada evento tipo El Niño genera distintas manifestaciones. El desconocimiento de esta realidad impide entender bien por qué se recomiendan y deciden determinadas acciones.

A inicios de 2017 parece estarse desarrollando el evento El Niño Costero, que fue totalmente imprevisto y que, por tanto, seguramente obligará a desarrollar medidas de manejo especiales, que deben ser amplia y oportunamente explicadas para que su implementación sea adecuadamente apreciada por el sector.

\subsection{Sobre la transparencia en la gestión de las}

principales pesquerías nacionales

Las principales pesquerías del Perú son: (1) anchoveta, (2) pota, (3) jurel-caballa, (4) merluza, (5) perico, (6) especies costeras y (7) macroalgas. La pregunta que se hizo fue: según su conocimiento, ¿considera usted que hay transparencia en la gestión de la pesca de estas especies?

Las respuestas dadas a esta pregunta indican que la transparencia es parcialmente cumplida según la especie de la que se trate. Otros enfoques aportados por los entrevistados son los siguientes:

a) Alta tasa de pesca ilegal. Sesenta por ciento de la captura artesanal de anchoveta proviene de pescadores informales, la calidad de la captura no es no óptima y es procesada en plantas que contaminan el ambiente. Se requiere una acción y sanción articulada entre PRODUCE, los GORE, SANIPES, OEFA, e incluso la Superintendencia Nacional de Aduanas y Adeministración tributaria (SUNAT).
La concesión de una cuota CHD para la anchoveta podría ser una buena medida para impulsar la producción de alimentos y contener la producción ilegal, pero esto va a depender también del fortalecimiento de la capacidad de control y vigilancia. El análisis de las exportaciones permitiría cotejar el correcto uso de los recursos.

Se debe contar con mecanismos que promuevan y faciliten la formalización de la pesca artesanal. Por ejemplo, exceptuarlos del pago del impuesto a la renta, pensiones, seguros y habilitación sanitaria de las embarcaciones y lugares de operación.

b) Procedimientos establecidos para la participación de los actores. Es necesario que PRODUCE e IMARPE implementen, en consulta con todos los grupos de interés, un protocolo de procedimientos que asegure la participación de los actores en todo el proceso de manejo de las pesquerías (incluyendo monitoreos - cruceros de IMARPE). Esto incrementará significativamente la transparencia y la confianza y credibilidad del sector en sus autoridades.

En general, los ROP no disponen de modo explícito la participación de los involucrados, por ejemplo, a través de reportes voluntarios. Esta carencia genera la percepción de poca trasparencia. Debe haber un acompañamiento en el diseño y aplicación de las normas. Se constata la mala práctica de mantene en secreto las medidas por adoptar, lo que genera desconfianza. Por ejemplo, el ROP de la pota está diseñado para la pesca industrial, pero en los cinco años transcurridos no han sido habilitados los correspondientes permisos de pesca. Tampoco se están desarrollando esfuerzos para evaluar la biomasa actual del recurso y el impacto que en ella ha tenido el prolongado evento El Niño 2014-2016.

c) Transparencia en la gestión de distintas pesquerías. En el caso de la anchoveta, jurel-caballa y merluza se considera que el nivel de transparencia es adecuado, pero en los otros casos no se puede afirmar lo mismo. Es posible que con la divulgación de los informes internos que IMARPE ya genera sobre el estado de las diferentes pesquerías, la percepción pública mejoraría ostensiblemente. Asimismo, no se ve una conexión entre IMARPE y las universidades que podría generar en cooperación, los monitoreos e investigaciones que se requieren para incrementar y difundir el conocimiento en aras de una mayor transparencia y participación en los asuntos del sector. Sin la suficiente información de campo no es posible contar con una gestión sin incertidumbres sobre el estado de las especies.

Dada la dinámica de algunas pesquerías, se hace necesario que IMARPE publique $y$ actualice oportunamente la información sobre descargas, pues esta información es útil para la gestión de las empresas. Esta necesidad es de conocimiento de las autoridades. Se debe desterrar la práctica de que la autoridad solo informe de modo privado las decisiones que va a tomar en temas cruciales como el establecimiento de cuotas u otras regulaciones. Hay lobbies e intereses económicos que frenan las modificaciones que son necesarias para mejorar el desempeño económico de las pesquerías. Por ejemplo, la falta de decisión en imponer la formalización y fiscalización es el reflejo de las presiones que ejercen algunos grupos de actores.

d) Rol de las DIREPRO en el sector pesca. Las DIREPRO, salvo excepciones, parecieran contar con personal poco capacitado y posicionado en sus obligaciones. La transferencia de competencias desde PRODUCE no está funcionado y los GORE no están asignando los recursos suficientes para cumplir sus obligaciones en el sector pesca. Es común apreciar en los muelles especies desovantes o fuera de talla a vista y paciencia de las autoridades, siendo esa supervisión una tarea de las DIREPRO.

e) Investigación para la gestión. La gestión de recursos pesqueros es un proceso sofisticado y alejado del conocimiento de la mayoría de los actores, lo que contribuye a generar una impresión de falta de transparencia. Se requiere un mayor número de profesionales especializados que puedan divulgar los procedimientos de forma simple, así como es preciso que las entidades del sector cuenten con personal informado y capacitado sobre las distintas herramientas metodológicas que emplea el Instituto.

La constante incorporación del conocimiento logrado con la experiencia en la gestión de la pesca es una necesidad y un reto. Gracias a eso, en anchoveta se ha avanzado y superado errores pasados para lograr una pesquería sostenible. En merluza se generaron problemas debido al desconocimiento de la naturaleza del mar peruano. La pota presenta la dificultad de 
por lo que el avance es más lento. En recursos costeros, $40 \%$ de la captura se explica por los desembarques de cinco especies claves.

En el caso de pesquerías artesanales, debe trabajarse eficazmente con sus gremios para lograr un ordenamiento adecuado de las especies. Sin embargo, el proceso de formalización es un aspecto que aún no ha sido abordado de modo conveniente. Y, por otro lado, se observa una alta fragmentación entre los actores artesanales, lo que impide la concertación de una acción efectiva.

\subsection{Medidas para incrementar la transparencia} en la gestión de la pesca

En este caso la pregunta formulada fue: ¿qué medidas específicas recomendaría usted para incrementar la transparencia en la gestión de la pesca en los casos mencionados?

a) Objetivos de la gestión. Los objetivos del manejo deben ser establecidos a través de procesos participativos según los principios del manejo ecosistémico de IUCN (Andrade et al., 2011). Las evaluaciones de los recursos deben ser publicadas para su discusión antes de establecer las cuotas. Asimismo, es preciso hacer públicas las estadísticas de pesca diariamente, empleando formatos y protocolos preestablecidos, lo que obliga a todas las instancias a asignar los recursos debidos para esta tarea. Debe incorporarse los reportes voluntarios de las empresas.

Es necesario, además, agilizar los procedimientos administrativos y consultas diversas aprovechando las capacidades informáticas actuales (online). También brindar sustento técnico y científico a las decisiones administrativas, ya que muchas veces se deniegan de modo poco transparente.

El control satelital debe ser pagado por PRODUCE, y las empresas deben abonar el costo del servicio al ministerio. Asimismo, es obligación de DICAPI detectar las embarcaciones que no cuentan con documentos de matrícula. En una segunda etapa, no debe permitirse el zarpe de embarcaciones sin permiso de pesca. Se ha de desplegar un seguimiento y control real de las descargas en muelle y otros puntos de descarga. No existe una verdadera fiscalización y, más bien, se observa tolerancia hacia la captura de especies con tallas menores que las establecidas.
IMARPE podría pasar a depender de la PCM para aliviarlo de posibles presiones internas y externas.

Medición del desempeño. Deben acordarse unos indicadores para medir el desempeño y la efectividad de la gestión (por ejemplo, según lo propuesto por Halpern et al., 2012 y Holland, 2010, entre otros) en diversos escenarios, con evaluaciones periódicas. Estas evaluaciones podrían estar a cargo de instituciones acreditadas. Asimismo, es preciso considerar la creación de indicadores de desempeño económico y ecosistémico de cada pesquería.

b) Más especies con ordenamiento pesquero. Se requiere desarrollar ordenamiento para un mayor número de especies. Los convenios que IMARPE tiene con universidades deben ser activados para incrementar significativamente el esfuerzo de investigación sobre el ecosistema. Se podría elaborar un Plan Nacional de Investigación Costera con apoyo de las ONG y organismos internacionales. De este modo se democratizaría la investigación, aliviando la carga que soporta IMARPE.

En ese sentido, debe fortalecerse a las Comisiones Ambientales Regionales (CAR) para que se sumen al esfuerzo en pro de la ordenación de las pesquerías artesanales. Los gobiernos regionales necesitan desarrollar y fortalecer sus capacidades para ejercer sus competencias cabalmente. Los GORE deben desarrollar planes de manejo para las actividades económicas que se llevan a cabo en el borde marino costero para el año 2021

Es necesario que las ONG participen del proceso en favor de una mayor transparencia. Debe tenerse presente que es preciso que cada pesquería sea adoptar una estrategia común para todas.

\subsection{Sobre las medidas de excepción cuando las evaluaciones pudieran estar sesgadas}

En la segunda temporada de anchoveta de 2015 y en la primera de 2016, PRODUCE dispuso medidas de excepción ante el desarrollo del evento El Niño. Se ordenó la ejecución de un nuevo Crucero de Evaluación inmediatamente después de otros (en la primavera de 2015 y el otoño de 2016), que halló un nivel de biomasa de anchoveta menor que el esperado; asimismo se realizaron pescas exploratorias en las que intervinieron barcos para apoyar en la evaluación de la anchoveta. En una auditoría científica hecha a IMARPE, la FAO recomienda fortalecer las relaciones con el sector productivo para aprovechar las embarcaciones comerciales como plataformas generadoras de información científica (Arreguín \& lanelli, 2014) $)^{2}$ Cuando ventos como El Niño, como en el caso descrito, la distribución de todos los recursos suele estar alterada, es decir, alejada de su patrón normal, lo que obliga a incrementar el esfuerzo de monitoreo para poder establecer con certeza la situación poblacional de las especies-objetivo. Sin embargo, estas medidas han generado cierta suspicacia aunque hayan sido técnicamente correctas.

La pregunta planteada en este caso fue: ¿qué acciones pueden emprenderse para que incluso las condiciones de excepción -que se han dado no solo en la pesquería de anchoveta sino en casi todas las pesquerías- estén previstas de modo transparente para que se genere la confianza que merece el uso de los recursos pesqueros?

a) Primero el principio precautorio. Científicos de todo el mundo recomiendan suspender las capturas ante fenómenos adversos. Por ello, sería interesante cuantificar el impacto causado al recurso cuando se realizan temporadas de pesca durante eventos $E$ Niño; sin embargo, otras especies se favorecen por este fenómeno, situación que ha de aprovecharse. Por ello, debe generarse un protocolo que distinga medidas que han de ser tomadas ante escenarios climáticos diferentes. Es preciso, asimismo, reconoce las limitaciones de las metodologías empleadas en la evaluación de las especies, y comentar las implicancias de tales limitaciones sobre los resultados en cada informe o diagnóstico que se emita. Asimismo, se necesitan procesos participativos basados en el consenso para que los resultados y acuerdos sean aceptados y respetados.

b) Información disponible para la validación de resultados. Se requiere ampliar las bases de datos, sobre todo en recursos hidrobiológicos cuyos parámetros de población no se conocen. De este modo las investigaciones que se harán cobrarán mayor fiabilidad. El incremento del monitoreo cuantitativo sobre más especies difícilmente podrá ser logrado sin el concurso de las universidades.

Retomar el uso de herramientas de evaluación como el Método de Producción de Huevos (MPH). Asimismo, hay modelos End-to-End, modelos geoestadísticos y probabilísticos que ya podrían ser utilizados, al menos de modo parcial (Oliveros, 2015; Joo et al., 2015; Lau, 2016; Castillo, 2017). También debe formalizarse la participación de las flotas pesqueras en apoyo a la labor de monitoreo de IMARPE, lo que representa un reconocimiento a una herramienta de acopio de información que viene utilizándose desde 1966. Se podría institucionalizar el desarrollo de cruceros y operaciones Eureka dentro de los ROP. A pesar de que estas operaciones se realizan desde hace más de cincuenta años, su desarrollo no está formalmente bajo ningún programa formal de monitoreo. Esto podría efectuarse a través de una resolución ministerial. El estándar tecnológico de IMARPE debe ser el mejor para estar en capacidad de recoger información de mayor calidad.

c) Manejo Precautorio Adaptativo (MPA). En el Perú se aplica un "manejo precautorio adaptativo" que está basado en el uso de todas las herramientas y procedimientos posibles para reducir la incertidumbre. Para ello, el monitoreo del mar debe ser lo más frecuente posible, pero debe generarse la normativa que elimine suspicacias alrededor del desarrollo de estas actividades.

No debería haber cruceros convencionales en condiciones anómalas. Las cifras que resultan de estas evaluaciones suelen ser discordantes, lo que agrega incertidumbre en la gestión. En estos casos, debe en cambio activarse la participación de todos los gremios de la industria en apoyo a IMARPE, a través de operaciones de monitoreo que impliquen utilizar la flota con financiamiento de las empresas. Para ello, sería conveniente redactar un protocolo o manual para el MPA, de modo que las medidas que se tomen sean no solo técnicamente correctas y transparentes, sino además contribuyan a reducir la incertidumbre. Es muy importante para la credibilidad de los resultados que la opinión pública apoye las medidas tomadas. 


\subsection{Transparencia en las recomendaciones d gestión de IMARPE}

Las recomendaciones de gestión que IMARPE genera para PRODUCE se remiten directamente al ministerio. $Y$ en ciertos casos son los propios grupos de interés quienes solicitan la intervención del Instituto, cuando existen condiciones especiales como las que se han dado para el erizo y los langostinos recientemente (se fundamentaron y autorizaron pescas exploratorias). La interrogante que se planteó en este caso fue: ¿qué acción debe tomar IMARPE como entidad fundamental del sector pesca para incrementar la transparencia de sus recomendaciones de gestión?

a) Trazabilidad y transparencia. IMARPE podría pasar a la PCM con el fin de blindarlo de presiones. No obstante, debe entregar información al público de modo frecuente, $y$ atender las recomendaciones hechas por la FAO en el marco de una auditoría técnica llevada a cabo al Instituto (Arreguin\& Ianelli, 2014) 3. IMARPE debe incrementar su transparencia y su visibilidad. Asimismo, es necesario un registro público de las interacciones o coordinaciones de IMARPE con partes interesadas (trazabilidad). Por ejemplo, la presentación de los resultados de las evaluaciones de las especies sometidas a pesquería debería ser pública. Debe procurarse el incremento de la confianza de los actores, por ejemplo embarcando representantes tanto de los gremios artesanales como industriales. IMARPE podría optar por la certificación de sus procesos y ejercer su autonomía.

b) Mesas de diálogo. Sería conveniente considerar la creación de mesas de diálogo para cada pesquería bajo la conducción de PRODUCE, pero con la decisión política de compartir un mucho mayor grado de informaciones y análisis para enriquecer los debates sobre las siguientes medidas de gestión. IMARPE debe anticipar las reacciones e impactos de sus decisiones, y fundamentar sus recomendaciones en la práctica y replantear sus recomendaciones cuando sea necesario.

La decimotercera recomendación de la FAO a IMARPE (Arreguin \& lanelli, 2014) indica: "Implementar esquemas de trazabilidad y transparencia como elementos de certeza y calidad del trabajo institucional. Si bien IMARPE goza de credibilidad y respeto por parte del sector pesquero, no es extraño que se den episodios cuestionando aspectos de procedimiento para la toma de decisiones; esto es normal en todo el mundo. Sn embargo, un aspecto táctico que contribuye a mejorar y mantener la certezay y credilifdeds de una estrategia que permita dar seguimiento a los procedimientos desarrollados, en este caso, para la recomendación de una medida de manejo
determinada (por eiemplo, una cuota, una veda). Si bien este esquema es recomendado para el IMARE, sería también importante definirlo para la participación de PRODUCE desde que recibe la información de IMARPE, hasta que se emite la medida de manejo para su aplicación" (página 13). IMARPE tiene sin embargo un portal o biblioteca o repositorio digital donde está registradas la mayor parte de sus investigaciones e informes
(http://biblioimarpe.imarpe.gob.pe:8080/).

El objetivo es que exista un Plan de Monitoreo para cada especie de importancia comercial, para lo cual se deben modificar los ROP.

Se debe tener presente que hay un número reducido de personas con conocimientos y experiencia para evaluar lo que hace IMARPE. Se requiere, por tanto, de un esfuerzo de formación de capacidades para acompañar adecuadamente la labor del Instituto en las mesas de diálogo. Este es un reto principalmente para las universidades.

\subsection{Sobre el nivel de información que IMARPE} podría compartir públicamente

Muchas de las informaciones que maneja IMARPE solo pueden ser producidas por el Instituto. Existen varias fuentes de información: sus publicaciones, los informes, los informes ejecutivos, los informes de crucero, las capturas diarias, etcétera. Sin embargo, hay mucho más. Se cuenta también con abundante información específica sobre muchas variables, pero ella no está disponible para muchos usuarios que esperan poder utilizarla con el fin de impulsar sus propios proyectos de desarrollo. La pregunta específica en este caso fue: ¿hasta qué nivel detallado de información se podría esperar que IMARPE comparta datos de calidad, pensando en la necesidad de que debería existir un vínculo mucho más dinámico entre Anstituto, las universidades, las empresas y la sociedad

Transparencia e información de uso público. Los estudios de IMARPE deben ser públicos como base de la transparencia. Hay numerosos informes internos que son reservados y que no deberían tener esa condición. La información que maneja IMARPE debe ser de conocimiento de entidades que necesiten utilizarla, principalmente las universidades. También debe ser de fácil acceso virtual para que se pueda utilizar según las necesidades de quienes la requieran ${ }^{4}$. Es necesario cambiar la cultura de protección excesiva. Asimismo, IMARPE puede proveer información simple para grupos de interés, y otra, más profunda, para científicos. FAO (Arreguin \& lanelli, 2014) ha emitido una recomendación específica referida a que se deben hacer explícitos los niveles de representatividad de los datos colectados por las diferentes fuentes de información ${ }^{5}$.

Por ejemplo, se necesita conocer las tendencias de las poblaciones por especies y zonas. Hay información histórica que puede utilizarse para propósitos del diseño de Planes de Manejo para Áreas Naturales Protegidas del ámbito marino; en ese terreno se ha avanzado muy poco.

Asimismo, debe aclararse el criterio de propiedad intelectual de las investigaciones de IMARPE. Si se establece que se trata de información pública, debe acogerse a la Ley de Transparencia ${ }^{6}$. IMARPE debe valorar la capacidad de cada universidad para generar investigación que puede ser desarrollada bajo su asesoría. Y tiene también que abordar aspectos socioeconómicos, una tarea no abordada hasta ahora.

El nivel de detalle de la información que IMARPE puede compartir dependerá del grado del vínculo que el Instituto pueda desarrollar en cooperación con universidades, no solo del ámbito nacional. Hay un historial de cooperación muy fructífera con Alemania Francia y los Estados Unidos, entre otros.

b) Protocolos para el acceso a la información. Son necesarios protocolos claros para el uso de la data de IMARPE, para salvaguardar los derechos del Estado, pues la información referente a pesquerías es de importancia económica para el Perú. Países de la región como Chile y Argentina publican sus informes y estadísticas de capturas por puertos. Se percibe, sin embargo, un recelo a compartir información.

Se sabe que IMARPE está estudiando hasta qué nivel de información se puede compartir. Esto es así porque es resulta frecuente hallar datos de campo que se toman a criterio del muestreador (quien decide qué registrar y qué no), lo que produce una disparidad de informaciones que puede sesgar los estudios que se realicen con base en esa data. Es responsabilidad de IMARPE entregar información adecuadamente interpretada.

Asimismo, en IMARPE se está trabajando en brindar información objetiva y aplicando el TUPA (que está en proceso de actualización). Se seleccionarán formatos para la publicación de información con base en el trabajo de grupos de estudio. En ese contexto se está considerando la tercerización de algunas labores con apoyo de universidades.

La recomendación 38 de la FAO a IMARPE (Arreguin $\&$ lanelli, 2014) ${ }^{7}$ establece la necesidad de fortalecer la productividad científica institucional con acciones específicas, en el marco de referencia del mandato establecido en su Misión. Sin embargo, el presupuesto de IMARPE sale del Estado y, por ende, la información y los estudios que genera son un bien público. Sin embargo, debe reservarse ciertos procedimientos en los casos en que la difusión de información pudiera afectar el desempeño de algunas pesquerías.
La decimoquinta recomendación de la FAO a I IARPE (Arreguin \& lanelli, 2014) indica: “Hacer explicicitos los niveles de representatividad de los datos
colectados por las diferentes fuentes de información. Es importante hacer explicita esta información por la generación de confianza (estadistica) en el proceso de investigación. En algunos reportes de investigación esto ha sido declarado formalmente, $y$ la sugerencia es que se realice de manera estándar para todas las pesquerias $y$ fuentes de datos. Este aspecto también es relevante para efectos de comparabilidad y complementariedad de la información dentro $y$ entre fuentes de datos" (página 13). La recomendación 16 profundiza en el tema y sugiere que se indique el nivel de confianza de cada estimado de biomas

“ Asimismo, la Ley N. 28245 o Ley Marco del Sistema Nacional de Gestión Ambiental establece, en su artículo 30, que toda persona tiene derecho a solicitar y recibir información sobre el estado y la gestión del ambiente y de los recursos naturales, conforme a lo establecido en la Constitución, la Ley N. 27806, Ley de Transparenciay Acceso a la Información Pública, las disposiciones legales vigentes sobre la materia y la presente ley, sin necesidad de invocar interés especial
alguno que motive tal requerimiento. Asimismo, el artículo 31 establece que, para los efectos de lo dispuesto en la Ley N No 28245 , se considera información ambiental cualquier información escrita visual on forma de base de datos de que dispongan las autoridades en materia de agua, aire, suelo, flora, faunay recursos naturales en general, asi como sobre las actividades o medidas que les afectan o puedan afectarlos. Recomendación 38: "Fortalecer la productividad cientifíca institucional con acciones especificas, dentrodel marcode referencia del mandato establecido por ejemplo, hacer explííito en los informes cientifícos el personal que colabora en su elaboración (aspecto relevante también en el contexto de trazabilidad), y fomentar las publicaciones en revistas indexadas. Sería importante analizar la posibilidad de establecer un sistema de incentivos a la productividad, haciendo énfasis en la calidad cientifica. Desde luego, esto debe darse como una externalidad positiva del trabajo cientifico desarrollado para la generación de recomendaciones para la gestión sostenible de los recursos pesqueros, sin deterioro del proceso que constituye la misión del IMARPE: 
4.7. Sobre el nivel de información que PRODUCE podría compartir públicamente

El sector pesquero formal está monitoreado satelitalmente asimismo suscapturasestánformalmente registradas y todos esos servicios son pagados por las mismas empresas. La preguntaen este caso fue: ¿considera usted que esas informaciones, que fundamentalmente están en manos de PRODUCE, tales como el SISESAT desembarques y capturas, sean de acceso público dado que se refieren a recursos de la nación?

a) Acceso público a la información del SISESAT. La información debe ser de uso público, porque los recursos pesqueros pertenecen a todos los peruanos. Hay preocupación por el estado de algunos recursos, y la razón de difundir la información del Sistema de Seguimiento Satelital (SISESAT) y desembarques pasa por la necesidad de fiscalizar que el ordenamiento se cumpla. Esto debe incluir además a la pesca artesanal. ser entregada con alguna demora debido a que esta tiene un valor de oportunidad cuya liberación podría afectar los intereses de algunas pesquerías muy especializadas.

La tendencia mundial va por el camino de poner a disposición pública por lo menos la información de sistemas satelitales $y$, por ese medio, la vigilancia puede incrementarse y beneficiar la gestión de los Estados. Asimismo, algoritmos que evalúan los desplazamientos de las flotas son útiles para actualizar las cartas sobre distribución de las especies-objetivo. Un ejemplo de estas aplicaciones puede comprobarse en publicaciones científicas (por ejemplo, en Bertrand et al., 2007 y Joo et al., 2014 y 2015).

El acceso a la información de SISESAT y capturas puede también abordarse desde un carácter voluntario. Algunas empresas han manifestado su Actualmente, el servicio de soporte al SISESAT es pagado por las mismas empresas, razón por la cual hay quienes argumentan que esta información tendría Sin embargo, en algunos casos la información puede buena disposición a efectuar reportes voluntarios

carácter privado; no obstante, según el Tribunal Constitucional, es el uso que se le da a la información lo que la convierte en información pública, sin importar quién asuma el costo de su generación ${ }^{8}$. También hay opiniones en el sentido de que, siendo los recursos hidrobiológicos propiedad del Estado, el pago a las empresas que prestan servicios de este tipo debe ser abonado por PRODUCE, y las empresas tendrían que compensar al Estado por este motivo.

Debe hacerse una indagación sobre el procedimiento seguido en este caso en otros países. En Argentina, por ejemplo, la información es accesible libremente a por ejemplo, la información es accesible libremente a la plataforma Global Fishing Watch (GFW) de gestión de datos que utiliza datos de satélites para observar la pesca comercial mundial. El sistema opera a través del análisis de las posiciones geográficas obtenidas de la red del Sistema de Identificación Automática (AIS) de embarcaciones equipadas con dispositivos compatibles de transmisión radial.

b) Uso práctico de la información del SISESAT. En una de sus recomendaciones a IMARPE, FAO establece la necesidad de utilizar los datos disponiblesyd sobre la dinámica de la flota para apoyar la asesoría a PRODUCE sobre el manejo de recursos (Arreguín \& lanelli, 2014)'. Lamentablemente, esta recomendación, así como otras, aún no ha sido implementada.

Hay otros usos potenciales que incluyen la determinación de la distribución de las especies especies objetivo. Asimismo, las empresas podrían beneficiarse en el sentido de que sus procesos de gestión interna mejorarían, agregando información a sus análisis sobre el desempeño y eficiencia de pesca de las flotas.

El seguimiento satelital, en cada tipo de pesquería, tiene distintos objetivos (en anchoveta, por ejemplo, se usa para conocer los caladeros de adultos y de juveniles). De todos modos, debe hallarse la manera de compartir la información, ya sea con retraso o no. Se debe reforzar los trabajos con observadores de campo en pesca artesanal para lograr una mayor cobertura,

\section{${ }^{8}$ Sentencia del Expediente N. 2579-2003-HD/TC-Lambayeque.}

"Recomendación 25: Examinar la manera de utilizar los datos disponibles y detallados sobre la dinámica de la flota (e.g., Joo et al., 2013) para apoyar asesoría a PRODUCE sobre el manejo de recursos y, por ejemplo, a la SNP. La relación entre la abundancia de peces y los patrones espaciales juega un históricos de distribución de peces para proveer un estadistico ponderado por la distancia a cada puerto principal : Podría esta información ser calibrada cor datos observados y ser utilizada para asesorar a las flotas de cada puerto de tal manera que la información suministrada con anticipación pudiera provocar alguna mejora en la eficiencia económica?" (página 16). también en alianza con universidades, para acceder al monitoreo de más caletas y puntos de desembarque. La idea debe ser que toda la información esté al alcance de los que puedan contribuir al análisis de las pesquerías.

\subsection{Métodos para la evaluación del manejo de las pesquerías}

Hoy en día existen métodos para evaluar cuán bien está siendo manejada una pesquería (como se cita, por ejemplo, en Kelletal. 2010 para claso de la se cita, por Atlántico Norte). La consulta en este caso fue: iestá de acuerdo con que se evalúe la gestión de la pesca de cada una de las especies mencionadas?

a) Implementación de los métodos de evaluación del manejo. La Evaluación de Estrategias de Manejo (MSE) es un conjunto de herramientas que identifican la mejor estrategia, balanceando los objetivos para cada pesquería. Hay un interés de la industria por iniciar este proceso con la anchoveta. Sin embargo, lidiar con la variabilidad climática también será una dificultad.

La implementación de evaluaciones independientes alentaría un manejo adecuado de los recursos. Aun así, la implementación debe ser planificada en lo que concierne a la identificación de entidades idóneas y de los fondos requeridos para este fin. Asimismo, IMARPE ya está empleando Métodos de Evaluación de Riesgo Ecológico en algunas pesquerías. Estos dos conjuntos de elementos son complementarios e incluyen la determinación del estado del hábitat y de las comunidades relacionadas con las especies objetivo.

Una herramienta de este tipo impulsaría la sostenibilidad de las pesquerías, pues incluye la propuesta de diversos escenarios $y$, en definitiva, permitirá mejorar la gestión. Los mercados, asimismo, responderían favorablemente si se implementan estas evaluaciones, pues esta es una condición indispensable para el futuro cercano en el marco comercial internacional. Ya hubo un acercamiento entre IMARPE e investigadores de la Universidad de Washington, aunque no se lograron acuerdos específicos. La meta es contar con indicadores de gestión.

b) Consultas a expertos. Una medida alternativa utilizada por IMARPE en el pasado y que tendría que mantenerse, es la convocatoria a expertos internacionales que participan en talleres sobre pesquerías específicas. Esto ha sido llevado a cabo para la anchoveta, la merluza, la pota, entre otras especies. Estas evaluaciones no solo deben llevarse a cabo para especies sino también por zonas, ya que la realidad de la pesca de pota, por ejemplo, no es la misma en Paita que en llo. Asimismo, deben considerarse los aspectos culturales y la idiosincrasia del pescador.

\subsection{Sobre el establecimiento de medidas} diferentes a las actuales para reducir los descartes

En el Perú se han establecido, por ejemplo, límites o tolerancia de pesca para juveniles, pero a menudo esos porcentajes son excedidos sin que esté en poder de los pescadores cumplir la normativa (nuestro conocimiento de la selectividad de artes de pesca es aún incompleto). En consecuencia, las capturas a menudo son descartadas en el mar, lo que genera impactos económicos y ecosistémicos que no es posible evaluar. La consulta en este caso fue: ¿cree usted que es posible implementar reglas diferentes para el control de capturas de las especies mencionadas, considerando, por ejemplo, que la norma basada en el porcentaje de tolerancia de juveniles de anchoveta o de captura incidental de otras especies no es eficaz?

a) Medidas prioritarias. Una medida que hasta ahora no se ha ensayado es la de optimizar el tamaño de malla para las redes de pesca. Se desconoce en qué estudio se basó el tamaño para anchoveta. Se debe, por tanto, desarrollar los experimentos tecnológicos para generar la norma que regule este aspecto, así como el diseño mismo de las redes.

El porcentaje de tolerancia debe estudiarse también, porque hay cambios en la biología de las especies que, bajo ciertas circunstancias, invierten su energía en desovar y no en crecer, porque detectan condiciones anómalas. Este es un tema que debe ser debatido amplia y técnicamente por lo menos en el caso de la anchoveta. La reducción de tallas que se observa es un fenómeno creciente que debe ser estudiado a profundidad.

Es preciso, asimismo, incentivar el reporte oportuno sobre la pesca de juveniles en las faenas de pesca. Se estima que en $30 \%$ de casos el recojo de la red se suspende por la presencia de juveniles, con lo que se busca evitar su mortalidad. Por otro lado, no se está considerando la presencia de peces amallados; es decir, el porcentaje de juveniles presentes en un 
lance de pesca no es metodológicamente calculado considerando los peces que se amallan en las redes.

b) Cambios normativos. La norma basada en el porcentaje de tolerancia genera un incentivo perverso en algunas especies, debido a que no existe a la fecha ningún método seguro para visualizar el porcentaje de juveniles antes de una captura. Si bien se han logrado mejoras recientes, está por optimizar el procedimiento de captación de evidencia de la presencia de juveniles con la finalidad de comunicar el cierre de zonas de modo más dinámico.

Otra medida posible es la de establecer un límite de captura de juveniles por volumen y no por porcentaje. Esto requiere que IMARPE establezca de modo transparente y estandarizado cuál es la cantidad de juveniles que se podría extraer sin afectar el equilibrio de la población. Alcanzado este límite, la temporada debe suspenderse o terminarse en alguna región particular. Está claro que la norma, como estaba recientemente, no permitía establecer el monto de las capturas de juveniles (se alentaba el descarte), pero ahora el escenario presenta mejores condiciones para un manejo más eficiente. Para esto, eliminar las sanciones por pesca de juveniles ha sido positivo, pero, al mismo tiempo, las infracciones por descarte deben ser mucho más severas.

Otra alternativa que debe incentivarse es la autorregulación por parte de las mismas empresas, de manera de disponer que las naves abandonen las zonas donde se detecten juveniles. También debe promoverse donde se detecten juveniles. También debe promoverse
la experimentación con nuevas tecnologías acústicas que al parecer ofrecen mejores posibilidades para determinar la talla relativa de los peces.

c) Pesca CHD. Para sostener el crecimiento de la actividad CHD podría exceptuarse de las vedas a las naves artesanales que acrediten fehacientemente que abastecen a la industria CHD. Esta flota tendría que estar directamente ligada a los establecimientos industriales con el fin de evitar el desvío, por ejemplo, empleando notas de pedido de plantas CHD, como requisito para obtener el permiso de zarpe. De la misma manera, debe analizarse cómo se aborda este problema en pesquerías de otros países. Si este tipo de normas evitan el descarte y se toman medidas prácticas de protección de juveniles, será correcto aplicarlas.
Los países que importan los productos pesqueros peruanos están crecientemente interesados en adquirir solo productos que provienen de pesquerías ecocertificadas. Asimismo, las ecocertificaciones pueden ser aprovechadas por el Estado como herramientas de gestión. La consulta efectuada fue: ¿está usted de acuerdo con estas ecocertificaciones y programas de mejora, cuya consecución requiere en algunos casos la intervención directa de PRODUCE o de IMARPE para conseguir la aprobación del proceso de evaluación y certificación?

a) Requerimientos para la ecocertificación. La certificación de la actividad harinera traerá mejoras a la actividad. Su implementación conducirá a mejoras en la gestión y a una mejor relación con los mercados, dada la preocupación que existe sobre la sostenibilidad de la pesquería de anchoveta.

IMARPE y PRODUCE deben participar directamente en este proceso, pues en un futuro $100 \%$ del mercado exigirá ecocertificaciones, de modo que debe anticiparse ese escenario. En el caso de pesquerías como la del perico y la pota se requieren reformas profundas. Para ello se debe implementar programas de mejora, cuyo solo inicio traerá un alivio a los mercados. Debe quedar claro, sin embargo, que IMARPE no es un ente certificador pero sí facilitador del proceso.

Para el país sería un gran avance impulsar las ecocertificaciones, como ha ocurrido en Chile, donde ya hay tres pesquerías certificadas. En Argentina ocurre lo mismo (incluida la anchoíta). En este momento en el Perú solo hay una empresa acuícola certificada con ASC, y otra empresa que está en el mismo proceso. Dada la similitud de las pesquerías peruanas con las de Chile, se debería aprovechar la experiencia allí obtenida.

b) Riesgos de algunas certificaciones. Un aspecto que debe ser cuidadosamente estudiado es el de la posibilidad de que el Estado pudiera perder el control de sus pesquerías al someterse a criterios de certificaciones que no contemplan las particularidades de cada ecosistema. La resiliencia de la anchoveta, por ejemplo, es más alta que la de especies similares de otros ecosistemas. Nieste aspecto ni la alta variabilidad climática han sido contemplados en un estándar como el de MSC (Marine Stewardship Council).
IMARPE está trabajando en un nuevo libro sobre la anchoveta, el cual contendrá un artículo sobre el esquema de gestión adaptativa desarrollado en el Perú con base en la experiencia práctica. Se está evaluando remitir este documento a una revista cientifica espec especializada en gestión para sustentar de modo científico el esquema de manejo de la anchoveta. En todo caso, se considera que avanzar en este tema requiere de una decisión política.

\subsection{Acerca de la adopción de esquemas de comanejo en las pesquerías de recursos} bentónicos

La transparencia implica también reconocer las limitaciones para la presencia del Estado en todos los lugares donde se le requiere. Al menos para el caso de especies sésiles (que están sobre el fondo del mar como las macroalgas y recursos bentónicos, es decir, que no se desplazan como sí lo hacen los peces), es una alternativa viable la cesión de derechos de uso territorial de estos recursos para los gremios organizados de pescadores. Es decir, el Estado, bajo un esquema de cogestión, asigna al pescador las responsabilidades de monitoreo, vigilancia, control y recolección de infon a cambio del derech bentónicos. La consulta en este caso fue: ¿está usted de acuerdo con estos esquemas de cogestión o cesión de derechos de uso de recursos bentónicos?

a) Prerrequisitos para los esquemas de cogestión. La asignación de derechos de uso territorial, o comanejo, es una buena alternativa que puede fortalecer la labor del Estado y tiene muchos antecedentes (como se describe, por ejemplo, en Pita et al., 2016). Sin embargo, debe haber evaluaciones periódicas por parte del Estado. Para ello se requiere una ley o instrumento equivalente (Áreas Especiales de Manejo, por ejemplo).

Para un esquema de este tipo el pescador ha de contar con ciertas aptitudes, debe estar capacitado, calificado y supervisado. Asimismo, es preciso un acompañamiento de las universidades $u$ otras entidades académicas y ONG. En todo caso, este esquema es un incentivo que alienta el uso sostenible de los recursos pesqueros; sin embargo, no todos los gremios de pesca artesanal tienen el liderazgo y capacidad para implementar esta modalidad. Se debe, entonces, implementar ciertos requisitos y procesos previos.
Podría contemplarse la creación de comités de administración o similares que guíen el proceso de implementación de estas "áreas especiales de manejo". Asimismo, la transferencia de derechos no debe ser permanente,ysinosecumplen las condiciones el derecho retorna al Estado. En el momento actual el esquema podría ser más sencillo de implementar en el caso de las macroalgas; este es un clamor de muchas comunidades.

b) Experiencias de cogestión. En Chile, el uso de este tipo de áreas (Áreas de Manejo de la Extracción de Recursos Bentónicos, AMERB) está extendido, y tiene éxito en $50 \%$ de casos (en ese país hay más de 1000 de estas áreas). Para el caso peruano debe analizarse las variables económicas, biológicas, ecológicas, pesqueras y jurídicas. Cubiertos estos aspectos, la cogestión contribuirá con la transparencia y uso sostenible de los recursos.

Haypesqueríasenlasqueasignarderechosterritoriales es la única manera de asegurar un aprovechamiento sostenible. En el Perú se tiene la positiva experiencia de la Comunidad de Pescadores Artesanales de Marcona (COPMAR), pero este no es el único caso; hay otras experiencias positivas y aleccionadoras en Ancón, Atico e llo. Los pescadores deben ser actores aliados para promover el uso racional del recurso y el uso eficiente del espacio marino.

Es necesario prestar atención a lo que funciona en el mundo, y este caso es un ejemplo. Sin embargo, la norma debe ser cuidadosamente diseñada para evitar caer en populismos; el Estado no debe renunciar a su derecho de control.

\subsection{Sobre el alto nivel de pesca ilegal e informal}

Se ha determinado que en el país existe un alto grado de pesca ilegal, no autorizada y no reportada, lo que incluye el uso de artes de pesca no autorizados. Y es de especial preocupación la caza de tortugas, aves marinas, delfines y lobos.Asimismo, seconstataunaltogrado de informalidad, tanto en personas dedicadas a la pesca artesanal como en el número de embarcaciones construidas y operando de modo irregular. Además, no funcionan los esquemas de gobernanza que incluyen a los gobiernos regionales. En este caso la consulta fue: ¿considera usted que el alto nivel de captura ilegal puede ser contenido? ¿Qué acción o acciones se deberían priorizar? 
a) Regularización de la situación legal de la flota artesanal. En San Andrés hay 150 bolichitos (10 TM de bodega), de los cuales menos de la mitad tienen licencia. En puerto solo se revisan las licenciadas, mientras las ilegales son ignoradas, lo cual fomenta esta actividad. Se requiere voluntad política para reordenar la pesca. Asimismo, debe haber un sinceramiento del tamaño de la flota anchovetera, y es preciso implementar un control satelital total. Se requiere asimismo una acción coordinada entre todas las entidades involucradas en la pesca para un control real. La asignación de derechos (una cuota segura de pesca, por ejemplo) puede ser una manera de reducir la informalidad y fomentar un uso más responsable de los recursos, y una mejor protección de los ecosistemas.

b) Decisión política. Demanda decisión política parar la pesca ilegal a través de coordinaciones entre PRODUCE, DICAPI, GORE, etcétera. Sin embargo, se debe diseñar un plan integral que incluya la educación ambiental, la difusión de las prácticas de preservación y otras formas de agregar valor de parte del propio pescador y sus familias. Se ha de procurar el mayor apoyo posible de parte de las ONG, y considerar el ecoturismo como ingresos del pescador. Se necesita estabilidad los ingresos del pes los cargos de funcionarios del Estado, pues la alta rotación impide que las políticas de este tipo sean implementadas con éxito. Y se debe reconocer que hay corrupción en la manera cómo se expiden certificados y matrículas en un gran número de embarcaciones, pues no se entiende cómo operan a vista y paciencia de las autoridades. Lamentablemente, este es un proceso largo que no está en la agenda de la mayoría de los gobiernos regionales.

c) Pesca ilegal. Para el caso de la pesca ilegal o caza de especies protegidas, se tendría que recurrir de la ley de flagrancia, pero tes a la ley de fagrancia, pero esto requiere de una sensibilización previa y del fortalecimiento de los procesos de fiscalización. Se debe asimismo detectar e intervenir los astilleros clandestinos y desarrollar la capacidad de controlar todos los puntos de desembarque y mercados pesqueros. Es necesario precisar las competencias de DICAPI respecto a este tema. La participación de los usuarios en el diseño e implementación de políticas para controlar la pesca ilegal es fundamental. En ese marco se debe impulsar la formalización y el desincentivo de ciertas prácticas a través de regulaciones simples. Sin embargo, hay que reconocer que este es un problema complejo sin solución a corto plazo. Se debe apuntar a solucionarlo con base en una educación de futuros pescadores y campañas para los actuales. Existen casos exitosos a nivel local en relación con la capacitación a los pescadores en temas de cuidado ambiental.

d) Acerca de los funcionarios públicos. Se percibe un cierto nivel de indolencia en los funcionarios públicos que deben actuar para atajar este problema, en particular en las regiones, que es donde no se ha desarrollado la capacidad de vigilancia y no se asignan los recursos requeridos, La carencia de una política marítima imp politica maritima impide al MEF hallar el mecanismo para asignar más recursos más allá de las partidas sectoriales actualmente disponibles. En ese sentido, se requiere una decisión política en el más alto nivel del Estado para diseñar y aprobar una política marítima integral. La mayor responsabilidad en este tema recae enICAPI entidadalaquesedebe (a) requeridos para ejercer cabalmente su función. En especial, urge señalar que DICAPI no cuenta con las competencias y presupuestos necesarios para atender la normativa que emana de PRODUCE. En ese sentido, las Comisiones Ambientales Regionales (CAR) deberín ser un apoyo importante para la atajar la pesca informal o ilegal.

\subsection{Sobre el uso que se da a los pagos por derechos} de pesca

En el país, el sector industrial paga derechos de pesca, y los montos recaudados no necesariamente son invertidos en el propio sector que los genera. La consulta en este caso fue: ¿le parece pertinente que se divulgue el uso que se les está dando a los derechos de pesca?

a) Acerca del uso de fondos provenientes de los derechos de pesca. El pago por derechos es magro, por lo que este mondo debe ser incrementado y asignado enteramente a cubrir las necesidades del sector (investigación, infraestructura, control, etcétera). En todo caso, se debe divulgar el uso que se le da a esta retribución económica, pues no se está compensando el esfuerzo hacia entidades que protegen los recursos. Por otro lado, los pagos por derecho de pesca deben centralizarse para definir las prioridades de su uso. Sin embargo, hay disposiciones previas que asignan $50 \%$ a las regiones, pero se debe procurar conocer en qué están invirtiendo esos fondos; $25 \%$ de los derechos sí se usan en el sector, y hay otro $25 \%$ cuyo destino se desconoce. b) Inversiones. Parte de la situación del sector se explica por la falta de inversiones en la pesca artesanal. En la década de 1990 los barcos calamareros tributaron US $\$ 130$ por tonelada de captura, pero hasta el día de hoy se desconoce el destino dado a esos recursos. Se debe evaluar si la cantidad recaudada es suficiente para investigación, regulación y fiscalización. Asimismo, se debería crear un mecanismo de reinversión y no de compensación en el sector directamente afectado por la pesca de anchoveta en sus segmentos artesanal e industrial. Los fondos recaudados deberían asignarse a la solución de los problemas existentes, en especial a la investigación científica; por ejemplo, para cuantificar el impacto de la actividad pesquera en las cinco millas.

4.14. Acerca de la necesidad de una intervención intersectorial para mejorar la gobernanza y la transparencia en el sector pesca

PRODUCE no es la única entidad con competencias en el sector pesca. También están DICAPI, los GORE, SERNANP, ANA, OEFA, SANIPES. Sin embargo, solo el primero aborda las responsabilidades de gestión, y se aprecia un bajo nivel de coordinación y articulación, que este caso fue: ¿cuálocur este caso fue: ¿cuál o cuáles considera usted que son las principales trabas para la ampliación de la transparen en la gestión de las diversas actividades pesqueras?

a) Percepciones sobre la gobernanza pesquera. Con los cambios de gobierno entran nuevos funcionarios con desconocimi décadade 1990CERPERerareconocidamundialmente, pero fue privatizada y su experiencia se perdió. Luego hubo la necesidad de empezar de cero con SANIPES. Asimismo, hay una falta de diálogo organizado con naturaleza interinstitucional. Se debe resolver la sobreposición de competencias entre entidades. Se sabe, sin embargo, que PRODUCE está invitando a estas instituciones a reuniones para hallar alternativas. Por otro lado, la normatividad vigente es compleja y contrapuesta. El ordenamiento que genera PRODUCE establece solo de modo declarativo que DICAPI y otras entidades como los GORE velarán por el cumplimiento de las disposiciones, pero esto se ha verificado en contadas ocasiones. Debe haber decisión política para implementar la intervención interinstitucional en el sector, alineando las atribuciones de cada entidad. Se verifica una limitada articulación e interés de la sociedad en la problemática del sector. Se estimula el consumo CHD, pero no se educa y sensibiliza al ciudadano sobre aspectos de sostenibilidad, consumo responsable y sanidad. El financiamiento a entidades debe pasar también por el cumplimiento de metas ligadas a la actuación transversal e interinstitucional. El diálogo entre entidades no está institucionalizado, y menos aún involucra a la sociedad. En la mentalidad de los funcionarios de todos los sectores no está la transversalidad.

b) Ministerio de Pesquería. La importancia alimentaria y socioeconómica con proyección al mundo de las pesquerías peruanas justifica contar con un ministerio propio. Además, los cargos directivos a nivel central y GORE deben ser por concursos idóneos para comprobar capacidades. Asimismo, es preciso contar con una masa crítica suficiente para abordar la complejidad de la situación. Se confunden roles y se generan conflictos innecesariamente. Se debe promover desdefuerauna mayor articulación, así como una mayor divulgación de la ciencia. En la década de 1990, FAO recomendó formar cuadros para la toma de decisiones en el Ministerio de Pesquería. Hoyestonose está dando por falta de profesionales experimentados para la interpretación de las recomendaciones de IMARPE PRODUCE debe revisar sus competencias ir la intervención compartidasy, a partir de riliconstrur la intervención intersectorial. Una superintendencia podría articular la coordinación. 


\subsection{SÍNTESIS DE UNA CONSULTA PÚBLICA (ON LINE) SOBRE EL ESTADO DE LA TRANSPARENCIA EN LA GESTIÓN DEL SECTOR PESCA}

Para complementar la entrevista hecha a los expertos se diseñó una encuesta que fue difundida en diversos foros, con el fin de solicitar la cooperación de profesionales ligados a la pesca. La plataforma utilizada fue Survey Monkey (https://es.surveymonkey.com/r/ TransparenciaPescaPeru) y comprendió un total de dieciséis preguntas aproximadamente relacionadas con las consultas hechas a los expertos. Se tuvo un total de 204 respue 18 de octubre hasta el 18 de noviembre. A continuación se presentan las respuestas dadas por los participantes, incluyendo comentarios sobre la coincidencia o discrepancia con la opinión de los expertos entrevistados.

5.1. Distribución de las personas encuestadas según las entidades en las que laboran

El mayor porcentaje de participantes pertenece a sector privado (37\%), seguido del sector público (32\%), universidades (16\%), ONG (9\%) y pesca artesanal (6\%). La mayor proporción de participantes tiene una amplia experiencia -más de veinte años en el sector (40\%)-, seguida de profesionales hasta con veinte años de experiencia (18\%) y hasta diez años de labor (18\%). El grupo más joven, hasta con cinco años de labor, comprendió $24 \%$ de las personas encuestadas.
Ochenta y dos de cada cien personas encuestadas coincidieron con la definición propuesta para ta transparencia ("transparencia en el conjunto de acciones quedemuestranlacorrectaadministración de los recursos pesqueros"). Los expertos consultados estuvieron también de acuerdo con la definición, y agregaron la consecuencia de la transparencia, la confianza en el funcionario público, y que la transparencia también pasa por los procesos de convocatoria a todos los grupos de interés en el proceso de diseño de normas, es decir, que no basta solo con su prepublicación.

Por otro lado, para $10 \%$ la transparencia consiste en la publicación de las estadísticas de pesca. Para $6 \%$ de las personas encuestadas, la transparencia consiste en aplicar las normas y administrar correctamente los recursos públicos de modo reservado. Dos de cada cien entrevistados no tenían opinión formada sobre el tema.

En cuanto a si se ejerce actualmente la transparencia en el sector pesca, $49 \%$ de los entrevistados contesta que se la ejerce parcialmente, frente a $46 \%$ que considera que no. Solo $4 \%$ sostiene que la transparencia es ejercida, y $1 \%$ no expresa opinión sobre el tema. Los expertos consultados consideraron que la transparencia actual es parcial, y que se requiere decisión política y más integración entre sectores que también tienen competencias en la pesca para poder satisfacer la definición de transparencia.

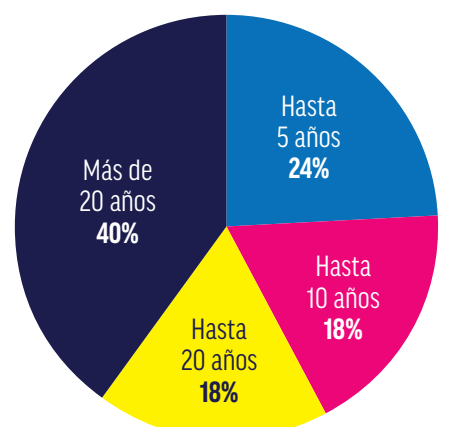

¿Cuál es su definición de "transparencia"?

¿Considera Ud. que se ejerce la transparencia en la gestión del sector pesca?

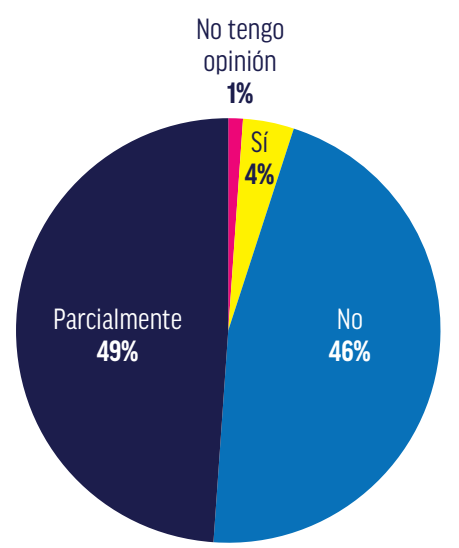

5.3. $\mid$ Sobre la participación de los grupos de interés y el cumplimiento de la Ley de Transparencia

Ante la consulta sobre si se debe crear comisiones que coordinen con el Estado los problemas que se presentan en el sector de la pesca, 93\% consideró que así debe ser, frente a $6 \%$ que considera que el sistema actual es el esquema correcto para ejercer el gobierno del sector. Los expertos consultados también consideraron que estas instancias públicas pueden aliviar la carga de las responsabilidades de funcionarios y autoridades.

Considera Ud. que los grupos de interés tendrian que tener mayor participación en la gestión?
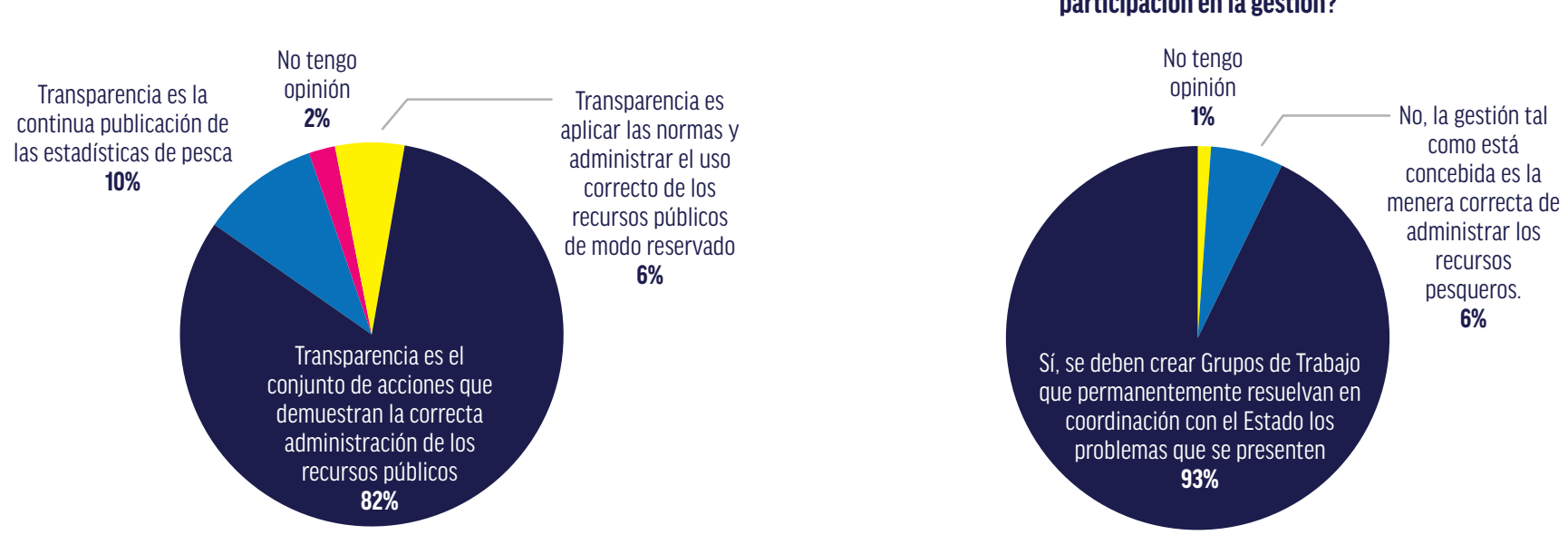


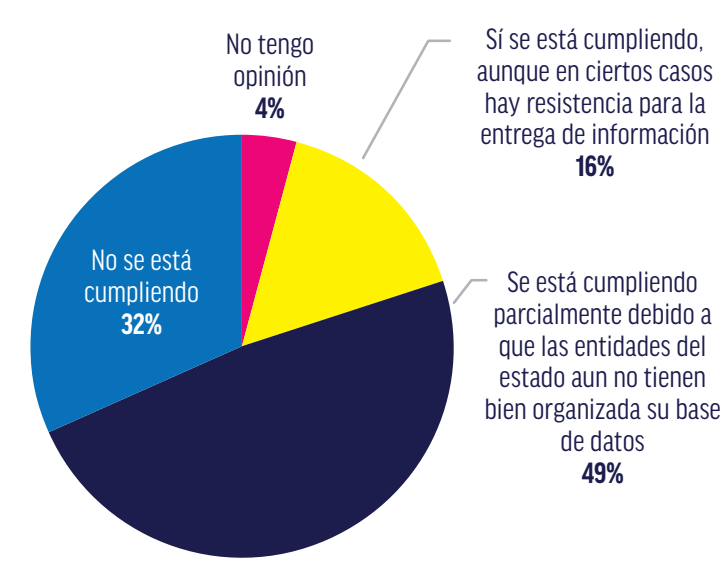

La siguiente consulta se refirió a la Ley de Transparencia, respecto a si esta se está cumpliendo o no. Esta ley está fundamentalmente orientada adisponer quelas entidades públicas hagan que todas las informaciones en su poder tengan carácter abierto y que, por tanto, estén accesibles al público, incluso sin que este tenga que dar cuenta de las razones por las que se requiere la información. En ese sentido, $49 \%$ de los encuestados considera que hay un cumplimiento parcial, debic sector están aún en proceso de organizar sus bases de datos; $32 \%$ manifiesta que no se está cumpliendo con la ley, y $16 \%$ sostiene que sí se está cumpliendo, pero con resistencias. La mayoría de los expertos entrevistados manifestó estar de acuerdo con la medida (promover la transparencia).

\subsection{Estado de la transparencia de la gestión para} las principales pesquerías

En este documento se ha incluido una evaluación preliminar sobre el estado de la transparencia en lagestión de las principales pesquerías, con especial referencia al contenido de sus correspondientes ROP. Para el caso de la encuesta pública se consultó cuál de las pesquerías es la que ofrece un mayor grado de transparencia. Se obtuvo que $49 \%$ de los encuestados consideró que la pesquería de anchoveta es la más transparente, seguida de la de las especies costeras (12\%), pota (11\%), merluza (9\%), macroalgas (7\%), jurel-caballa (7\%) y perico (5\%). Los expertos consultados en general coinciden con esta opinión, pero señalan que un componente fundamenta de la transparencia es la disposición de información, y lamentablemente esta es una condición que no se da actualmente. ¿En cuál de estas pesquerias considera usted que hay más
transpsarencia en la gestión del sector pesca?

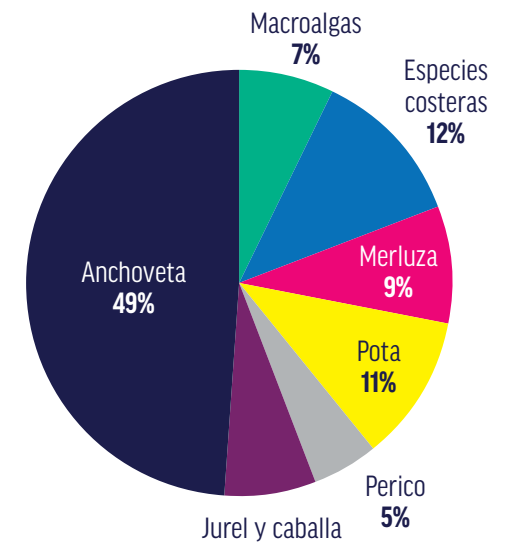
¿En cuál de estas pesquerias considera usted que hay menos
transparencia en la gestion del sector pesca?

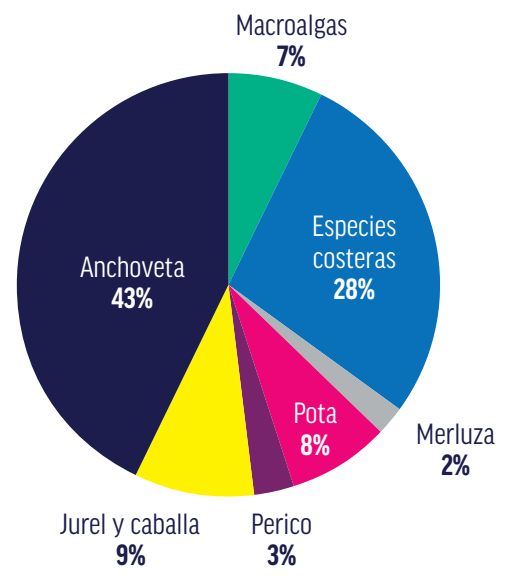

Respecto de la pregunta sobre en cuál de las pesquerías hay menos transparencia, el resultado es contradictorio y revela una polarización de las opiniones sobre la transparencia en la gestión de las pesquerías. En este caso, los resultados indican que $43 \%$ de los encuestados considera que la anchoveta es la menos transparente de las pesqueri tienen menos transparencia, seguidas por el jurel-caballa (9\%), pota (8\%), perico (3\%) y merluza (2\%). Los expertos entrevistados tuvieron una opinión de consenso sobre la informalidad que campea en casi todas las pesquerias, de modo que este factor es el principal problema que se ha de abordar para incrementar el nivel de transparencia en la gestión de las pesquerías nacionales.
La segunda temporada de pesca de 2014 no se llevó a cabo debido a un bajo nivel de biomasa de anchoveta detectado por IMARPE. Sin embargo, en el otoño de 2015 una nueva medición arrojó una biomasa inesperadamente alta en comparación con la evaluación anterior. En la primavera de ese año el crucero de evaluación arrojó un bajo nivel de biomasa, lo que generó suspicacias respecto a este nuevo resultado. Se dispuso entonces la realización de una Exploración Acústica Conjunta entre naves científicas y de la industria que estaban convenientemente equipadas y calibradas, y esta vez se obtuvo un nivel de biomasa que justificaba el otorgamiento de una cuota de pesca. El caso se repitió en el otoño de 2016.

Se hacuestionado la adopción de medidas extraordinarias como las descritas, que además incluyeron periodos de pesca exploratoria y el desarrollo adicional de una Operación Eureka en el primer caso. Estas acciones han sido llevadas a cabo en varias oportunidades (el Programa Eureka de IMARPE con la industria fue iniciado en 1966, hace más de cincuenta años). No obstante, y en aras de la transparencia, estas medidas complementarias a la gestión tendrían que estar contenidas en el ROP respectivo, o en un protocolo, con el fin de definir en qué circunstancias y de qué modos se puede aplicar medidas de excepción que no sean percibidas con escepticismo y que, en cambio, podrían ser presentadas de modo público a todos los grupos de interés.

En ese sentido, la encuesta incluye dos preguntas relativas a la gestión. La primera se refiere a si se está de acuerdo con modificar el ROP o en diseñar directivas o protocolos adicionales para casos como el descrito en los párrafos precedentes: $87 \%$ de los encuestados se manifestó de acuerdo con la implementación de tales directivas o protocolos que incrementarían la transparencia en la gestión; 7\% de las encuestas indicó que la prepublicación de las medidas de gestión es suficiente; $5 \%$ consideró que el sistema actual, centrado en PRODUCE y sin participación pública, es adecuado. Los expertos entrevistados manifestaron mayoritariamente estar de acuerdo con esta medida.
¿Además de los Reglamentos de Ordenamiento Pesquero (ROP) deben existir Directivas adicionales?

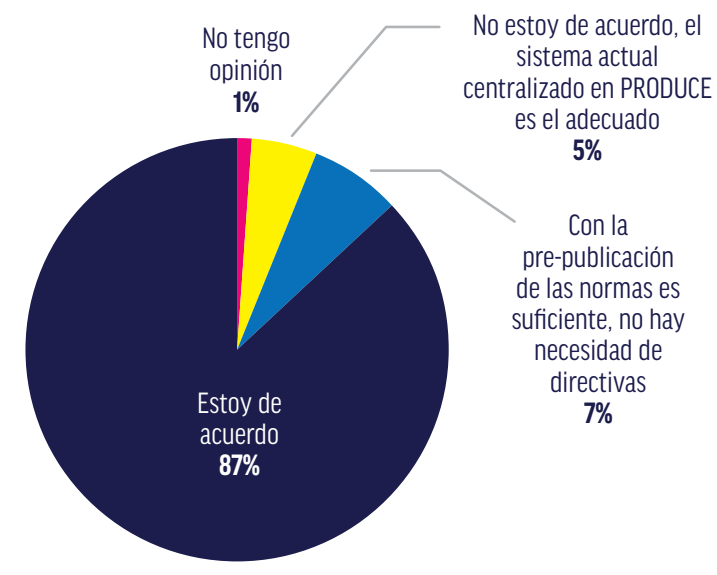

Está usted de acuerdo con que se adopte un método de evaluación independiente sobre la eficacia de la gestión de cada pesqueria?

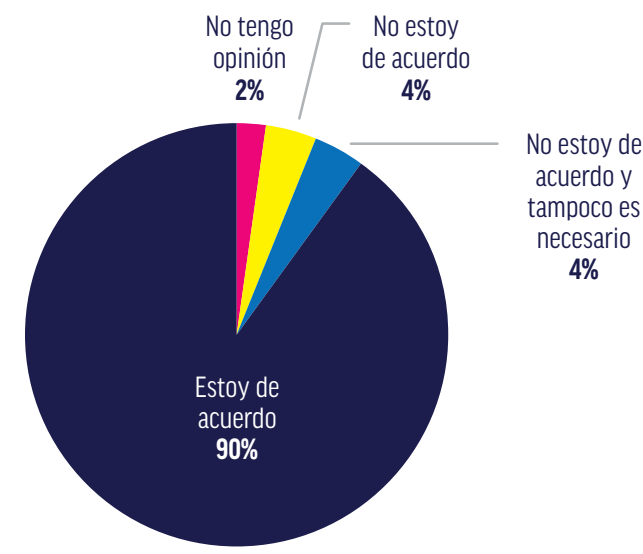

La segunda pregunta se refirió a la consulta sobre si se considera conveniente implementar Estrategias de Evaluación deIManejo(MSE) que, de modoindependiente, evalúen ciertos aspectos de la gestión de cada pesquería. Los MSE analizan periódicamente, por ejemplo, los puntos de referencia biológica preestablecidos y proponen escenarios de manejo en distintas circunstancias. Algunas pesquerías importantes del mundo ya utilizan estas herramientas. Noventa de cada cien personas encuestadas manifestaron estar de acuerdo con la implementación de esta herramienta; $4 \%$ dijo que no estaba de acuerdo, por considerar que esta herramienta no era necesaria; otro $4 \%$ expresó su desacuerdo con la medida. Los expertos que fueron entrevistados también manifestaron mayoritariamente estar de acuerdo con esta medida. 
5.6. Sobre la publicación de la información de SISESAT y el establecimiento de nuevas

reglas para el control de capturas

Se plantearon dos preguntas relacionadas con el seguimiento y control de capturas (Housholder, 2004) ${ }^{10}$. La primera pregunta a los encuestados fue sobre el carácter público que podría tener la información recogida por el SISESAT. Dado que los recursos nacionales son propiedad de la nación, se propone que la información de SISESAT, que se usa para monitorear las actividades de las flotas, sea puesta a disposición pública no solo como una medida de transparencia, sino también para servir para otros fines complementarios a la pesquería, e incluso para instituciones cuya función podría beneficiarse de esta medida. Por ejemplo, las universidades podrían apoyar a IMARPE en la aplicación de algoritmos desarrollados en el Instituto para poder producir cartas frecuentes sobre la distribución de las especies. También se podría hacer seguimiento sobre la prohibición que existe de pescar en las ANP administradas por la RNSIIIPG (SERNANP). Contar con estas informaciones permitiría además realizar estudios sobre el esfuerzo de pesca y la eficiencia del uso de recursos como el combustible. Asimismo, disponer de esta información puede incrementar $y$ complementar la vigilancia que ya se está realizando con otros medios y sistemas (por ejemplo, SIMTRAC de DICAPI o el Global Fishing Watch).

Cincuenta y cinco de cada cien entrevistados manifestaron estar a favor de la medida y $33 \%$ se mostró de acuerdo siempre que se impongan algunas restricciones (demoras) en la publicación de la información para salvaguardar los intereses de algunas pesquerías muy especializadas. A su vez, $4 \%$ dijo no estar de acuerdo por considerar que es una medidainnecesaria,y $3 \%$ expresóquenoestaba de acuerdo Los expertos consultados manifestaron estar de acuerdo con la medida, puntualizando que en algunos casos deben existir restricciones. Asimismo, algunos de los expertos indicaron que se tendría que analizar la factibilidad de la medida en lo que concierne a los contratos existentes entre las empresas pesqueras y las compañías proveedoras de estos servicios; además, se planteó la posibilidad de modificar el sistema, con el fin de que sea PRODUCE quien lo financie, con cargo a una compensación de las empresas.

¿Cree Ud. que la información del IISESAT debe ser de acceso público?

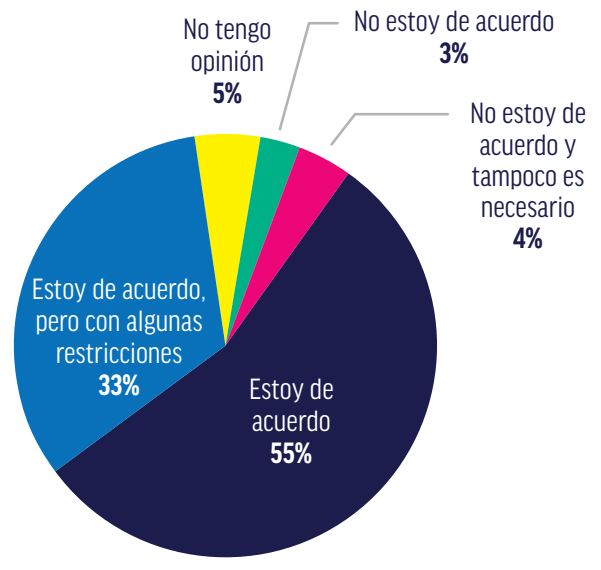
¿Es necesario implementar nuevas reglas de control de captura? La
incidencia de juveniles sigue siendo muy alta, y los descartes tambiên.

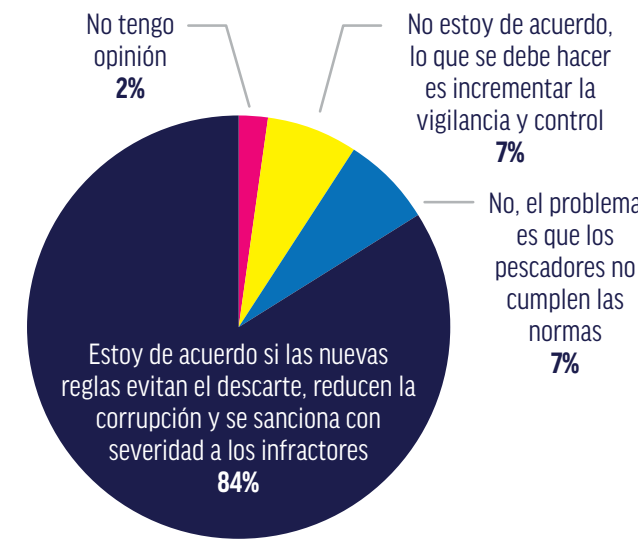

La segunda interrogante se refirió a si deben establecerse nuevas reglas para el control de captura. Las normativas vigentes prohíben y sancionan la captura de juveniles, desovantes y otras especies no autorizadas, aunque fijan límites de tolerancia que en general se miden en el porcentaje en número de especímenes. En la práctica esta medida ha causado controversias y demandas, ya que las disposiciones sobre tamaños de malla para las redes, que reguladas, han probado ser inadec por lo menos para impedir la captura de juveniles y de otras especies.

Evidentemente, las normas tendrían que ser modificadas para considerar aspectos de la selectividad de las redes, o habría que cambiar las reglas de control de capturas y tambiénel procedimiento para determinar los porcentajes por no haber sido eficaces. La situación reciente generó un incentivo perverso para descartar las capturas, con el consiguiente daño al ecosistema, más el agravante de que esta información no llega a conocimiento de IMARPE o PRODUCE.

Ochenta y cuatro de cada cien encuestados se manifestaron a favor de la emisión de nuevas reglas para el control de capturas siempre que consigan evitar los descartes y se impongan sanciones más severas para los infractores: $7 \%$ consideró que el problema se origina por incumplimiento de los pescadores: igual porcentaje cree que, en cambio, debe incrementarse el control y la vigilancia. Y la mayoría de los expertos consultados se manifestaron a favor de este tipo de medida, siempre que se logre implantar un sistema dinámico de cierre de zonas, además de implementar el reporte voluntario de parte de las empresas, lo que significa un apoyo adicional a las labores de PRODUCE e IMARPE.

\subsection{Sobre el esquema de derechos de uso} territorial y el fortalecimiento de capacidades en las instituciones a cargo de contener la

informalidad en el sector pesca

Se propusieron dos preguntas sobre las opciones de gestión a través de la cesión de derechos de uso territorial, y sobre la necesidad de fortalecer instituciones para contener la alta informalidad existente en las pesquerías artesanales. En el primer caso se trata de un sistema de cogestión por el cual el Estado concede derechos exclusivos de extracción (de recursos bentónicos, por ejemplo) a cambio de asignar responsabilidades de control, monitoreo y evaluación a grupos formalizados y organizados de pescadores. Esta opción facilita la labor del Estado y empodera a las comunidades.

\section{¿Deben asignarse derechos de pesca exclusivos a organizaciones de} pescadores formalizados a cambiode asisnorles responsabilidades?

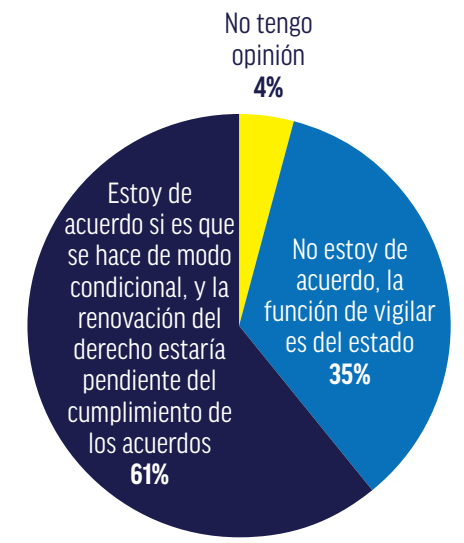

¿Qué entidad considera ud. que deberia desarrollar más capacidades teniendo en cuenta la alta informalidad del sector pesca?

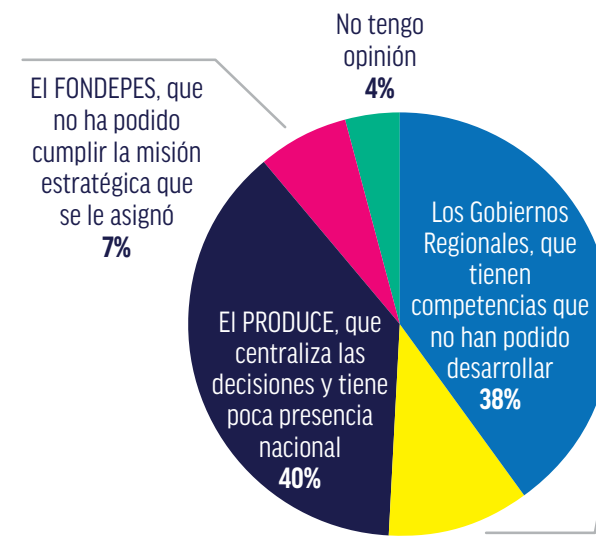

- La DICAPI, que no cuenta con
los recursos para contener
la informalidad
t11\%

Sesenta y una de cada cien personas encuestadas se manifestaron a favor de esta medida, siempre que el derecho concedido esté sujeto al cumplimiento de las obligaciones asignadas; $35 \%$ dijo que no estaba de acuerdo por considerar que la vigilancia es función exclusiva del Estado. Los expertos consultados, en general estuvieron, se mostraron a favor de la propuesta que en realidad no es novedosa, pues se viene implementado desde 2003 en el distrito de San Juan de Marcona, en la región Ica. Tres decretos supremos sostienen una valiosa experiencia comunitaria para la recuperación y uso sostenible de los ecosistemas acuáticos (Zavala, 2014) a través de un Programa Piloto Demostrativo que ya cuenta con una zonificación, propuesta de plan de manejo para la extracción de recurso bentónicos y línea de base para la biodiversidad y aspectos ambientales a lo largo de $23 \mathrm{~km}$ de playas, cuya gestión es compartida por dieciséis OSPA que conforman la Comunidad de Pescadores Artesanales de Marcona (COPMAR). Si bien existen otras experiencias comunitarias a lo largo de la costa del país (Nakandakari, 2016), la de COPMAR es la más completa y duradera, pero aún no se cuenta con el marco normativo que establezca la existencia de Áreas Especiales de Manejo que tendrían que ser equivalentes a la experiencia tenida en Chile y otros países con las $A M E R B$.

La segunda pregunta estuvo dirigida a consultar cuáles son las entidades que deben fortalecer sus capacidades para lograr contener el alto grado de informalidad que se observa en la pesca artesanal: $40 \%$ de las personas encuestadas consideró que PRODUCE es la entidad que más atención debe prestar para mejorar sus procesos internos, con el fin de alcanzar una mayor presencia e influencia nacional; $38 \%$ dijo que son los gobiernos regionales los que requieren asignar más recursos para cumplir las funciones delegadas por PRODUCE en el 
marco del proceso de descentralización del país; $11 \%$ manifestó que es DICAPI la entidad que mayor necesidad tiene de fortalecer sus capacidades para contener la informalidad, y $7 \%$ consideró que es el FONDEPES la entidad llamada a mejorar su desempeño en este tema. La mayor parte de los expertos consultados opinó que es DICAPI la entidad que con la mayor prioridad debe mejorar su labor, en el marco de las competencias que la ley le asigna en el caso de la pesca marina.

5.8. $\quad$ Acerca del uso que se da a los derechos de pesca y la atención que el Estado brinda a las pesquerías

Se hicieron dos preguntas sobre la necesidad del sector pesca de reinvertir en sí mismo los pagos que se realizan por concepto de derechos de pesca, en función de la atención que brinda el Estado a las distintas pesquerías. ¿Está Ud. de acuerdo con que se asigne el $100 \%$ de los derechos de pesca
a actividad de investigación de desarrollo en el mismo sector pesca?

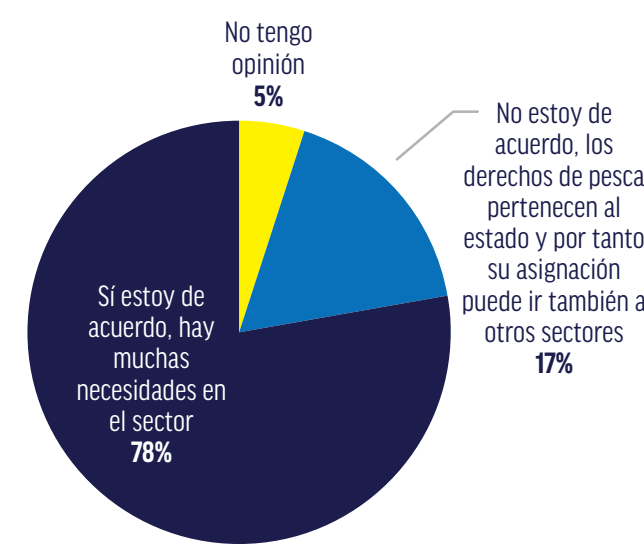

¿Considera Ud. que está equilibrada la atención que el Estado le da a distintas pesquerias?

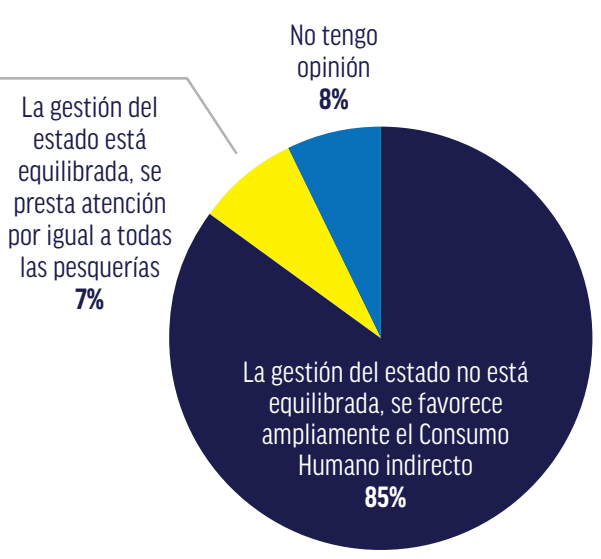

En el caso de la primera pregunta, la consulta se refiere a que el sector tiene muchas necesidades. La falta de inversiones en el estudio del fenómeno socioeconómico de la pesca artesanal y en infraestructura, así como la poca o nula atención de entidades que también tienen explican el grado de informalidad y de pesca ilegal que existe actualmente. El sector necesita hacer uso de todos los recursos posibles, y debe gestionar la intervención intersectorial que se requiere para abordar este complejo problema.Entreesosrecursosestánlospagosporderechos de pesca, que hasta hace poco tiempo eran empleados en en otras actividades. La mitad de esos recursos es asignada a PRODUCE, $25 \%$ va a los gobiernos locales, $20 \%$ a los gobiernos regionales y $5 \%$ a las universidades públicas de la región. Sin embargo, no se conoce fehacientemente el destino que se da estos fondos. Setenta y ocho de cada cien personas encuestadas manifestaron estar a favor de que se demuestre que $100 \%$ del fondo generado con los derechos de pesca se invierta efectivamente en el sector, y $17 \%$ opinó que es correcto que los derechos de pesca se inviertan también en otras áreas. Los expertos consultados comparten la opinión mayoritaria, y uno de ellos señaló que los derechos de pesca tributados por las flotas calamareras internacionales que operaron en el Perú en las décadas de 1990 y 2000 tributaron en promedio US\$130 por tonelada extraída. Entre 1991 y 2009, la captura industrial de pota totalizó 1,1 millones de toneladas.

La segunda pregunta se refiere a si la atención del Estado está equilibrada entre $\mathrm{CHD}$ y $\mathrm{CHI}$ en materia de manejo. Al respecto, $85 \%$ de las personas encuestadas señaló que la gestión no está bien equilibrada y que favorece al $\mathrm{CHI}$; en cambio, $7 \%$ opinó que sí estaba bien equilibrada. Los expertos consultados coincidieron con el punto de vista mayoritario y reconocieron que el sector $\mathrm{CHI}$ ha recibido mayor atención a lo largo de los años en mérito recibimay a el aceite de pescado, pero aceptaron asimismo que el caso de la pesca artesanal es mucho más complejo y que la solución a los distintos problemas generados tiene varios frentes $y$ varias entidades responsables. En vista de su importancia para la seguridad alimentaria, la pesca artesanal tendría que ser objeto de una política de Estado que considere en primer término los derechos socioeconómicos de un sector crecientemente empobrecido.

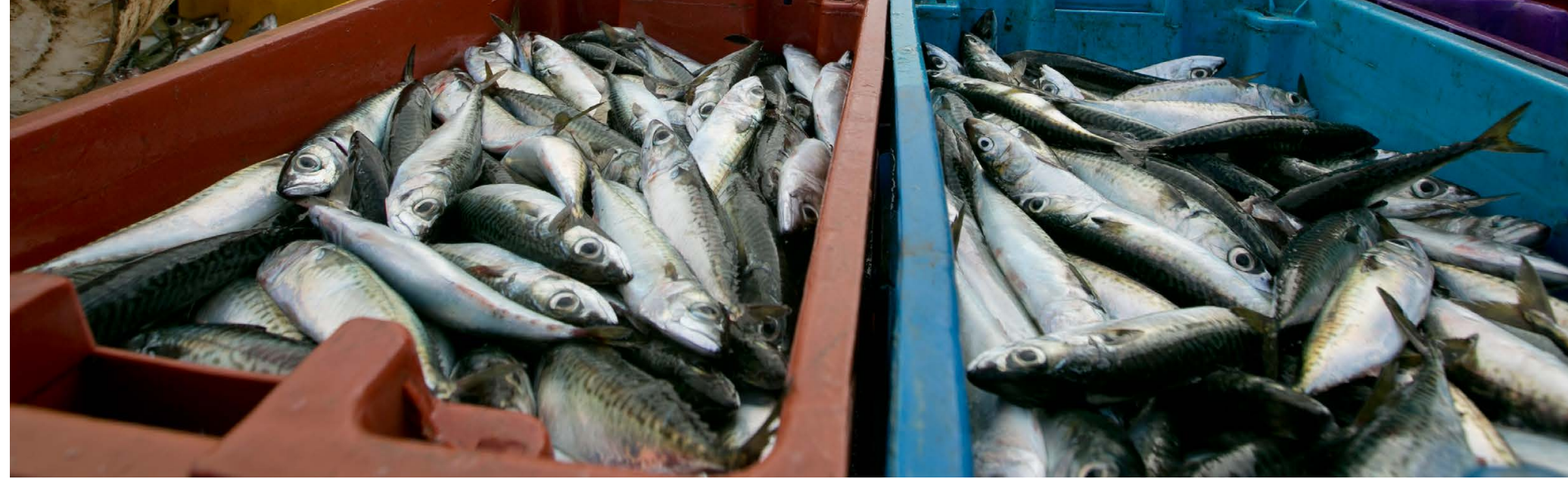

\subsection{CRITERIOS PARA PRIORIZAR ACCIONES EN FAVOR DE LA TRANSPARENCIA}

Según Winter (2009), el propósito del ordenamiento pesquero es la sostenibilidad, que es un objetivo que solo puede alcanzarse construyendo una gobernanza eficaz, por encima de los intereses particulares. Sin embargo, gobernar es una labor agobiante en un sistema como el peruano, donde las competencias del sector pesquero no están centralizadas sino fragmentadas, y en el que se percibe un bajo nivel de compromiso de las instituciones que, como PRODUCE, tienen competencias directas o indirectas en el sector. En este documento se pueden hallar múltiples referencias al bajo nivel de la acción intersectorial.

El común denominador es la falta de atención al principio de transparencia. Los ROP, que son el instrumento para la gobernanza y la sostenibilidad de las pesquerías, en varios casos invocan la participación de los actores o grupos de interés en un proceso de consultas que no está realmente institucionalizado. Asimismo, varios de ellos incluyen mecanismos para la generación de regímenes provisionales máslaxosen losquesemodifican suspropias disposiciones, incluso contraviniendo los intereses y objetivos principales de la norma. La relajación de tales mecanismos está documentada en casos como el del ROP de la anguila y el de la merluza (De la Puente \& Sueiro, 2013).

Otros ROP regulan aspectos de la actividad pesquera sin considerar los costos que demandará la verificación de su cumplimiento, con lo que reducen los incentivos para que se cumpla la norma. Este es el caso del ROP para la actividad CHD para anchoveta (DS N. 005-2012-PRODUCE) (Paredes, 2013). Por otro lado, los ROP de la pota, el jurel y la caballa, la merluza y el atún y especies afines no regulan la actividad pesquera artesanal más allá de reincidir en los requerimientos de acceso que se encuentran en la Ley General de Pesca y su Reglamento, así como en la norma sanitaria. Esto es sumamente problemático para la pesquería artesanal dado que, al no estar debidamente regulada, no restringe el acceso de los pescadores artesanales a los recursos.

Ello fomenta el crecimiento informal del esfuerzo pesquero $y$, a la vez, problemas de sostenibilidad y de ingresos para los pescadores artesanales. Próximamente será creado el Seguro Obligatorio de la Pesca Artesanal (SOPA, Proyecto de Ley N.. 01014-2016/PRODUCE), una buena medida para proteger a los pescadores, pero se requieren varias otras alternativas complementarias. Adicionalmente, algunos ROP no son implementados por las autoridades regionales por temor a generar conflictos sociales; es el caso del ROP de las macroalgas marinas, o el ROP de la anchoveta para el CHD. Lo mismo ocurre con el ROP de las actividades extractivas artesanales y de menor escala del ámbito marítimo adyacente al departamento de Tumbes.

En síntesis, se percibe en el sector pesca una marcada desconfianza en las medidas de ordenación y regulación actuales, que han promovido el crecimiento de la informalidad en el sector artesanal. En contraste, el sector industrial es conducido en términos generales de un modo correcto. Las claves en este caso han sido: (1) el control estricto de sus actividades, (2) el despliegue de un esfuerzo de monitoreo del estado poblacional de las especies objetivo y (3) la generación de un marco 
normativo que, aunque imperfecto y con carencias por resolver, ha logrado consolidar una gobernanza que es funcional.

Con base en esa experiencia, con el consenso identificado a raíz de las consultas efectuadas, y a partir de las experiencias y tendencias internacionales, se pueden proponer los siguientes criterios o principios para fortalecer la gestión y transparencia de las pesquerías nacionales:

\subsection{La decisión política debe estar alineada con} los objetivos y metas de la sostenibilidad

Se requieren decisiones políticas que estén en armonía con la transparencia y la sostenibilidad de las pesquerías en lo que concierne a sus componentes ecológicos, económicos y sociales. La decisión política comprende la capacidad de asignar los recursos requeridos para la implementación de marcos normativos diseñados de modo participativo, y orientados a implementar formalmente un manejo ecosistémico adaptativo basado en la experiencia práctica. Asimismo, ella debe estar orientada a la consecución de objetivos y metas plasmadas en un nuevo marco normativo -o bien profundamente modificado-, basado en principios precautorios, más aún considerando los posibles escenarios generados por el cambio climático y la alta variabilidad del ecosistema.

El marco normativo actual debe ser modificado a la luz de las reales capacidades de investigación y de las posibilidades de las tecnologías de detección y pesca. Hay una alta demanda de conocimientos necesarios para el manejo (aspectos biológicos y ecológicos), lo que tendría que ser abordado por IMARPE en cooperación con las universidades y otros entes académicos. Se requiere movilizar los recursos disponibles (por ejemplo, el FOCAM y los derechos de pesca) para asignarlos a líneas de investigación que respondan a las necesidades y prioridades regionales. Por ejemplo, la mayoría de las DIREPRO carece de personal calificado y en número suficiente para abordar cabalmente sus funciones en el sector pesca.

El sector marino en general, y la pesca artesanal y la maricultura en particular, tienen potencialidades de desarrollo que requieren la intervención del Estado para catalizar su rol promotor, a través de inversiones en infraestructura y obras sanitarias. También para diversificar las actividades económicas hacia el turismo, las energías renovables, la investigación científica, el control de la contaminación, etcétera. Asimismo, los estudios sobre valorización económica de los servicios ecosistémicos se hallan en una fase incipiente (Salgado et al., 2015). CEPLAN no ha desarrollado a la fecha una política marítima que permita al MEF asignar los recursos financieros para cubrir las carencias que impiden desarrollo económico en el que es considerado el mar más rico del planeta.

\subsection{Una fuerte institucionalidad para una gestión} transparente y transversal de las pesquerías

Se necesitan instituciones fuertes, con capacidad de asumir sus atribuciones, con personal profesional y técnico multidisciplinario que conozca la realidad de la pesca en el terreno. Se requiere, asimismo, una fuerte interacción entre las entidades con competencias en el sector pesca, cuyo ente coordinador podría constituirse en una Superintendencia Nacional de Pesca y Acuicultura protegida de presiones e intereses económicos o jurisdiccionales.

En particular, es necesaria una mayor fortalezay presencia de DICAPI para zanjar con los temas de corrupción e ilegalidad, que han perm embarcaciones se desplace libremente sin matrícula, con matrícula falsa o sin permiso de pesca vigente.

Se requiere que los programas de vigilancia satelital cuenten con los últimos adelantos tecnológicos posibles e incorporen al íntegro de las flotas. Hay alternativas tecnológicas económicas que pueden ser utilizadas para estos propósitos. Asimismo, es preciso implementar un sistema de control del desempeño de las empresas involucradas en la supervisión y vigilancia en los puntos de descarga.

Es esencial que todos los sistemas de control y vigilancia estén integrados, y que permitan el acceso transparente y multisectorial a entidades que requieren orientar su gestión según el desempeño de la pesca (PRODUCE, DICAPI, IMARPE, RNSIIPG, AGRORURAL, DIREPRO, universidades).

Es necesario que las informaciones sobre lances, capturas, desembarques, composición de las capturas, estructura de tallas y otras mediciones biológicas estén disponibles de modo abierto para la investigación científica, las inversiones sostenibles y para promover la transparencia en el uso de datos que conciernen a bienes que son propiedad de la nación.
Se requiere fortalecer la COMUMA para agilizar sus procesos internos; implementar el Índice de Salud del Océano (IdSO) como herramienta para evaluar la gestión sectorial respecto a los recursos y servicios ecosistémicos: aplicar metodologías de evaluación independiente del desempeño de la gestión pesquera, como se describe en los acápites 3.3 y 3.4 de este documento.

\subsection{Institucionalización del diálogo y la}

participación en el diseño del marco normativo

Es preciso cambiar la mentalidad del funcionariado público, y los MOF de las entidades del sector tendrían que ser modificados para dar cabida a la interacción y retroalimentación constante entre PRODUCE, IMARPE, universidades y otras entidades que tienen la capacidad de contribuir en un proceso de mejora constante. Múltiples esfuerzos y aportes de la sociedad civil, incluyendo iniciativas ecosistémicas como la certificación de pesquerías y los métodos de evaluación del manejo no son aprovechados por el Estado, debido a prácticas generadas por un diseño burocrático de las entidades, que cultivan la reserva como estrategia y que, por tanto, no interactúan ni se instruyen de la cambiante realidad social, económica, científica y tecnológica.

Para modificar esta estructura de las instituciones, el diálogo requiere ser institucionalizado en el sector $y$ debe ser también extendido a todas las entidades que tengan competencias en la pesca y la acuicultura. En un proceso realmente democrático la actual prepublicación de las normas no es suficiente: se requiere de un diseño participativo de ellas que asegure su cumplimiento y no la resistencia que actualmente se observa, por ejemplo, respecto a la nueva Ley de Acuicultura. En especial, las normas deben diseñarse considerando la realidad práctica de lo que se pretende regular. Asimismo, con base en el diálogo, deben establecerse los mecanismos para la validación e incorporación de información generada por la sociedad civil y el mercado en los procesos de toma de decisiones.

Es necesario también el desarrollo de una Estrategia Nacional de Educación Ambiental que permita mejorar la comprensión de los ciudadanos y del mercado en materia de la gestión de los bienes y servicios que provee el océano, su importancia y su relación con el bienestar de la sociedad peruana. El mar viene siendo continuamente contaminado por prácticamente todas las actividades económicas que se realizan en la vertiente occidental de los Andes, y sus impactos ya son claramente apreciables
(Fajardo, 2013), lo que demanda también la atención del Ministerio de Vivienda, un sector que hasta ahora se ha mantenido ajeno a la discusión sobre la sostenibilidad de los recursos marinos. Asimismo, los ministerios de Turismo y Energía y Minas no interactúan con los ministerios directamente vinculados al mar (PRODUCE, DEFENSA, MINAM, MINAGRI). Estos hechos deben ser conocidos por la ciudadanía para alentar la generación de una opinión pública bien informada y sensibilizada.

6.4. Asignación de derechos para contener la informalidad y promover la sostenibilidad

Hardin (1968) fue el primero de los economistas en abordar la "tragedia de los bienes comunes". Otra manera de tratar este concepto es a través de una expresión en boga entre los pescadores artesanales: "lo que es de todos es de nadie". En efecto, el funcionariado público, en general, niega este principio de la economía de los recursos naturales, sosteniendo que "no es posible asignar derechos de propiedad sobre bienes que el ecosistema produce naturalmente y que nos pertenecen a todos". El resultado de hacer de esta última definición un precepto para la administración pública es lo que nos ha conducido al estado actual de deterioro del estado de los recursos costeros.

Por su parte, en los gobiernos regionales -salvo pocas excepciones- las DIREPRO se han convertido en agencias de empleo en las que una persona sin capacitación alguna (saber nadar, por ejemplo, o saber enfundarse un traje de buceo) puede acceder al carné de pescador, labor que por lo general se desarrolla a tiempo parcial para generar ingresos adicionales. El resultado es el creciente empobrecimiento del verdadero pescador artesanal.

La sostenibilidad requiere un cuidado de los recursos. En los sitios más aislados de la costa del Perú, como en Marconay Atico, las experiencias comunitarias han tenido éxito porque la labor de pescador es una profesión; es decir, se dedican a ella quienes realmente dependen de la pesca. Estos grupos organizados han logrado contener el boom de empleos que se observa en otras regiones, vigilan y denuncian la presencia de embarcaciones y personas que no son de la zona y que pretenden extraer recursos libremente, sin observar las normas de protección establecidas localmente. En estas zonas los pescadores han desarrollado el lema "si yo cuido, yo cosecho". Y el cuidado funciona. Entonces, los funcionarios del Estado deben comprender que no pueden estar presentes en todas las playas, puntas, islas y caletas, pero pueden 
aprovechar la experiencia acumulada (en Marcona con la COPMAR, por ejemplo) para delegar facultades a cambio de asignar responsabilidades de control y vigilancia. La cesión de derechos de uso territorial es una posibilidad que está en manos del Estado implementar, en el caso de zonas donde existan comunidades organizadas de pescadores, a las que asimismo hay que empoderar a través de la implementación formal de los COREVIPA.

Con el fin de lograr el éxito del esquema de cesión de derechos para el uso sostenible de los ecosistemas se requiere el acompañamiento de entidades académicas. En Chile se halló que los casos exitosos de este tipo de áreas de comanejo (que, por lo demás, son más de mil) están en general relacionados con su interactuación con entidades académicas (universidades, ONG) que asesoran y apoyan a los pescadores en el cumplimiento de las obligaciones que les impone el Estado (Moreno \& Revenga, 2014; Gelcich \& Donlan, 2015)

Se requiere, asimismo, mucha investigación económica y social alrededor de esta naciente experiencia. La Dirección General de Políticas de PRODUCE cuenta con una unidad para estos propósitos, de modo que su tarea debería trascender para alentar el desarrollo económico de la pesca artesanal, con prioridad en las zonas de comanejo.

Finalmente, es conveniente resaltar la coincidencia de opinión entre los expertos consultados y encuestados, en el sentido de que debe implementarse el marco normativo para desarrollar esta opción de manejo pesquero, que además va a contribuir a aliviar la pesada carga que portan los funcionarios públicos.

\subsection{Monitoreo y vigilancia ecosistémica con}

participación de los grupos de interés

Según FAO (Arreguín \& lanelli, 2014), IMARPE destaca en el mundo entre las instituciones de su tipo por la gran cantidad de información de calidad que genera y que es puesta al servicio de la gestión de las pesquerías. Sin embargo, esa entidad de la ONU sostiene que no es suficiente. La diversidad y complejidad de las pesquerías peruanas es tal que se requiere diversificar aún más los esfuerzos de monitoreo.

En ese sentido, Arreguín \& lanelli (2014) señalan que IMARPE debe valorar toda posibilidad de incorporar más datos (por ejemplo, recurriendo a las flotas de pesca). Desde el lado metodológico, IMARPE viene desarrollando monitoreos y probando nuevas tecnologías para extender su capacidad de seguimiento de los recursos costeros.

Las campañas, cruceros o monitoreos que realiza IMARPE son en realidad actividades multidisciplinarias en las que e recoge información sobre varios componentes del ecosistema. Sin embargo, los informes que el Instituto presenta a PRODUCE por lo general abordan la situación de la especie objetivo sin considerar su entorno, y muchas veces sin incluir la descripción del estado de las especies que habitan el mismo nicho ecológico. Hasta el año 2011, 政 gestión pesquera hacia un manejo ecosistémico.

Esto quiere decir que actualmente no se aprovecha la gran oportunidad de mostrar cuál es la situación de otras especies igualmente evaluadas junto con la anchoveta, y otras especies-objetivo (algunas de ellas son mejores indicadores que la anchoveta respecto, por ejemplo, al impacto de El Niño sobre el ecosistema). Asimismo, en IMARPE ya se evalúa acústicamente la biomasa de macrozooplancton, y se mide en 3D el hábitat pelágico; también se estudia la abundancia relativa de depredadores en el mar ya tienen un carácter ecosistémico y, por tanto, los informes pueden ser enriquecidos a través de un enfoque analítico más amplio.

Asimismo, IMARPE, como entidad estratégica del sector pesca,podríaestablecerexplícitamentelosrequerimientos de información para la progresiva implementación del enfoque ecosistémico, y convocar el apoyo público para la generación de esa información, su sistematización, análisis y comunicación a los tomadores de decisiones y a sociedad civil. IMARPE debe asimismo abrir sus bases de datos para la cooperación con universidades de dentro y fuera del país, con el fin de alentar las investigaciones ecológicas, económicas y sociales que el sector requiere para su diversificación y uso sostenible.

En el caso de los monitoreos y vigilancia de la calidad ambiental del mar, se ha observado que diversas entidades públicas y privadas realizan esfuerzos paralelos y casi siempre sobrepuestos (IMARPE, ANA, OEFA, DICAPI, DIGESA, empresas privadas, gremios de empresas privadas, gobiernos regionales). La Política Nacional del Ambiente no está siendo considerada en este aspecto. Todos los esfuerzos de monitoreo tendrían que estar integrados para potenciar el uso de los recursos y ampliar la capacidad de monitoreo.
El Perúes un país importante para la seguridad alimentaria mundial. Tres de nuestras pesquerías son las mayores del mundo en su tipo (anchoveta, pota, perico). El potencial para la maricultura y el cultivo de macroalgas es enorme y no requiere de agregados (como en el caso de la crianza de peces), lo cualc embarso contaminación. En relación con este problema, se espera el diseño de un Plan de Acción Nacional que integre a todos los sectores involucrados.

\subsection{Evaluación del manejo adaptativo y proceso} de mejoras continuas

La faceta operacional del Manejo con Enfoque Ecosistémico (MEE), cuya implementación tiene como punto focal nacional a IMARPE, es el Manejo Pesquero Adaptativo (MPA). El Perú e IMARPE tienen una buena reputación mundial gracias al buen trabajo hecho con la anchoveta, no obstante el altamente impredecible pero productivo ecosistema oceánico frente a nuestras costas.

Sin embargo, se debe impulsar un proceso de mejoras continuas, idealmente supervisadas por la opinión pública, para asentar el principio de transparencia respecto a la labor de todas las entidades con competencias a el sector. Los sucesos recientes que han conmovido ambiente político internacional (Caso Lava Jato) deben hacer reflexionar a todos los funcionarios y actores de sector estatal sobre la conveniencia de desarrollar un alto nivel de transparencia en el uso de los recursos públicos $y$ en la administración de los recursos naturales.

El Estado debe entonces facilitar la implementación de sistemas que evalúen la gestión intersectorial en sus varias facetas: (1) en la investigación para la evaluación de las poblaciones marinas, entregando información suficiente y oportuna para su verificación independiente; (2) en la generación de recomendaciones, para constatar que las medidas adoptadas están comprendidas en los escenarios de manejo previstos en el marco normativo o en los protocolos correspondientes; (3) en la participación de los grupos de interés, que debe darse de modo amplio y formal, tanto en el diseño de las normas como en su implementación, discusión y seguimiento de los resultados del manejo; (4) en la adopción de herramientas de evaluación independiente del manejo, y que permitan la mejora de las metodologías y la representatividad de los indicadores; (5) en la adopción de herramientas que evalúen el riesgo de las actividades economicas (no solo la pesca) sobre los recursos explotados y especies asociadas, más aún considerando la vulnerabilidad del Perú respecto a la variabilidad climáticay los aún inciertos niveles de impacto del creciente cambio climático; $y$, (6) en la adopción de modalidades de promoción de la sostenibilidad como las ecocertificaciones de pesquerías y de acuicultura, dirigidas a que los consumidores finales ingieran únicamente productos que provengan de pesquerías sustentables.

Por último, deben tenerse presentes las definiciones de la OCDE sobre la transparencia, que la vincula directamente sarencia es el proceso por el cual la información de las condiciones existentes es accesible para la toma de decisiones y acciones, de manera visible y entendible"). Asimismo, vale la pena recordar que la FAO (1995) recomienda a los Estados y a las organizaciones $y$ arreglos subregionales o regionales de ordenación pesquera que aseguren la transparencia en los mecanismos de ordenación, y en el proceso de adopción de decisiones en esta materia. También la FAO (2012) enumera principios y directrices que incluyen la transparencia enfocada desde el punto de vista del uso de la información, la generación de leyes, políticas y toma de decisiones, la rendición de cuentas y la lucha contra la corrupción (FAO, 2015: "definir con claridad y dar amplia publicidad a las políticas, procedimientos y leyes, empleando lenguajes $y$ formatos adecuados $y$ accesibles a todos"). 
El consenso amplio observado durante el proceso de consultas públicas realizadas en el marco del estudio indica que hay un ambiente favorable para introducir reformas de tipo político e institucional en la gestión del sector pesca.

Se ha hallado que, en cuanto a la forma en que se diseñan y ejecutan las normas, el sistema actual es poco transparente y no es bien percibido, incluso en el propio Estado. Se ha encontrado también que la carencia de capacidades y recursos (principalmente en los GORE y en DICAPI) para hacer cumplir las normas es la primera causa raíz de la alta informalidad a la que se ha llegado en la pesca artesanal.

El problema principal es, entonces, la creciente presión sobre los recursos costeros y la pesca ilegal, tanto a nivel de orilla como de embarcaciones. No se tiene una idea cabal de la cantidad e identidad de recursos extraídos sin control, incluyendo la caza de especies protegidas como las tortugas, lobos, aves y delfines. Abordar estos temas en sus detalles implica una reorganización de algunas entidades, la adopción de una estrategia intersectorial que aborde estos problemas, y la asignación de recursos adecuados para su implementación.

\section{Especificamente, se recomienda:}

1) Institucionalizar la transparencia por medio de la creación de Comités de Coordinación Intersectorial o similares para cada pesquería, lo que permitiría articular los esfuerzos del Estado con los del sector privado, universidades, ONG ygremios. Lanecesidad de contar con estas instancias, coordinadas por personas capacitadas en la conducción de grupos humanos, debe estar plasmada en el correspondiente ROP, con el fin de garantizar su implementación a través de la aprobación de las "Reglas de Participación" que aseguren la representatividad y positiva participación de los actores directamente involucrados. El diseño de todas las normas, así como su implementación y discusión de resultados, debe recoger los puntos de vista de cada Comité.

2) Realizar un nuevo censo de la pesca artesanal, convocando la participación de las entidades con competencias en el tema, también con presencia de las universidades y de la sociedad civil en el proceso de diseño, ejecución y análisis de la información. Esta acción es imprescindible para ordenar el sector, y debe conducir a la intervención de los astilleros y de las embarcaciones que operan de modo ilegal. Se debe recurrir a las tecnologías disponibles (drones, fotografías, etcétera) para determinar con precisión y en el momento oportuno el número y tipo de embarcaciones existentes.

3) El íntegro de la flota artesanal debe ingresar en el SISESAT y, a su vez, este debe integrarse a SIMTRAC. Hay alternativas tecnológicas más asequibles y prácticas que la emisión en tiempo real para el caso de las naves más pequeñas. La información generada debe ser abierta para las aplicaciones tales como monitoreo de áreas protegidas, estudios económicos, gestión de las empresas, estudios ecosistémicos e incremento de la vigilancia con participación de la sociedad civil.

4) Reformar la Ley de Pesca, su Reglamento y/o modernizar sus ROP. Eliminar, por ejemplo, a través de nuevos ROP, las inconsistencias de normas como la que solo permite producir harina con los residuos de la producción CHD, o la que dispone la vigilancia en plantas cuando la fuerza del control debe estar colocada en los puntos de descarga, muchos de los cuales -la mayoría informales- no están siendo monitoreados. Los ROP deben, asimismo, incorporar protocolos para las medidas de manejo adicionales que se requiera desarrollar respecto a escenarios tales como la detección de una biomasa menor que la esperada durante las evaluaciones.
5) Institucionalizar el comanejo de las pesquerías en donde existan grupos organizados y formalizados de pescadores, a través de un marco normativo que asigne derechos y obligaciones según corresponda, lo que por un lado permitirá aliviar la labor de los GORE y PRODUCE respecto a sus competencias y, por otro, impulsará la formalización de los pescadores, el diseño de planes de manejo para grupos de especies y el monitoreo y seguimiento de la performance ecosistémica de cada pesquería. Esta recomendación, asimismo, requiere la formalización y empoderamiento de IOS COREVIPA.

6) El país requiere una política marítima que debe ser diseñada por CEPLAN, para incrementar el flujo de inversiones estatales en el sector marino. En el caso pesquero específicamente, es preciso mejorar la infraestructura sanitaria, de desembarque y provisión de hielo y agua potable. DICAPI y DIREPRO requieren recursos financieros y humanos para sostener una presencia completa en sus ámbitos de jurisdicción. Una política marítima debe también abordar el problema del adecuado tratamiento de las aguas servidas que se vierten permanentemente en el mar. La mayoría de ríos costeros se halla en una condición inerte, sin vida, debido a la concentración de contaminantes en las desembocaduras, que son el hábitat reproductivo de muchas especies.

7) Es necesario diseñar Planes de Acción Nacional (PAN) para la movilización de recursos orientados a generar el conocimiento biológico y ecológico necesario para diseñar más ROP, para más especies o bien para grupos de especies. Es limitado el conocimiento con el que se cuenta actualmente para acometer esta labor. Se requiere articular los esfuerzos de universidades, ONG y de la sociedad civil en general, también para llamar la atención de los consumidores sobre la necesidad de respetar las vedas y tallas mínimas, así como promover un consumo responsable. También algunos sistemas de abastecimiento directo y de venta de recursos hidrobiológicos necesitan ser supervisados, pues actualmente no forman parte de la cadena de monitoreo. Finalmente, las estadísticas de pesca no son publicadas y tampoco lo son los valores de las transacciones, lo que impide valorizar adecuadamente la actividad. 
Accenture (2009). Assessment of On-Pack, Wild-Capture Bertrand S., A. Bertrand, R. Guevara-Carrasco \& F. Gerlotto Seafood Sustainability Certification Programmes and (2007). Scale-Invariant Movements of Fishermen: The Same Seafood Ecolabels. An Inde Development Partners (ADP).

Alegre, A., F. Menard, R. Tafur, P. Espinoza, J. Argüelles, V. Maehara, O. Flores, M. Simier \& A. Bertrand (2014).
Comprehensive Model of Jumbo Squid Dosidicus gigas Trophic Comprehensive Model of Jumbo Squid Dosidicus gigas Trophic Ecology in the Norther
vol. 9, issue 1, e85919.

Amorós, S., R. Gozzer \& V. Melgar (2015). Caracterización $\mathrm{y}$ análisis de la cadena productiva de la pesquería de perico (Coryphaena hippurus) en el Perú. Lima: Programa Marino de WWF Perú.

Andrade, A., S. Arguedas \& R. Vides (2011). Guía para la A licacín $Y$ monitoreo del Enforle ECositénico, IUCN UNESCO, Conservación Internacional, CEM, UCI, FCBC, ELAP.

Arana, P. (2008). Pesquería del bacalao de profundidad: un caso especial entre las especies de aguas profundas. Lambayeque: Escuela de Ciencias del Mar / Pontificia Universidad Católica de Valparaíso. Curso sobre Pesca en Aguas Profundas. 72 diapositivas.

Ardron. J. A., N. Clark, K. Seto, C. Brooks, D, Currie \& E. Gilman E. (2014). Tracking 24 Years of Discussions about Transparency in International Marine Governance: Where do We Stand? Stanf Environ Law J., 33(2), 167-90.

Arreguin-Sánchez, F. \& J. lanelli (2014). Informe final de la Auditoría Técnica Internacional del Instituto del Mar del Perú. Lima: FAO, Oficina Regional para Latinoamérica y el Caribe.

Avadi, A., I. Vásquez-Rowe \& P. Fréon (2014). Eco-Efficiency Assessment of the Peruvian AnchovetaSteel and Woodenfleets using the LCAbDEA Framework. Journal of Cleaner Production, volume 70, 1 may 2014, 118-131.

Avadi, A.\& P. Fréon (2014). A Set of Sustainability Performance Indicators for Seafood: Direct.

Banco Mundial (2008). Implementing the Extractive Industries Transparency Initiative. Applying Early Lessons from the Field. The World Bank 17(2), 331-337.

Birkinshaw, P. (2006). Transparency as a Human Right. En C. Hood \& D. Heald (eds.), Transparency: the Key to Better Governance? (pp. 47-56). New York: Oxford University Press.

Black, J. (1997). Transparent Policy Measures. En Oxford Dictionary of Economics (p. 476). Oxford: Oxford University Press.

Butterworth, D. S. (2007). Why a Management Procedure Approach? Some Positives and Negatives. ICES Journal of Marine Science, 64, 613-617.

Butterworth, D.S.,N. Bentley, J. A.A. De Oliveira, G. P. Donovan, L. T. Kell, A.M. Parma, A. E. Punt, K. J. Sainsbury, A. D. M. Smith, \& T. K. Stokes (2010). Purported Flaws in Management Strategy Evaluation: Basic Problems or Misinterpretations? ICES Journal of Marine Science, 67, 567-574.

Carbajal W. (2013). Identificación de grupos de interés en el golfo de Sechura y litoral de Lambayeque tanto a nivel de conocimientos, actitudes y prácticas así como a nivel de levantamiento de percepciones y expectativas, respecto al área protegida, fauna y recursos marinos de la Isla Lobos de Tierra (ILT). Proyecto GEF-UNDP-Humboldt y WWF Peru.

Castillo, R., A. Tejada, V. Castañeda \& R. Pastor (2011). Diagnóstico y estado de la macroalga parda aracanto (Lessonia nigrescens) en el litoral de Arequipa, Perú 2007. Inf. Inst. Mar Peru, vol. 38, 4, 429-440.

Chávez, F, A. Bertrand, R. Guevara-Carrasco, P. Soler \& J. Csirke (2008). The Northern Humboldt Current System: Progress in Oceanography. 79, 95-105.

Christensen V., S. de la Puente, J. C. Sueiro, J. Steenbeek \& P. Majluf. (2014). Valuing Seafood: The Peruvian Fisheries Sector. Marine Policy 44, 302-311.

CIAT (2016a). Exploratory Stock Assessment of Dorado (Coryphaena hippurus) in the Southeastern Pacific Ocean. Coryphaena hippurus) in the Southeastem Pacifc Orean. Scientific Advisory Committee Seventh Meeting. La Jolla,
California (USA). 9-13 May 2016. Brief History, Present Status and a View towards the Future.

(
CIAT (2016b). Exploratory Management Strategy Evaluation (MSE) of Dorado (Corvphaena hippurus) in the Southeastern Pacific Ocean. Scientific Advisory Comnittee Seventh Meeting. La Jolla, California (USA). 9-13 May 2016.

FAO (2016). Estado de la pesca y acuicultura mundial (SOFIA). y Alimentación.

FAO (1995). Códligo de conducta para la pesca responsable. Roma: Organización de las Naciones Unidas para la Agricultura y Clark N., J. Ardron \& L. Pendleton.(2015). Evaluating the Basic Elements of Transparency of Regional Fisheries Management Organizations. Marine Policy 57, 158-166.

Clark, N., J. Ardron \& L. Pendleton (2015). Evaluating the Basic Elements of Transparency of Regional Fisheries Management Organizations. Marine Policy 57, 158-166.

Cruz N., R. Castillo, J. Mamani \& J. Rugel (2012). Plan de negocios de macroalgas marinas en el sur del Perú. Inst. Mar Perú. Volumen extraordinario.

Cullis-Suzuki S. D. Pauly (2010). Cullis-Suzuki S., Pauly D Failing the High Seas: A Global Evaluation of Regional Fisheries Management Organizations. Mar Policy 34, 1036-1042.

Daley R., I. Knuckey, J. Dowdney, A. Williams, C. Bulman, M. Sporcic, M. Fuller \& T.Smith (2007). Ecological Risk Assessment (ERA) for Effects of Fishing. Report for Great Australian Bight Trawl Sub-Fishery of the Southeasetern Shark and Scalefish Fishery. Report for the Australian Fisheries Management Authority. Canberra, Australia.

De la Puente, O., J.C. Sueiro, C. Heck, G. Soldi \& S. de la Puente (2011). La pesquería peruana de la anchoveta: evaluación de los sisterion Trabajo del CSA N. 1. Centro para la Sostenibilidad Ambiental de la Universidad Peruana Cayetano Heredia.

De la Puente, S. \& J. C. Sueiro (2013). Reporte temático sobre la gobernanza en el sector marino peruano. Proyecto GEFPNUD-Humboldt.

De León, P. (2008). Hacia un concepto de transparencia: origenes e importancia. Disponible en: http://ca-bi.com/blackbox/wpcontent/uploads/downloads/2012/08/Transparencia1.pdf

FAO. (2015). Voluntary Guidelines for Securing Sustainable Small-Scale Fisheries in the Context of Food Security and Poverty Eradication. Roma: Organización de las Naciones Unidas para la Agricultura y Alimentación. Alimentación.

FAO (2012). Directrices voluntarias sobre la gobernanza responsable de la tenencia de la tierra, la pesca y los bosques en el contexto de la seguridad alimentaria nacional. Roma: Organización de las Naciones Unidas para la Agricultura y Alimentación.

FIUPAO (2014). Foro Pesquería de Pota y Propuestas de Solución. Federación Integración y Unidad de la Pesca Artesanal del Perú. Congreso de la República. Informe.

Flores, D., J. Zavala, S. Donayre, A. Guardia \& H. Sarmiento (2015). Evaluación poblacional de Chondracanthus chamissoi (C. Agardh, 1820) en las bahías de Pisco y Paracas, otoño 2010. Inf. Inst Mar Perú, vol. 42, n. 4, 504-509.

Fox, J. (2007). The Uncertain Relationship between Transparency and Accountability. Development in Practice $17(4), 663-671$.

Fréon, P., A. Avadi, W. Marin \& R. Negron (2014). Environmentally Extended Comparison Table of LargeVersussmall-and Medium-Scale Fisheries: The Case of the Peruvian Anchoveta Fleet Can. J. Fish. Aquat Sci 71, 1-16.

Galarza, E.\&J Kámiche (2015). Pesca artesanal: oportunidades para el desarrollo regional. Documento de Investigación. Lima: Universidad del Pacífico.

GEF-PNUD (2015). Análisis de diagnóstico ecosistémico transzonal. ADET Chile-Perú. Proyecto GEF-PNUD-Humboldt. PIMS 4147.

GEF-PNUD (2016). Programa de Acción Estratégica. Proyecto GEF-PNUD-Humboldt.

GEF-PNUD (2016). Programa de Acción Estratégica (PAE Chile-Perú) Proyecto GEF-PNUD-Humboldt. PIMS 4147. 
Gelcich, S. \& J. Donlan (2015). Incentivizing Biodiversity Conservation in Artisanal fishing Communities through Territorial User Rightsand Conservation Biology, vol. 29, n. 4, 1076-1085.

Gibbs, M. (2008). Network Governance in Fisheries. Marine Policy 32, 113-119.

Grafton, R. Q., T. Kompasa, R. McLoughlin \& N. Rayns (2007). Benchmarking for Fisheries Governance. Marine Policy, 31, 470-479.

Grigorescu, A. (2003). International Organizations and Government Transparency: Linking the International and Domestic Realms. Int'I Stud. Q. 47, 643-644.

GORE Piura (2014). Plan de Manejo Integrado de los Recursos de la Zona Marino Costera de Sechura. Consultora: Ingeniera Isabel Pizarro Cornejo. Gobierno Regional de Piura y ProGobernabilidad.

Gupta, A. \& M. Mason (2016). Disclosing or Obscuring? The Politics of Transparency in Global Climate Governance. Current Opinion in Environmental Sustainability, 18, 82-90.

Halpern, B., C. Longo, D. Hardy, K. McLeod, J. F. Samhouri et al. (2012). An Index to Assess the Health and Benefits of the Global Ocean. Nature 488, 615-620.

Hardin, G. (1968). The Tragedy of Commons. Science, v. 162 $1243-1248$

Hauge, K. H. K. N. Nielsen \& K. Korsbrekke (2007). Limits to Transparency - Exploring Conceptual and Operational to Transparency - Exploring Conceptual and Operational
Aspects of the ICES Framework for Providing Precautionary Aspects of the ICES Framework for Providing Precautionary
Fisheries Management Advice - ICES Journal of Marine Science Fisheries Ma $738-743$.

Heald, D. (2006). Transparency as an Instrumental Value. En C. Hood \& D. Heald (eds.), Transparency: The Key to Better Governance? (pp. 59-73). New York: Oxford University Press.

Heck, C. (2015). Hacia un manejo ecosistémico de la pesquería peruana de anchoveta. Análisis del marco legal y administrativo para reformar el manejo de la pesquería peruana de anchoveta. Lima: Sociedad Peruana de Derecho Ambiente.

Hervás,A.\&L.Ambrosio (2013a). Resumen dela preevaluación bajo el estándar MSC (Marine Stewardship Council) de la pesquería de perico en Perú. Lima: WWF Perí.

Hervás, A. \& L. Ambrosio (2013b). Proyecto de Mejoramiento Pesquero para la Pesquería de Perico en el Perú. Resumen del Documento de Evaluación de la Problemática y Posibles Alternativas. Lima: WWF Perú.

Hobday, A., A. Smith, I. Stobutzki, C. Bulman, R. Daley, J. Dambachera et al. (2011). Ecological Risk Assessment for the Effects of Fishing. Fish. Res., volume 108, issues 2-3, 372-384.

Holland, D. S. (2010). Management Strategy Evaluation and Management Procedures: Tools for Rebuilding and Sustaining Fisheries. OECD Food, Agriculture and Fisheries Working Papers, N.․ 25, OECD Publishing.

Hollyer, J. et al. (2011). Democracy and Transparency. J. Pol. 73, 1191-1205.

Hood C. (1991). A Public Management for All Seasons ? Public Administration, vol. 69, Spring (3-19)

Hood, C. (2006). Transparency in Historical Perspective. En C. Hood \& D. Heald (eds.), Transparency: The Key to Better Governance? New York: Oxford University Press.

Human Consumption Products from Peruvian Anchoveta Fisheries and Freshwater Aquaculture. Ecological Indicators 48, 518-532.

IATI (2015). Informe anual 2015 de la IATI. http://www. aidtransparencynet/

INEI (2012). Censo de la Pesca Artesanal 2012. Lima: Instituto Nacional de Estadística e Informática. Separata.

INEI-PRODUCE (2012). I Censo Nacional de la Pesca Artesanal del Ámbito Marítimo. Lima: Instituto Nacional de Estadística e Informática - Ministerio de la Producción. 33 diapositivas.

Inga, C. E. \& E. Ordinola (2001). Desembarques pesqueros en el litoral del departamento de Tumbes, 1996-2001. Inf. Prog. Inst. Mar Perú 159. Callao, Perú

Joo, R., S. Bertrand, J. Tam \& R. Fablet (2013). Hidden Markov Models: The Best Models for Forager Movements? PLOS ONE 8(8): e71246.
Joo, R., A. Bertrand, M. Bouchon, A. Chaigneau, H. Demarca I. Tam, M. Simier, D. Gutiérrez, M. Gutiérrez, M. Segura, R. Fablet \& S. Bertrand (2014). Ecosystem Scen ios Shape Fishermen Spatial Behavior. The Case of the Peruvan Anchow Oceanography 128, 60-73.

Joo, R., O. Salcedo, M. Gutiérrez, R. Fablet \& S. Bertrand (2015). Defining Fishing Spatial Strategies from VMS Data Insights from Theworld's Largest Monospecific Fishery. Fisheries Research 164, 223-230.

Kell, L., P. De Bruyn, M. Soto \& H. Arrizabalaga (2010). An example of the use of Management Strategy Evaluation for North Atlantic albacore, using Multifan-CL and FLR. Collect. Vol. Sci. Pap. ICCAT, 65(4): 1498-1506.

Mamani J., R. Castillo, A. Gonzales, V. Castañeda, J. Rujel. (2012). Plan de mejora de la producción de las algas pardas en el sur del Perú. 2011 - 2015. Volumen extraordinario. Inst. Mar Perú. 32 pp.

Martinez E., E. (2005). Informe sobre la situación de la pesca artesanal y posibilidades de aplicación del extensionismo pesquero en las comunidades de pescadores artesanales de norte de Perú. Futuro Sostenible.

Moreno A. y Revenga C. (2014).Sistema de gestión pesquera artesanal basado en derechos de uso territorial en Chile, The Nature Conservancy, Arlington, Virginia, USA. 36 pp.

Nakandakari A. (2016). Experiencias de autogestión y comanejo de pesquerías costeras en el Perú: una revisión institucional. The Nature Conservancy. Informe del Taller sobre la gobernanza del sector pesca y acuicultura en la Región Lima. Concejo Departamental Lima. Colegio de Ingenieros de Perú, 52-55.

OCDE.(2004). Principios de Gobierno Corporativo de la OCDE. Organización para la Cooperación y Desarrollo Económico. 68.pp.

Oge K. (2016). Which transparency matters? Compliance with anti-corruption efforts in extractive industries. Resources Policy 49: 41-50.

Oliveros R. (2015). End-to-end modelling for an ecosystem approach to fisheries in the Northern Humboldt Current Ecosystem. Tésis doctoral. Universidad de Montpellier 2. 128 pp.
Ordinola E., El López, I. Gonzales, P. Montero, K. Romero, E. Torres, M. Vera, C. Inga. (2010) Delimitación y caracterización debancos naturales de invertebrados bentónicos comerciales

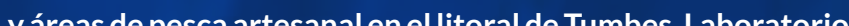

Paredes\&DelaPuente(2014).Situación actualdelapesquería de la pota (Dosidicus gigas) en el Perú y recomendaciones para su mejora. Consorcio de Investigación Económica y Social (CIES) y Ministerio de la Producción (PRODUCE). 112 pp.

Paredes C. (2010). Reformando el Sector de la Anchoveta Peruana Progreso Reciente y Desafíos Futuros. Instituto del Perú, Cuadernos de Investigación Edición N. 10. Universidad San Martin de Porres.

Paredes C. (2013). Eficiencia y equidad en la pesca peruana: la reforma y los derechos de pesca. Instituto del Perú, Lima, $114 \mathrm{pp}$.

Paredes C., U. Letona. (2013). El futuro de la anchoveta y la normativa pesquera. Análisis y propuestas de política. World Wildlife Fund, WWF. Universidad de San Martín de Porres, USMP.Lima, $107 \mathrm{pp}$

Pauly D., D. Zeller. (2016). Catch reconstructions reveal that global marine fisheries catches are higher than reported and declining. Nature Communications 7:10244, DOI: 10.1038/ ncomms10244.

Perramon J. (2013). La transparencia: concepto, evolución y retos actuales. Revista de Contabilidad y Dirección Vol. 16, pp. 11-27.

Pita P. D. Fernández-Vidal J García-Galdo, R. Muíño. (2016). The use of the traditional ecological knowledge of fishermen,cost-effective tools and participatory models in artisanal fisheries:Towards the co-management of common octopus in Galicia (NWSpain). Fisheries Research 178: 4-12.

Salgado H., C. Gonzales, J.C. Sueiro, S. de la Puente. (2015). Estimación del Valor Económico Total (VET) de los Bienes y Servicios Ecosistémicos del Gran Ecosistema Marino de la Corriente de Humboldt (GEMCH). Proyecto GEF-PNUDHumboldt. 127 pp. 
Smith, A., A. Hobday, H. Webb, R. Daley, S. Wayte, C. Bulman, J. Dowdney, A. Williams, M. Sporcic J. Dambacher, M. Fuller, D. Furlani, T. Walker. (2007) Ecological Risk Assessment for the D.Fects of Fishine: Final Report R04/1072 for the Australin

Suárez de Vivero J., J. Rodriguez, D. Florido. (2008). The paradox of public participation in fisheries governance. The rising number of actors and the devolution process. Marin Policy 32: 319-325.

Tomaselli I. (2006). Estudio de tendencias y perspectivas de sector forestal en América latina. Informe de la subregión de Cono Sur. FAO, $136 \mathrm{pp}$

UNEP. (1992). United Nations Environment Programme. Rio Declaration on Environment and Development; Principle 10. In: Proceedings of the United Nations Conference on 10. In: Proceedings of the United Nations Confer

Varjopuro R., T. Gray, J. Hatchard, F. Rauschmayer, H. Wittmer (2008). Introduction: Interaction between environment and fisheries-The roleof stakeholder participation. Marine Policy 32 (2008) 147-157.

Vasquez J., R. Castillo, J. Zavala, A. Tejada, J. Mamani. (2012). Programa de investigación de las algas pardas en el sur de Perú: 2011-2015. Volumen extraordinario. Inst. Mar Perú. 55 pp.

Vera M., I. Gonzales, E. Ordinola, C. Inga. (2010). La actividad extractiva de los recursos hidrobióng extrénface lo las modalides de arrastre, cerco y cortin.

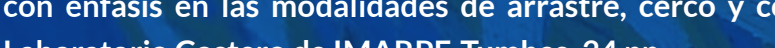

Winter (2009). Towards sustainable fisheries law. A comparative Analysis. IUCN, Gland, Switzerland. 340 p.

Zavala J. (2014). Evaluación de Programa Piloto Demostrativo (PPD). Proyecto GEF Humboldt: Hacia un manejo con enfoque ecosistémico del gran ecosistema marino de la corriente de Humboldt. $49 \mathrm{pp}$

Zavala J. (2015). Análisis Diagnóstico Ecosistémico para el Sitio piloto de la Isla Lobos de Tierra. Proyecto GEF-UNDPHumboldt. 85 pp.

\section{Nombre y apellido}

Ing. Henry Quiroz López

Blgo. Renato Guevara-Carrasco

Blgo. Marco Espino Sánchez

Sr. Alfonso Miranda Eyzaguirre

Lcdo. Raúl Arteaga Bengoa

Ing. Armando Jordán Parra

Eco. Elena Conterno Martinelli

Sr. Francisco Miranda Ávalos

Blgo. Simone Pisu

Dra. Úrsula Letona Pereyra

CAlm. Héctor Soldi Soldi

Sr. Erich Pacheco

Sr. Humberto Speziani Cuevas

Ing. Alfredo Almendariz Abanto

Eco. Pablo Echevarría Martínez de Bujo

Sr. Michael J. Akester

Ing. Mario Escudero Malatesta

Ing. Carlos Castellanos Frischi

Blga. Joanna Alfaro Shigueto

VAlm. Javier Gaviola Tejada

Ing. Juan Alcázar Zamora

Sr. Gonzalo Llosa Talavera

Blgo. Mariano Valverde Romero
Entidad

Colegio de Ingenieros del Perú

Instituto del Mar del Perú

Instituto del Mar del Perú

Sociedad Nacional de Industrias

DIREPRO Piura

Colegio de Ingenieros del Perú CIP N. 23467

Sociedad Nacional de Pesquería

OANNES

Sustainable Fisheries Trade

Congreso de la República

Ministerio de la Producción

Conservación Internacional

Tecnológica de Alimentos S. A.

Asociación Pesquera para el Consumo Humano

Compañía Americana de Conservas

GEF-PNUD

Astilleros Maggiolo S.A

Fondo Nacional de Desarrollo Pesquero

ProDelphinus

Instituto del Mar del Perú

Inversiones Prisco

Ministerio del Ambiente

RNSIIPG - SERNANP 


\section{OCEANA $\begin{gathered}\text { Protegeiendolos } \\ \text { Occenos del Mundo }\end{gathered}$}

f OceanaPeru ㅇo oceana_peru $\boldsymbol{y}$ Oceana_Peru $\square$ peru@oceana.org peru.oceana.org 